\title{
An Exploratory Manipulation of Openness to Experience
}

\section{By}

\section{Zachary M. van Allen}

A thesis submitted to

the Faculty of Graduate and Postdoctoral Affairs

In partial fulfillment of the requirements for the degree of

\section{Master of Arts}

In

Psychology

Carleton University

Ottawa, Canada 


\begin{abstract}
The trait-state isomorphism hypothesis holds that personality traits and states (i.e., traitrelated behaviour) are characterized by similar outcomes (Fleeson, 2001). For example, both trait and state extraversion are associated with positive affect, and negative affect is associated with both trait and state neuroticism. However, research has not yet investigated whether the traits and states of 'openness to experience' are isomorphic. Openness reflects a general tendency to engage with abstract and sensory information and is associated with creative thinking (Feist, 1998), personal growth (Shmutte \& Ryff, 1997), and to a lesser extent, positive affect (Steel, Schmidt, \& Shultz, 2008). In the present experiment, participants $(\mathrm{N}=210)$ completed a pretest assessment, five daily exercises designed to either be inert (control condition) or engage the behaviours and cognitions associated with openness (experimental condition), a post-test assessment, and a two week follow up assessment. Results supported the isomorphism hypothesis for positive affect but not creative thinking ability or personal growth.
\end{abstract}




\section{Acknowledgements}

I am indebted to Dr. John Zelenski for his excellent mentorship and thoughtful guidance throughout the completion of this Master's thesis and throughout my studies in general. Dr. Chris Davis has been a positive influence on my development as a researcher, and I thank him for his insightful commentary during my prospectus and thesis defenses. The suggestions of Dr. Jim Davies informed an improved final version of this document. Finally, I thank Eve-Marie BlouinHudon for many enjoyable conversations on the topics of 'openness to experience', statistics, and thesis writing. 


\section{Table of Contents}

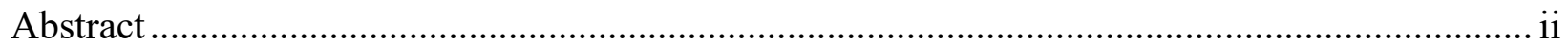

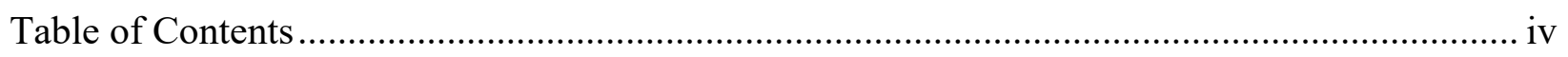

List of Appendix ........................................................................................................ vi

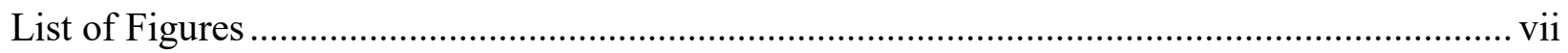

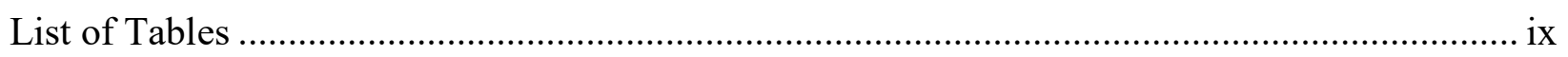

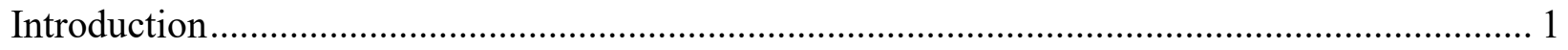

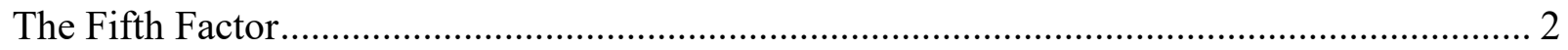

Openness as Motivated Cognition....................................................................................... 5

Openness and Cognitive Processes ........................................................................................ 7

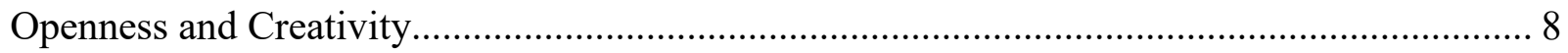

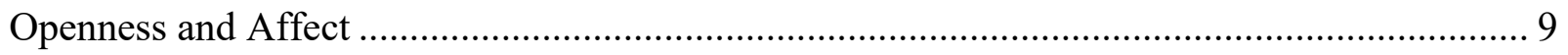

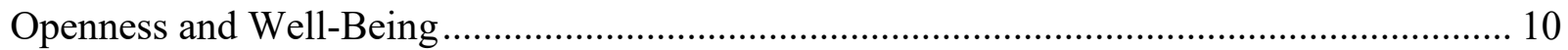

Manipulating Openness ................................................................................................ 13

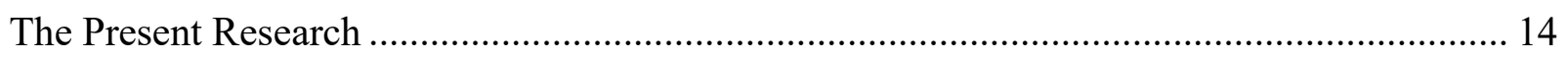

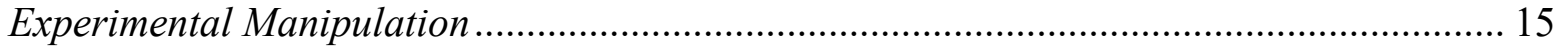

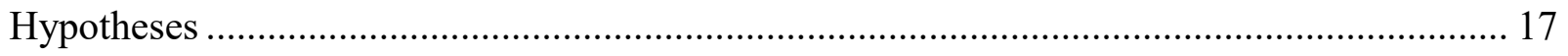

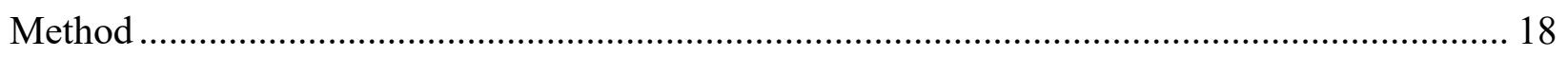

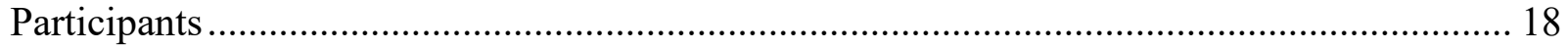

Procedure

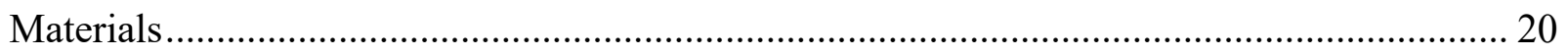

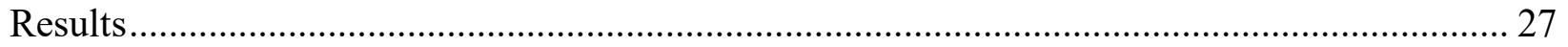

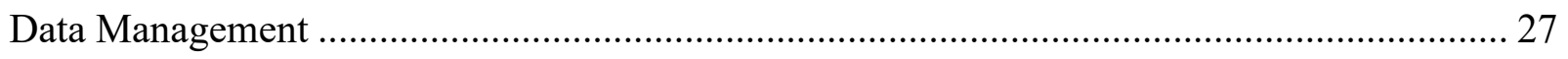

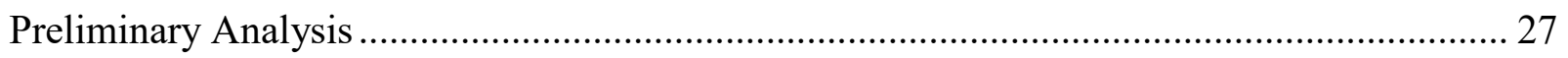

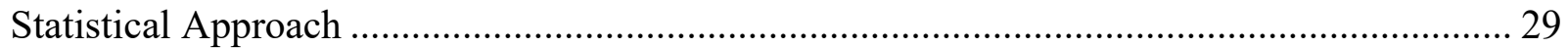

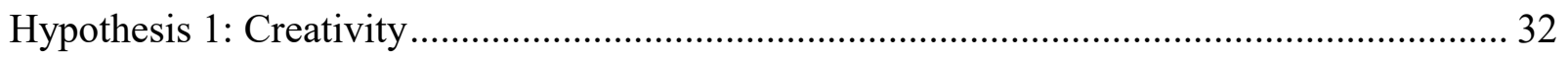

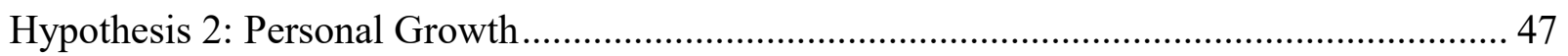

Hypothesis 3: Authenticity ……………………………………………………………..... 51

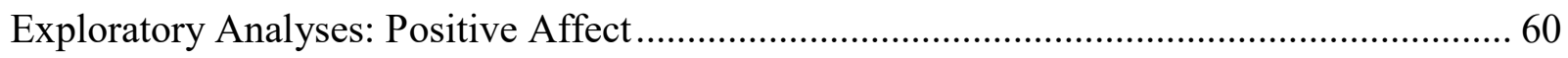

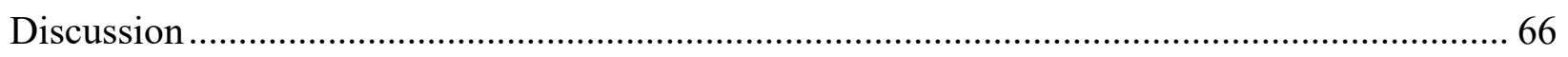

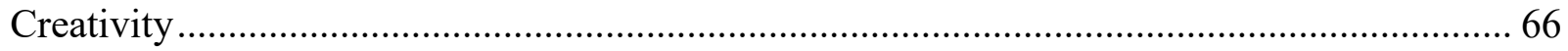




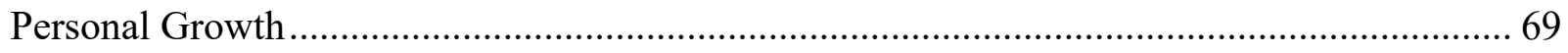

A

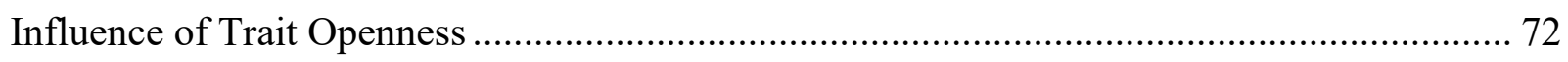

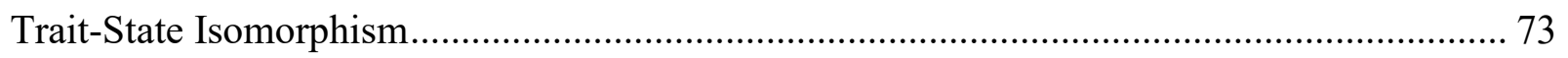

Limitations and Future Research................................................................................... 74

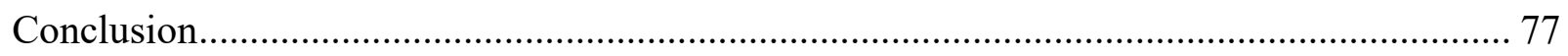

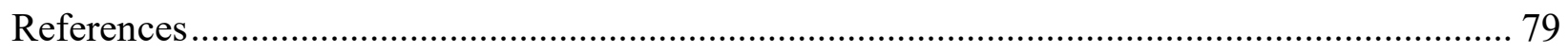

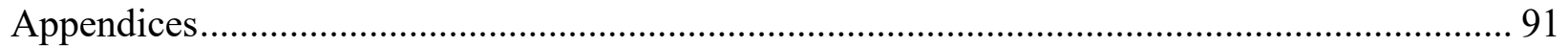




\section{List of Appendix}

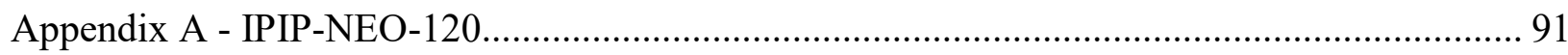

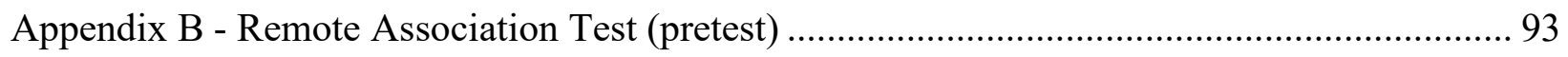

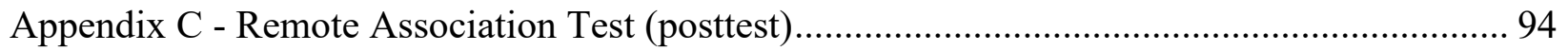

Appendix D - The Meaning in Life Questionnaire ............................................................ 95

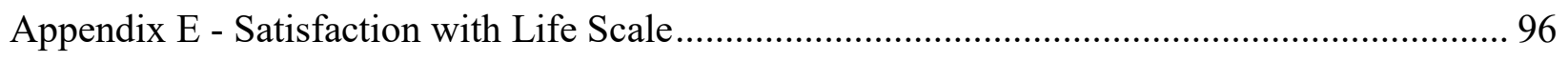

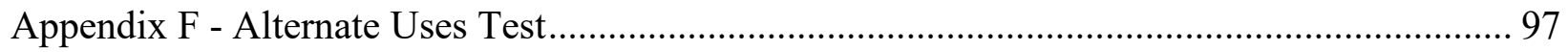

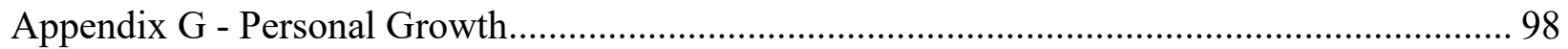

Appendix H - Authenticity and Effort Questionnaire ........................................................ 99

Appendix I - Authenticity and Effort (Daily Log) .......................................................... 100

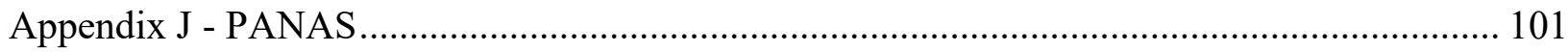

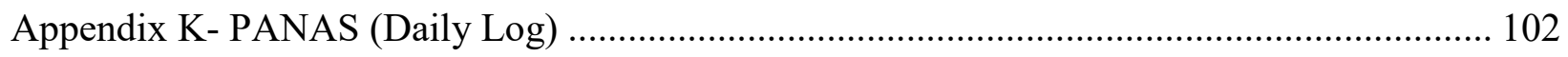

Appendix L - Experimental Condition Daily Log Instructions ......................................... 103

Appendix M - Experimental Condition Daily Log Tasks.................................................. 105

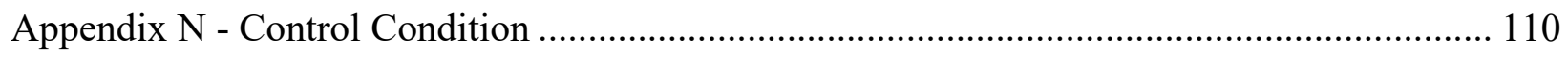

Appendix O - Control Condition Daily Log Task …........................................................ 111

Appendix P - Exploratory Analyses: Negative Affect................................................... 115

Appendix Q - Exploratory Analyses: Effort ................................................................ 120 


\section{List of Figures}

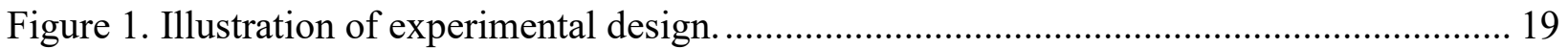

Figure 2. Mean word counts by condition over time.................................................. 28

Figure 3. Mean curiosity and confidence ratings for the curiosity manipulation...................... 29

Figure 4. Mean alternate uses task 'originality' scores over time (daily assessments).............. 33

Figure 5. Mean alternate uses task 'flexibility' scores over time (daily assessments)............... 36

Figure 6. Simple slopes for time by word count interaction predicting alternate uses tasks

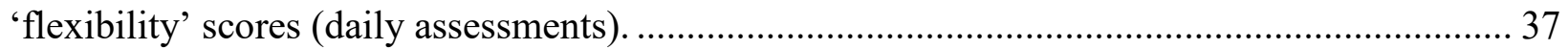

Figure 7. MLM models for alternate uses task 'flexibility' scores (daily assessments)............. 38

Figure 8. Mean alternate uses task 'fluency' scores over time (daily assessments).................. 39

Figure 9. Probing time by word count interaction for alternate uses task fluency scores (daily

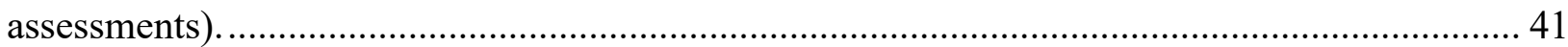

Figure 10. Mean alternate uses task ‘elaboration' scores over time (daily assessments)........... 42

Figure 11. Mean remote association task over time (pretest and posttest). ............................ 46

Figure 12. Mean personal growth scores over time (pretest, posttest, and follow-up)............... 48

Figure 13. Simple slopes for condition by trait openness interaction predicting personal growth

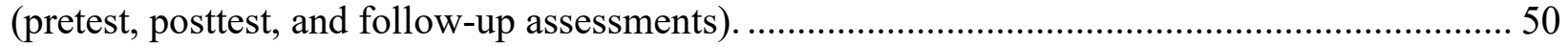

Figure 14. Mean authenticity scores over time (daily assessments)....................................... 52

Figure 15. Simple slopes for condition by trait openness interaction predicting authenticity

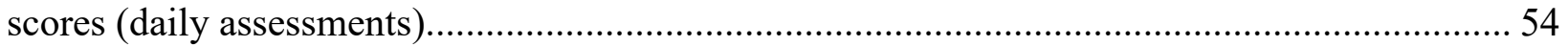

Figure 16. Mean authenticity scores over time (pretest, posttest, and follow up assessments)... 55

Figure 18. Simple slopes for condition by trait openness interaction predicting authenticity

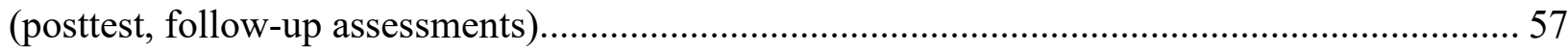

Figure 19. Mean positive affect scores across time (daily assessments).. ............................. 61

Figure 20. Simple slopes for condition by trait openness interaction predicting positive affect

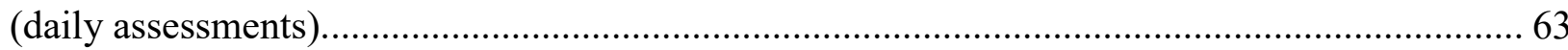

Figure 21.Mean positive affect scores across time (pretest, posttest, and follow up). ............... 63

Figure 22. Simple slopes for condition by trait openness interaction predicting positive affect

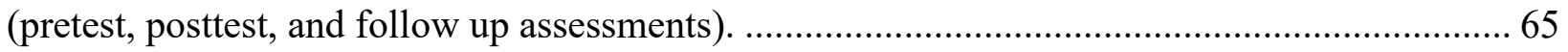

Figure 23. Mean Negative Affect scores across time (daily assessments) ........................... 115

Figure 24. Simple slopes condition by time interaction predicting for Negative Affect........... 117 
Figure 25. Simple slopes for condition by word count interaction predicting negative affect (daily

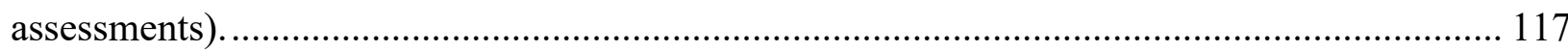

Figure 26. Means for Negative Affect over time (pretest, posttest and follow up)................ 118

Figure 27. Means for effort over time (daily assessments)............................................... 120

Figure 28 Simple slopes for condition by trait openness interaction predicting effort.............. 122

Figure 29. Means for effort over time (pretest, posttest, and follow-up assessments)............. 123

Figure 30. Simple slopes for control by word count interaction predicting effort (pretest, posttest,

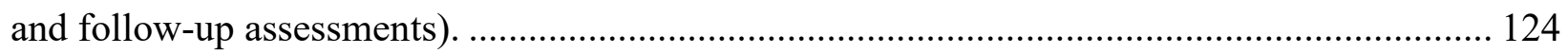




\section{List of Tables}

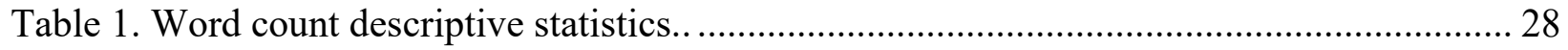

Table 2. Alternate uses task 'originality' descriptive statistics (daily assessments)..................... 33

Table 3. MLM models for alternate uses task 'originality' (daily assessments). ......................... 35

Table 4. Alternate uses task means and SDs for flexibility......................................................... 35

Table 5. Alternate uses task 'fluency' descriptive statistics (daily assessments).......................... 38

Table 6. MLM models for alternate uses task 'fluency' scores (daily assessments).................... 40

Table 7. Alternate uses task 'elaboration' descriptive statistics (daily assessments). ................... 42

Table 8. MLM models for alternate uses task 'elaboration' scores (daily assessments).............. 44

Table 9. Summary of statistically significant findings from Model $\mathrm{E}$ for alternate uses task...... 45

Table 10. Remote association task descriptive statistics (pretest and posttest)........................... 46

Table 11. Personal growth descriptive statistics (pretest, posttest, and follow up assessments). . 47

Table 12. MLM models for personal growth (pretest, posttest, and follow-up assessments). ..... 50

Table 13. Authenticity descriptive statistics (daily assessments). ................................................. 51

Table 14 MLM models for authenticity (daily assessments)....................................................... 53

Table 15. Authenticity descriptive statistics (pretest, posttest, and follow up assessments)........ 54

Table 16. MLM models for authenticity (pretest, posttest and follow-up assessments). ............. 56

Table 17. Summary of statistically significant findings from Model E across all tests................. 59

Table 18 Positive affect descriptive statistics (daily assessments)............................................. 60

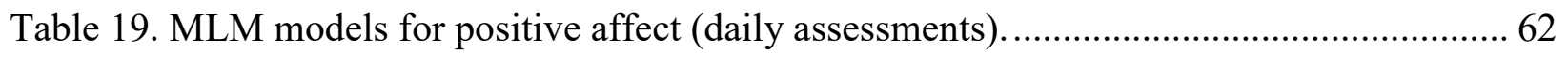

Table 20. Positive affect descriptive statistics (pretest, posttest and follow up assessments)...... 63

Table 21. MLM models for positive affect (pretest, posttest, and follow-up assessments). ........ 65

Table 22. Negative affect descriptive statistics (daily assessments)......................................... 115

Table 23. MML models for negative affect (daily assessments)............................................. 116

Table 24. Negative affect descriptive statistics (pretest, posttest, and follow up assessments). 117

Table 25. MLM models for negative affect (pretest, posttest and follow up assessment). ........ 119

Table 26. Effort descriptive statistics (daily assessments)......................................................... 120

Table 27. MLM models for effort (daily assessments)................................................................ 122

Table 28. Effort descriptive statistics (pretest, posttest, and follow-up assessments)................ 122

Table 29. MLM models for effort (pretest, posttest, and follow-up assessments). .................... 124 


\section{Introduction}

Trait openness can be characterized as an inclination towards introspection, curiosity, aesthetic appreciation, affective sensitivity, and the exploration of ideas (Goldberg, 1990; McCrae, 1994; Connelly, Ones, Davies, \& Bukland, 2014). This tendency to explore and engage with abstract, sensory, and intellectual information likely underlies many of the positive outcomes associated with openness. For example, open individuals are inclined towards personal growth (Shmutte \& Ryff, 1997), demonstrate adaptive reactions towards stress (Williams, Rau, Cribbet, \& Gunn, 2009), and score higher on tests of creative thinking ability (Carson, Peterson, \& Higgins, 2005; Feist, 1998; Silva, Nusbaum, Berg, Martin, \& O'Conner, 2009). Additionally, the trait of openness is associated with creative achievement in the arts and sciences (Feist, 1998), the enjoyment of mind-wandering (Wilson et al., 2014) and the increased propensity to experience aesthetic chills (McCrae, 2007) and awe (Shiota, Keltner, \& John, 2006). Finally, experience sampling studies have found the behaviours associated with openness are accompanied by elevated feelings of authenticity regardless of one's individual disposition (Fleeson \& Wilt, 2010).

Given the many benefits associated with openness, an intriguing possibility is that these outcomes could be cultivated by mimicking the behaviours associated with openness. This proposition is supported by research into 'enacted extraversion'. Trait extraversion is robustly associated with positive affect, and multiple laboratory experiments have demonstrated that individuals experience increases in positive affect when they behave in an extraverted manner (Fleeson, Malanos, \& Archer, 2002; Zelenski et al., 2012; Zelenski et al., 2013), and this effect does not appear to depend on dispositional levels of extraversion (Zelenski et al., 2013). This research is grounded in the density distribution model of personality and the idea that traits and 
states are at least somewhat isomorphic (Fleeson, 2001). That is, personality states are similar to traits in affective and behavioural content but are manifested in momentary experience, such as over the course of minutes or hours instead of years (Fleeson, 2010).

Based on the findings of these laboratory based 'enacted extraversion' experiments, some have suggested that it may be possible to manipulate 'open behaviors' in a similar manner to elicit the positive cognitive benefits associated with openness (e.g. Smillie, 2013; Blackie, Roepke, Forgeard, Jayawickreme, \& Fleeson, 2014; Forgeard \& Eichner, 2014). For example, researchers have cited the possibility of manipulating openness to facilitate outcomes such as creativity (Forgeard et al., 2014) and post-traumatic growth (Blackie et al., 2014). However, to date, this approach of 'acting well to be well' has yet to be applied to openness.

\section{The Fifth Factor}

In the empirical tradition of identifying traits, the hierarchical structure of personality is derived by statistically revealing patterns of covariation in self-report personality assessments. This methodological approach repeatedly yields a five factor solution to defining personality trait space commonly referred to as the 'big five' (cf. Ashton \& Lee, 2001). For example, individuals who identify as being curious, imaginative, intellectual, original, or prone to fantasy also generally endorse being aesthetically and emotionally sensitive; together, these characteristics, among others, comprise the fifth factor in the five factor model of personality most commonly called 'openness to experience'.

Relative to the other big five factors of extraversion, agreeableness, neuroticism, and conscientiousness, the composition of traits thought to encompass the fifth factor has been subject to much debate. For example, some taxonomies classify introspection as a defining feature (e.g., Connelley et al., 2015; Goldberg, 1999) while others do not (e.g., Ashton \& Lee, 
2001; Costa \& McCrae, 1992). This discrepancy illustrates the fact that there are many empirically sound ways to define personality trait space. Given the lack of consensus on the precise nature of the fifth factor I will provide a brief overview of its differing conceptualizations.

Over the years various labels have been proposed for the fifth factor including 'inquiring intellect' (Fiske, 1949), 'intellect' (Goldberg, 1990), 'imagination' (Saucier, 1992), 'intellect/ imagination' (Ashton \& Lee, 2001), 'openness to experience' (McCrae \& Costa, 1997), and most recently 'openness/ intellect' (DeYoung, Quilty, \& Peterson, 2007). Currently, the most common label and conceptualization is openness to experience as defined by McCrae \& Costa (1997) and assessed by measures such as the NEO PI-R (Costa \& McCrae, 1992) and its open-source derivative the NEO-IPIP (Goldberg, 1999).

In the widely used measurement of the Big Five, the NEO PI-R, Openness to Experience is comprised of six facets: ideas (preference for intellectual interests), aesthetics (appreciation for beauty and art), fantasy (possessing an active imagination), actions (preference for novelty and variety), feelings (emotional depth and sensitivity) and values (socio-politically progressive ideals). According to this classification system, 'open' individuals are generally “imaginative, sensitive to art and beauty, emotionally differentiated, behaviorally flexible, intellectually curious, and liberal in values. Closed people are down-to-earth, uninterested in art, shallow in affect, set in their ways, lacking curiosity, and traditional in values" (McCrae \& Costa, 2007; pp. 258).

Although the tradition of 'openness to experience' is relatively ubiquitous in personality psychology, a growing body of literature is adopting the compound openness/intellect label reflecting the finding that openness and intellect represent related but distinct 'aspects' of the 
fifth factor (Ashton, Lee, Vernon, \& Jang, 2000; Saucier, 2003; DeYoung et al., 2007; Nusbaum $\&$ Silva, 2005). The big five aspects scale (BFAS; DeYoung et al., 2007) assesses personality at a level between the big five and their corresponding facets and separates each of the big five into two distinct 'aspects' or 'meso-traits'. The openness aspect reflects engagement with perceptual or sensory information (fantasy, aesthetic appreciation) and the intellect aspect reflects engagement with abstract information (quickness of understanding, enjoyment of solving complex problems; DeYoung et al., 2014). Research using the big five aspects scale has demonstrated that the openness and intellect differentially predict outcomes associated with the fifth factor. For example, the openness aspect has been found to predict creativity but not fluid intelligence while the opposite is true for the intellect aspect (Nusbaum et al., 2011). Thus, this approach provides some insight into the structure, functions, and outcomes of the fifth factor. In addition to the divergent views over the label and conceptualization of openness as a whole, independent empirical undertakings attempting to identify the 'correct' number and composition of facets for the fifth factor have arrived at differing conclusions (Saucier \& Ostendorg, 1999; Connelly et al., 2014; Woo, Chernyshenko, Longley, Zhang, Chiu, \& Stark, 2014). For example, in contrast to Costa \& McCrea's NEO-IP-R, the HEXACO-IS (Lee \& Ashton, 2004) considers aesthetic appreciation, inquisitiveness, creativity, and unconventionality to be the defining characteristics of openness. In another recent example, Connelly et al (2015) conducted a meta-analysis on data from psychological test manuals used in the validation of 85 scales conceptually related to openness and identified four 'pure' markers of openness (aestheticism, openness to sensations, non-traditionalism, and introspection) and a number of compound facets, or facets associated with openness and other big five traits, including innovation/creativity, variety-seeking, and tolerance. 
Despite the diverse and sometimes inconsistent conceptualizations, strong common themes pervade throughout each attempt to describe the fifth factor; At a broad descriptive level individuals scoring high on the fifth factor exhibit a "recurrent need to enlarge and examine experience" (McCrae \& Costa, 1997, p.826) facilitated through the exploration of sensory and abstract information. Regardless of its precise conceptualization every measure of the big five assesses openness ${ }^{1}$ and an increasing amount of empirical attention has been paid to understanding its processes and outcomes.

\section{Openness as Motivated Cognition}

Openness to experience is a personality dimension primarily associated with cognitive traits (Zillig, Hemenover, \& Dienstbier, 2002). The conceptual overlap of openness and constructs developed outside of the big five framework provide insight into the characteristics of these traits. For example, need for cognition (Cacioppo \& Petty, 1982) is a psychological construct that refers to individual differences in the tendency to engage in and enjoy thinking and is highly correlated with openness to experience. In a sample of Caucasian females Berzonsky and Sullivan (1992) observed that need for cognition was highly correlated with the ideas facet of openness to experience $(r=.78)$ and modestly correlated with the facets of values, actions, and feelings $(r=.29-.39)$.

The open individuals' need for cognition also manifests itself in a high tolerance for ambiguity and a low need for cognitive closure. Need for closure is a construct that measures the desire for predictability, order, and structure as well as discomfort with ambiguity (Webster \& Kruglanski, 1994) and is strongly and inversely related to openness. For example, in a recent

\footnotetext{
${ }^{1}$ Throughout this document I will refer the fifth factor broadly as 'openness' for ease of communication. When discussing research employing Costa \& McCrae's NEO-IP-R I will refer to 'openness to experience' and when discussion research employing DeYoung et al.'s 'openness/intellect' aspects I will state so explicitly.
} 
study using a large sized sample openness to experience and need for closure had a correlation of $r=-.50$ (Onraet, Van Hiel, Roets, \& Cornelis, 2011). Thus, openness is not only defined by the pursuit and enjoyment of cognition, but by the acceptance of ambiguity and a reduced need for cognitive closure.

Given the tendency for individuals high in openness to seek out and enjoy cognitive stimulation, it is not surprising that open individuals are also more likely to become immersed in thought. The construction of absorption (Glisky, Tataryn, Tobias, Kihlstrom, \& McConkey, 1991), as assessed by the multidimensional personality questionnaire (Tellegen, 1982), refers to the tendency to become immersed in ones thoughts and imagining and is highly intercorrelated with openness to experience. The tendency for open individuals to become immersed in thought may underlie the positive relationship between openness and the frequency and enjoyment of daydreaming (Wilson et al. 2014).

Trait curiosity, or the tendency to seek out novel, complex, and challenging stimuli, is also strongly intercorrelated with openness (Kashdan \& Steger, 2007). The strong conceptual overlap between curiosity and openness is evidenced by the fact that curiosity is sometimes, but not always, included as a facet of openness and that both curiosity and openness are characterized by an exploratory tendency towards novel and complex stimuli. The motivation or desire to seek out cognitive stimulation is thought to be influenced by dopaminergic systems in the brain. DeYoung et al., (2005) posit that dopamine, a neurotransmitter that potentiates approach and exploratory behaviour, regulates the motivational components of openness in a manner similar to its regulation of extraversion (e.g. Depue \& Collins, 1999). Likewise curiosity, a defining characteristic of openness, has been implicated as a motivational mechanism of the reward sensitivity system (Depue, 1996). Thus, open individuals are driven to seek out reward in 
abstract information much in the same way that extraverted individuals are more driven to seek out reward in the concrete/behavioural domain. Beyond the likely role of the domapinergic system, several other processes have been proposed to underlie openness.

\section{Openness and Cognitive Processes}

One cognitive process associated with openness is implicit learning. Implicit learning refers to the ability to automatically detect complex covariation in sensory stimuli and is characterized by unconscious, associative and automatic learning processes (Kaufman, DeYoung, Gray, Jimenez, Brown, \& Mackintosh, 2010). Kaufman et al., (2010), using the big five aspect scale as a measure of openness/intellect, found that implicit learning is significantly related to the aspect of openness but not intellect, while intellect predicts working memory and general intelligence (Kaufman, DeYoung, Gray, Jimenez, Brown, \& Mackintosh, 2010). Although a causal direction could not be established this research suggests that high levels of openness is associated with greater implicit learning ability. It has been suggested that increased implicit learning could be a contributing factor to the aesthetic sensitivity associated with openness (DeYoung, 2014).

Another mechanism associated with openness to experience is latent inhibition. First discovered in rats and later studied in humans, latent inhibition is a preconscious gating mechanism that allows animals with complex nervous systems to ignore stimuli previously

experienced as irrelevant (Peterson \& Carson, 2000). Historically, low latent inhibition has been associated with mental disorders, most notably acute schizophrenia wherein individuals are unable to filter/gate irrelevant thoughts and sensory stimuli from intruding into conscious awareness. However recent findings suggest that decreased latent inhibition is also associated with openness to experience and extraversion (Peterson et al., 2000; Peterson, Smith, \& Carson, 
2002; but see Burch, Hemsley, Corr, \& Pavelis, 2005). This decreased ability to screen out irrelevant information seems likely to facilitate the "permeability of consciousness" (McCrae \& Costa, 1997) associated with openness. Interestingly, decreases in latent inhibition also appear to be involved in one of the most robust outcomes associated with openness: creativity (Carson, Peterson, \& Higgins, 2003).

\section{Openness and Creativity}

Creativity, or the production of abstract or material products that are both novel/original and useful/adaptive (Feist, 1998), is associated with openness to the extent that Johnson (1994) proposed 'creativity' as an alternative label for the fifth factor. There are diverging approaches to the classification of creativity (for a review see Mumford, 2003); however, creativity is often assessed in terms of creative achievement and creative ability.

Openness to experience is strongly associated with self-reported creative achievement (King, Walker, \& Broyles, 1996; Silva, Nusbaum, Bergm Martin, \& O’Connor, 2009). At the trait level openness to experience is equally related to creative achievement in both the arts and sciences (Feist, 1998); however, recent research employing the big five aspects scale found that openness predicts creative achievement in the arts and intellect predicts achievement in the sciences (Kaufman, Quilty, Grazioplene, Hirsh, Gray, Peterson, \& DeYoung, 2015).

The cognitive process most often associated with creative ability is divergent thinking. Divergent thinking, or the ability to produce multiple solutions to a single problem (Guilford, 1950), is assessed with tests such as alternate uses task (Christensen, Guilford, Merrifield, \& Wilson, 1960) which assesses the ability of the test-taker to describe as many possible uses for a common household object such as a brick or pen. Of the big five personality traits, openness and extraversion are the strongest predictors of divergent thinking (McCrae, 1987; Silva et al., 2009; 
Sung \& Choi, 2009; King et al., 1996). Interestingly, creative thinking has also been found to be facilitated by positive emotions (Isen, Daubman, \& Nowicki, 1987; Isen, 1999; Baas, De Dreu, \& Nijstad, 2008; cf. Kaufmann \& Vosburg, 2010).

\section{Openness and Affect}

Open individuals are characterized by a greater sensitivity to emotions. For example, feelings facet of openness in the NEO-IPIP-120 accesses the extent to which participants "feel others' emotions" and "experience [their own] emotions intensely". This enhanced affective sensitivity is evidenced in correlations between openness subscales of the highly sensitive persons scale (Aron \& Aron, 1997; Evans \& Rothbart, 2008). For example, across two studies Sobocko and Zelenski (2015) observed strong correlations between openness and the highly sensitive persons scale subscales of aesthetics (measuring sensitivity to aesthetic stimuli; $r=.47$ \& .51) and orienting sensitivity/openness (measuring awareness of internal and external sensory events; $r=.46 \& .42$ ). Thus, open individuals are more aware of and sensitive to, their emotional states.

The relationship between openness and positive emotions has been subject to increasing empirical attention. The most recent large-scale meta-analysis (Steele et al., 2008) on personality and well-being found that openness, as assessed by the neuroticism-extraversion-openness scale (Costa \& McCrae, 1992), is significantly related to positive affect $(r=.20)$ but not negative affect $(r=-.02)$. Consistent with this finding, Ching et al., (2014) employed an experience sampling methodology and found that openness was a significant predictor of positive affective states in daily life across five cultures $(\beta=.18-.25)$. However, positive affect is a broad construct and multiple lines of research have found positive associations between openness and more specific types of positive emotions. For example, Shiota and colleagues (2006) investigated 
the associations between the big five and the dispositional positive emotions scale (DPES) and found strong correlations between openness to experience and several subscales of the DPES including love $(r=.28)$, compassion $(r=.40)$, amusement $(r=.20)$ and awe $(r=.49)$.

Furthermore, Letzring \& Adamcik (2015) found that openness was a significant predictor of several positively valenced items on the positive and negative affect schedule (PANAS; Watson, Clark \& Tellegen, 1988) including: 'inspired' $(\beta=.30)$, 'determined' $(\beta=.16)$, and 'interested' $(\beta=.16)$. Similarly, Mitte and Kampfe (2008) also found openness to be strongly associated with the positive affective state of interest.

Finally, McCrae (2007) has argued that aesthetic chills, or the "experience of chills or goosebumps in response to aesthetic stimulation" (McCrae, 2007 pp.5), is the best universal marker of openness. McCrae (2007) analyzed data from 51 cultures (total $\mathrm{N}=21,156$ ) and found that the item assessing aesthetic chills in the NEO-IP-R was the item most strongly associated with openness to experience across the 51 cultures.

\section{Openness and Well-Being}

Trait openness has been linked with various indicators of well-being including subjective assessments of happiness (Steele et al., 2008), and authenticity (Sheldon, Ryan, Rawsthrone, \& Ilardi, 1997). Authenticity, or the valuation that one's behaviour is in concordance with one's 'true self', has also been found to covary with the behaviours associated with openness. For example, across three experiments employing an experiencing sampling methodology Fleeson and Wilt (2010) found that behaviour associated with extraversion, openness, agreeableness, conscientiousness, and emotional stability was consistently related to feelings of authenticity, regardless of individual disposition. This same pattern of results has also been reported in cross- 
sectional research (Sheldon et al., 1997) and may be influenced by the role of positive emotions in appraisals of authenticity (Lenton, Slabu, Sedikides \& Power, 2013).

As previously discussed, Steele and colleagues (2008) observed in their meta-analysis that openness was a significant predictor of positive emotions. However, the meta-analysis did not reveal meaningful relationships between openness and other indicators of well-being such as the subjective assessment of being satisfied with one's life. The generally null relationship between openness and life satisfaction is a consistent finding using typical (i.e. university aged) samples. However, an interesting exception to this finding is that openness predicts life satisfaction in older adults. For example, Stephan (2009) analyzed the relationship between openness and life satisfaction at the trait and facet level in a sample of retirement aged individuals; results suggested that openness, and in particular openness to ideas and feelings, was a positive predictor of life satisfaction for older adults. The author posits that being open could fulfill older adults' basic psychological needs for personal growth.

Personal growth, as measured by the psychological well-being scale (PWB; Ryff, 1989), assesses the extent to which individuals possess a sense of continued growth and development, and is consistently associated with openness and extraversion (Schmutte \& Ryff, 1997). Schmutte and Ryff (1997) have suggested that individuals with this combination of traits have the inclination (via openness) and the energy (via extraversion) to pursue growth opportunities. This finding is consistent with the theoretical conceptualization of plasticity (a combination of openness and extraversion) as a general exploratory tendency.

In addition to an elevated penchant for pursuing growth opportunities, open individuals may also be better suited to adapt to stressful situations than their less open peers. Williams and colleagues (2009) asked participants to discuss a previously experienced stressful event in semi- 
structured interview. Openness to experience was associated with an increased parasympathetic response, lower systolic and diastolic blood press, and increases in positive affect immediately following 'reliving' the stressful event. The authors posit that this pattern of results is indicative of positive cognitive engagement (Williams, Rau, Cribbet, \& Gunn, 2009).

Williams et al., (2009) did not analyze their findings at the facet level; however, it seems reasonable to suggest strong involvement of the feelings and ideas facets of openness in the positive cognitive engagement in reliving negative events. A similar phenomenon is observed in the emotional disclosure literature wherein expressive writing on past negative events is associated with well-being benefits including increased life satisfaction and mental health (Lyubomirsky, Sousa, \& Dickerhoof, 2006). Although emotional disclosure studies typically do not interpret results in terms of personality related cognitions, the process of exploring one's feelings and re-analyzing past events overlaps considerably with the behaviours/cognitions assessed by the feelings and ideas facets of openness. Thus, at the facet level, openness to feelings and ideas are likely involved in the association between openness and positive adaptations to negative events.

Another openness facet associated with well-being outcomes is curiosity. Research into the relationship between the 24 strengths of character identified in the VIA-IS (Peterson and Seligman, 2004) and well-being revealed that curiosity is consistently and robustly associated with life satisfaction (Park, Peterson \& Seligman, 2004). Furthermore, Kashdan and Steger (2007) used a daily diary methodology to examine the relationship between well-being and both trait and state curiosity and found that on the days when individuals high on trait curiosity were more curious they reported greater life satisfaction, presence and search for meaning, and more frequent growth oriented behaviours. Interestingly, it has been proposed that regulating curiosity 
may be a means to facilitate creativity (Kashdan \& Finchman, 2002); this proposition has been echoed by calls to manipulate openness in general as a means of influencing creative thinking (Blackie et al., 2014).

\section{Manipulating Openness}

Two notable studies have manipulated openness. One study found that cognitive training in an elderly population increased trait openness. Seventy eight elderly participants $\left(\mathrm{M}_{\mathrm{age}}=72.9\right)$ completed inductive reasoning training adapted from the ACTIVE trials (Advanced Cognitive Training for Independent and Vital Elderly; Ball et al., 2002) combined with Sudoku and crossword puzzles of the course of 16 weeks and reported greater increases in trait openness than a waitlist control (Jackson, Hill, Payne, Roberts, \& Stine-Morrow, 2012). In another study, researchers demonstrated that long term changes in trait openness can be induced with pharmacological substances. Specifically, MacLean and colleagues (2001) administered psilocybin (the active ingredient in hallucinogenic mushrooms) to participants and found that self-reported openness was elevated immediately following the experimental session as well as over a year later.

However, the most promising avenue for manipulating openness in the general population is through eliciting 'open' states. Personality states are similar to traits in affective and behavioural content but are manifested in momentary experience, such as over the course of minutes or hours instead of years (Fleeson, 2001). Interestingly, some traits and states appear to be associated with similar outcomes. For example, the robust association between trait extraversion and positive affect is also observed at the state level. That is, whether through experiencing sampling methods or via experimental manipulation of extraverted behaviour, extraverted states are associated with positive affect regardless of individual disposition 
(Fleeson, 2001; Zelenski et al., 2013). Likewise, this effect is also evident with neuroticism; neuroticism at both the trait and state level is characterized by elevated levels of negative affect (McNeil \& Fleeson, 2006). Taken together these findings suggest that these traits and states are at least partially characterized by similar outcomes. This phenomenon has been dubbed trait-state isomorphism (Fleeson, 2001). Although no published experiments have investigated whether openness is also isomorphic, based on the aforementioned research, manipulating open states seems a plausible method for facilitating the outcomes associated with trait openness.

\section{The Present Research}

Based on Fleeson's (2001) density distribution approach to personality, the present research asks the questions can participants be instructed to 'act open,' and if so, what outcomes are associated with 'acting open'?

In order to test these questions I have designed a semi-longitudinal study consisting of eight time points spanning the course of three weeks. On the first day participants completed a pre-test assessment online (Time 1) that assessed personality, affect, creative thinking ability, and well-being. For the following five days participants completed one condition-specific task each day via daily online logs (Time 2-6). In the experimental condition these tasks were meant to induce the behaviour and cognitions associated with one of five selected facets of openness; in the control conditions participants completed a series of mundane writing tasks. In addition to the exercises, each daily log was accompanied by a brief online survey that presented participants with a test of creative thinking (alternate uses test) and self-report questionnaires assessing affect and authenticity. Following the five daily exercises, a post-test assessment (Time 7) and two-week follow-up assessment (Time 8) were administered. The purpose of these posttest and follow-up assessments was to test exploratory hypotheses. For example, openness is 
associated with a proclivity towards personal-growth behaviour. Thus, it is possible, although not strongly predicted, that engaging in more open behaviours could facilitate changes in the tendency to engage in growth behaviour.

\section{Experimental Manipulation}

Creating the experimental manipulation involved two key components: selecting a representative set of characteristics thought to comprise openness, and choosing/creating activities to engage the cognitive processes associated with each characteristic ${ }^{2}$.

Given the lack of consensus regarding the defining characteristics of openness I arrived at a selection of characteristics rationally. As a starting point I began with Costa and McCrea's (1992) conceptualization of openness to experience as it represents the 'mainstream' view of openness. The six facets of openness to experience include: ideas, aesthetics, values, feelings, actions, and fantasy.

Research clearly demonstrates the aesthetics and ideas facets to be the best markers of openness (e.g. Johnson, 1994). Additionally, evidence supports the notion that open individuals are more sensitive to and aware of their internal emotional states (e.g. Connelly et al., 2015, Sobocko \& Zelenski, 2015). Thus, the preference for ideas, the appreciation of aesthetics, and emotional awareness were retained as defining characteristic of openness for the purposes of this study.

The remaining three facets of actions, values, and fantasy however, were not retained. DeYoung, Peterson and Higgins (2005) observed that of all of the NEO PI-R facet of openness, the actions facet was the least correlated with trait openness to experience $(r=.40)$ and the most

\footnotetext{
${ }^{2}$ The selection process for the representative characteristics are presented here; the specific activities are describes in the materials section.
} 
related to trait extraversion $(r=.44)$. Therefore, insofar as openness to experience represents abstract/cognitive exploration and extraversion represents concrete/behavioural exploration the 'actions' facet, with its emphasis on behavioural flexibility, may not be an ideal marker of openness (DeYoung et al., 2005, DeYoung et al., 2014).

Trait openness is negatively correlated with political conservatism, dogmatism, and rightwing authoritarianism (McCrae \& Costa, 1997) and the values facet of openness to experience represents openness to liberal values rather than values in general. For example the open source version of the NEO-IP-R, the IPIP, re-labeled the values facet 'liberalism' and included items such as "tend to vote for liberal political candidates". However, recent research suggests that political orientation is best associated with a combination of openness, agreeableness (especially the politeness rather than compassionate aspect; Hirsh, DeYoung, Xu, \& Peterson, 2010) and the orderliness components of conscientiousness (Carney, Jost, Gosling, \& Potter, 2008). Thus, among other reasons, manipulating cognitions associated with political liberalism as a manipulation of openness is problematic given its relationship with three of the big five traits.

The tendency to engage in fantasy was omitted as a characteristic of openness for pragmatic reasons. Wilson et al (2014) conducted several studies that involved 'prompted fantasy' and found that participants often had difficulty following the instructions when in the lab or at home and over $30 \%$ of participants self-reported cheating on the task by engaging with external stimuli such as cell phones and laptops. Thus, given the variety of characteristics empirically demonstrated to partially define the fifth factor, and the likely prospect that a prompted fantasy manipulation would be problematic, I decided to exclude fantasy as a characteristic of openness for the purposes of the manipulation.

Finally, I opted to include two characteristics of openness which are not included as 
facets of openness to experience but that have been empirically demonstrated to be defining characteristics of openness: introspection (e.g. Connelly et al., 2015; Goldberg, 1990; Goldberg, 1999 ) and curiosity (e.g. Goldberg, 1990; Noftle, Schnitker, \& Robins, 2011). Thus, I

operationalized openness as a composite of traits that describe the tendency to explore ideas and emotions, to be introspective, curious, and aesthetically appreciative.

\section{Hypotheses}

Hypothesis 1a: Based upon the robust relationship between openness and creativity (e.g. Feist, 1998), I hypothesize that scores from the alternate uses tests administered after each daily exercise will be greater in the openness condition than in the control condition.

Hypothesis $1 b$ : As an extension to hypothesis 1a I will test the hypothesis that scores on the remote association task will improve in the openness condition but not in the control condition from pre-test to posttest assessments.

Hypothesis 2a: Given the relationship between openness and personal growth (Schmutte et al., 1997), I will test the exploratory hypothesis that individuals in the openness condition will report an increased inclination towards personal growth across time points.

Hypothesis 2b: Based on enacted extraversion research that has found the benefits associated with the state are not contingent upon the trait (e.g. Zelenski et al., 2012), I hypothesize that the effect proposed in hypothesis $2 \mathrm{a}$ will not be significantly affected by high vs low levels of trait openness.

Hypothesis 3a: Flesson et al., (2010) have found that behaviours associated with openness are accompanied by elevated levels of state authenticity. Thus, I hypothesis that the experience of completing the daily experimental (openness) exercises will be accompanied by greater levels of authenticity than will the daily control exercises. 
Hypothesis 3b: As an extension of hypothesis 3a, I will test whether self-reported authenticity differs across the pre-test, posttest and follow-up assessments and whether this proposed effect differs depending upon condition.

Hypothesis 3c: Similar to hypothesis $2 \mathrm{~b}$, should a long term effect be present on selfreported authenticity, I hypothesize that such an effect will not be dependent upon levels of trait openness.

These three sets of hypotheses are informed by previous research. However, this experiment is exploratory and all noteworthy findings, whether significant or null, will be reported.

\section{Method}

\section{Participants}

Two hundred and fifty-one participants were recruited through Carleton University's SONA system to participate in an online. Two hundred and twenty-one cases were included in analyses. Thirty cases were excluded due to incomplete pre-test assessments $(\mathrm{n}=8)$, failing to complete any daily $\operatorname{logs}(\mathrm{n}=13)$, and for concurrent participation in a separate well-being intervention $(n=9)$. Full participation was rewarded with a $2.25 \%$ grade increase $(.5 \%$ for pretest survey, $.25 \%$ for each of 5 daily logs, and $.5 \%$ for posttest survey). Additionally, for every completed daily log participants were entered in a draw for a chance to win $\$ 250$. Finally, those who complete an optional follow-up survey 2 weeks following the posttest assessment were entered in a second $\$ 250$ draw.

\section{Procedure}

Participants registered for an online study entitled "Examining the relationship between well-being and cognition". Following registration participants were emailed a link to the pretest 
survey which contained questionnaires assessing personality, creative thinking, meaning in life, satisfaction with life, personal growth, emotions, and feelings of authenticity. Participants were then randomly assigned to the experimental or control condition and presented with conditionspecific instructions for completing the remainder of the experiment (see materials sections). A demographic questionnaire was then administered, followed by a short written debriefing.

For the five days following the pretest survey, participants completed online daily logs. Daily logs 1-4 consist of condition-specific writing tasks followed by a creativity assessment and a series of questionnaires assessing affect, authenticity, and effort experienced while completing the task. In lieu of a writing task, participants completed a trivia task in the fifth daily log.

A posttest assessment was administered the day following completion of the fifth daily $\log$, and for those who opt-in, an additional follow-up survey was administered two-weeks later. With the exception of a personality measure, the posttest and follow-up assessment contained an identical set of questionnaires as the pretest assessment. A diagram of the experimental design is presented in Figure 1.

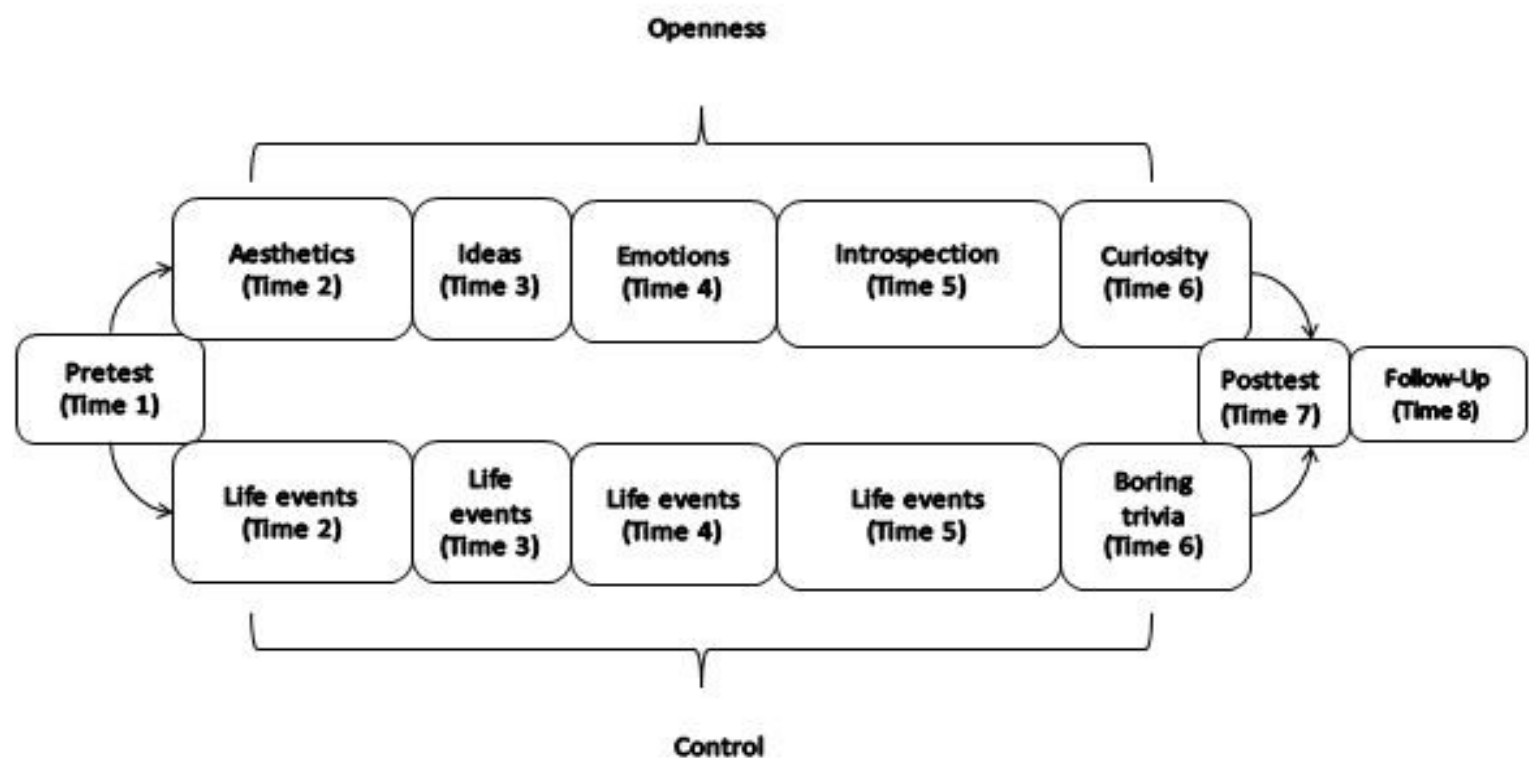

Figure 1. Illustration of experimental design. 


\section{Materials}

IPIP-NEO-120. The IPIP-NEO-120 (Johnson, 2014) was created as public-domain alternative to Costa and McCrae's (1992) NEO Personality Inventory (NEO PI-R). The NEO PI$\mathrm{R}$ is a commercially available personality inventory that assesses the five traits of the five factor model (openness, conscientiousness, extraversion, agreeableness, and neuroticism) as well as six lower-order facets for each trait. Using items from the International Personality Item Pool (IPIP; Goldberg et al., 2006) Johnson created a 300-item scale (IPIP-NEO-300) assessing the constructs of the NEO PI-R. The IPIP-NEO-300 was then reduced to a 120-item scale (Johnson, 2014) by retaining only the four most reliable items used to measure each of the 30 facets.

The IPIP-NEO-120 was administered at Time 1(Appendix A). Participants were presented with a list of 120 behaviour descriptive statements/phrases such as "worry about things" and "believe in the importance of art" and were asked to indicate the degree to which each statement accurately describes them on a 1 (very inaccurate) to 5 (very accurate) Likert scale. Scores for each of the five traits and thirty facets were calculated by averaging the response values across items contained within each scale. Alpha coefficients for openness, conscientiousness, extraversion, agreeableness, and neuroticism were $.80, .86, .86, .87$, and .88 , respectively.

Remote Association Test. The remote association test (RAT; Mednick, 1962) is a measurement of creative thinking. Two separate versions of the RAT were administered during pretest (Appendix B) and posttest (Appendix C) assessments. In each version participants were presented with a series of stimulus word triads (ex. AGE/ MILE/ SAND) and prompted to provide a solution (ex. STONE) which, when paired with each stimulus word, would form compound words (ex. STONEAGE/ MILESTONE/ SANDSTONE). 
I compiled two 25 item versions of the RAT using items developed by Bowden and JungBeeman (2003). Bowden and Jung-Beeman (2003) developed 144 compound word remote association problems and published normative data regarding the percentage of respondents $(\mathrm{n}=$ 289) who correctly answered each problem. Using this data I compiled a list of 50 items rank ordered by percentage of correct responses (range: 96\%-34\%). In order to create two versions of the RAT with comparable difficulty even numbered items were assigned to version 1 , and odd numbered items to version 2 . The RAT is scored by taking the sum of correct responses.

Meaning In Life Questionnaire. The meaning in life questionnaire (MILQ; Steger, Frazier, Oishi, \& Kaler, 2006) is a 10-item self-report measure used to assess a subjective sense of meaning in life during pretest, posttest, and follow-up assessments (Appendix D). The MILQ is comprised of two subscales: search and presence. The presence subscale (5-items) assesses the extent to which the respondent feels they have a sense of meaning in their life while the search subscale (5-items) assesses the extent to which the respondent is actively seeking to obtain a sense of meaning. On a 1 (absolutely false) to 7 (absolutely true) Likert scale participants will rate items such as "I understand my life's meaning" (presence) and "I am looking for something that makes my life feel meaningful" (search). The direction of the Likert scale was modified from its original form in order to assure continuity among the other measures used in the study. Alpha coefficients were acceptable for both the presence (.87) and search (.89) subscales at Time 1.

Satisfaction With Life Scale. The satisfaction with life scale (SWLS; Diener, et al., 1985 ) is a 5-item self-report measure designed to assess global life satisfaction and was administered at pretest, post-test, and the follow-up assessments (Appendix E). On a 1-7 scale where 1 indicates strongly disagree and 7 indicates strongly agree participants rated the extent to 
which they agree to the statements such as "In most ways my life is close to ideal" and "The conditions of my life are excellent." The SWLS was administered during pretest and post-test assessments, was scored by calculating the sum of the 5 items, and had an alpha coefficient of .88 at Time 1.

Alternative Uses Test. The alternative uses test (AUT; Christensen et al., 1960) assesses creative thinking by prompting respondents to list as many possible uses as they can for a common household object. The AUT was administered immediately following the conditionspecific task in each daily logs (Appendix F). The five objects presented to participants in the five daily logs were a brick, a newspaper, a paperclip, a pillow, and a shoebox. Following scoring convention, each AUT response set was scored according to four components: originality (the relative uniqueness of each response), fluency (total number of responses), flexibility (the number of conceptual categories), and elaboration (the amount of detail provided in each response). Originality scores were derived through assigned a score of 0-2 for each response; responses that comprised more than $5 \%$ of the total responses were assigned a score of 0 , responses that made up less than $5 \%$ of the total responses were given a score of 1 , and a score of 2 was assigned to each response which made up less than $1 \%$ of the total responses. Responses scored for elaboration were provided a value ranging from $0-2$ which represented the degree of detail in each response. I scored each of the components while remaining blind to experimental condition.

Personal Growth. The psychological well-being scale (Ryff, 1989; Ryff \& Keyes, 1995) is comprised of six subscales which assess the constructs of self-acceptance, environmental mastery, purpose in life, positive relations with others, autonomy, and personal growth. The 14item personal growth subscale was administered at pretest, posttest, and follow-up assessments 
(Appendix G). Using a 1 (strongly disagree) to 6 (strongly agree) likert scale participants indicated the degree to which they agree with statements such as "For me, life has been a continuous process of learning, changing, and growth" and "I am the kind of person who likes to give new things a try". The personal growth subscale is scored by calculating the mean response value across the 14-items; the alpha coefficient for the personal growth subscale was .88 .

Authenticity and Effort Scale. The authenticity and effort scale was adapted from previous enacted trait research (Fleeson, et al., 2002) by Whelan (2014). This measure assesses how authentic respondents feel in their behaviour and the extent to which they feel that their behaviour requires effort. Pretest, posttest and follow-up assessments included a 15-item version (Appendix $\mathrm{H}$ ) of the measure, while a 7-item version was administered during each of the five daily logs (Appendix I). The 15-item version includes 5 items assessing effort and 10 assessing authenticity while the 7 -item version includes 2 items assessing effort and 5 assessing authenticity. In both versions participants responded to items such as "I was my true self" and "It was very easy to behave the way I did" on a 1 (strongly disagree) to 7 (strongly agree) likert scale. The 15 -item version instructed participants to respond in the context of how they felt over the course of the previous week while in the 8-item version participants were asked to respond in the context of how they felt over the course of completing their condition-specific activity. The authenticity and effort subscales were calculated by averaging response values contained within each subscale and demonstrated acceptable internal reliability at Time 1 (authenticity $a=.86$, effort $a=.66$ )

The Positive And Negative Affect Scale. The positive and negative affect scale (PANAS-X; Watson \& Clark 1994) presents a series of emotion descriptive adjectives and asks the respondent to indicate the extent to which their feelings are consistent with each item using a 
1-5 likert scale where 1 indicates "very slightly or not at all" and 5 indicates "extremely." The full PANAS-X is comprised of 60 items which are divided into four general categories: the general dimensions, the basic negative emotions, basic positive emotions, and other affective states.

A modified 45-item version of the PANAS-X was administered during pretest, posttest, and follow-up assessments (Appendix J). The 45-item version included all items of the PANAS$\mathrm{X}$ except for those included in the basic negative emotions category and instructed participants to respond in the context of how they have felt over the course of the past week. The basic negative emotions category included additional items used to assess more nuanced negative states (e.g. fear, guilt, etc.) than those included in the basic version of the PANAS. Given the lack of association between openness and negative affect (Steele et al., 2008) these additional items were not considered necessary. Alpha coefficients for the positive and negative affect subscales used in analyses were acceptable at Time 1 (positive affect $a=.89$; negative affect $a=.84$ ).

A 27-item version was administered during each of the five daily logs (Appendix K). This brief version of the PANAS-X consisted of items from the positive affect (10), negative affect (10), serenity (4), and fatigue (3) subscales. Participants were instructed to respond in the context of how they felt over the course of completing their condition-specific activities.

Daily Logs Tasks (Experimental Condition). Participants completed a series of tasks contained within the five online daily logs. The purpose of these tasks was to engage the individual characteristics of openness. When possible, tasks employed in previous research were adapted to fit the nature of the experiment. Tasks included a series of fifteen minute writing assignments that encouraged introspection and cognitive exploration of aesthetics, ideas, and feelings as well as a trivia task designed to elicit curiosity. During the pretest assessment 
participants were presented with the instructions in condensed form (Appendix L) and asked to record their intended writing topics. Task instructions for days 1-4 were reiterated in the daily logs; on day 5 the trivia task took the place of the writing assignment (Appendix M).

The first daily log addressed aesthetic appreciation. Instructions to reflect on aesthetics were adapted from 'beauty logs' used in previous research (Diessner, Rust, Solom, Frost, \& Parsons, 2006). Diessner et al. (2006) found that writing about natural, artistic and moral beauty in weekly 'beauty logs' for twelve weeks lead to an increase in trait hope. Instructions, adapted from Diessner et al (2006), prompted participants to spend fifteen minutes writing about something beautiful that is 1) from nature; 2) man-made; and 3) in human-nature.

The second daily log addressed reflection on feelings. In order to facilitate reflecting on feelings participants were prompted to spend fifteen minutes writing down their deepest thoughts and emotions regarding two meaningful life events. Instructions were adapted from emotional disclosure literature (Lyubomirsky, Sousa, \& Dickerhoof, 2006; Pennebaker \& Francis, 1996).

The third daily log addressed introspection. Reflecting upon personal characteristics via written exercises is a commonly employed task utilized in self-affirmation research and was thought to be a suitable introspective exercise. In these tasks participants are asked to rank order eleven values/characteristics (Cohen, Aronson, \& Steele, 2000) in order of personal relevance and asked to explain 1) why their top ranked values/characteristics are important to them and 2) to specify a time then the value/characteristic was particularly important. Instructions were adapted from self-affirmation research (Cohen et. al., 2000).

The fourth daily log addressed the exploration of ideas. A survey of relevant research did not yield an established method for inducing an exploration of ideas. Thus, instructions were crafted for the purpose of the experiment. Participants were prompted to spend fifteen minutes 
writing about one or two of the most interesting ideas/concepts that they have come across during their university experience. Specifically, participants were asked to briefly describe the idea/concept and elaborate on why they find it to be particularly interesting.

The purpose of the fifth log activity was to elicit a state of curiosity. Curiosity was elicited via the presentation of trivia items; a method derived from Kang et al. (2009). In order to observe the neurological effects of curiosity Kang et al (2009) presented participants in an fMRI machine with a series of trivia items. For each presented item participants rated their level of curiosity and their confidence level that they knew the answer; forty trivia items and corresponding average participant ratings for each item were published in an appendix. As this method has been successfully employed in previous research, it was deemed a suitable manipulation of state curiosity for the purposes of the experiment.

Participants were presented with twenty-two trivia items such as "what is the only country in the world where women dominate the government" and asked to rate on a 1 (not at all) to 7 (likert scale) the degree to which they were curious to know the answer, and the extent to which they are confident they know the answer. The items presented to participants were those which had an average curiosity rating of four or above in the Kang et al (2009) sample.

Daily Logs Tasks (Control Condition). Across daily logs 1-4, participants in the control condition were asked to "record, in as much detail as possible, the happenings of your life in the past 24hrs" (Appendix N). In the fifth daily log participants were presented with trivia items thought to elicit little or no curiosity in the average respondent (Appendix O). Two items, with low average curiosity ratings, were selected from the Kang et al. sample and twenty items were created for the purpose of the experiment. Items such as "Who is the current Prime Minister of 
Canada?" and "H20 is the chemical compound for what substance" were crafted with the intent they would not elicit curiosity in the average respondent.

\section{Results}

\section{Data Management}

Prior to statistical testing I conducted exploratory data analysis to check for outliers and violations of general linear model assumptions. The distributions of all dependent variables were approximately normal. Although some outliers were observed visually in boxplots no cases were identified to be consistent outliers across multiple variables. Thus, no additional cases were excluded.

\section{Preliminary Analysis}

In order to address the possibility that participants engaged with the activities to varying degrees depending on experimental condition I compared the frequency of words written in the daily assignments between conditions. Word counts were computed in R ( R Development Core Team, 2008) using the 'stringi' package (Gagolewski \& Tartanus, 2015). Overall participants wrote more words per writing exercise in the openness condition $(M=213.40, S D=83.36)$ than

in the control condition $(M=186.40, S D=106.78), t(219)=2.08, p=.04, d=.28$. As shown in Table 1 and Figure 2, the differences in word count between conditions were small in the first (aesthetics vs control) and third (ideas vs control) daily tasks $(d=.08 ; d=.09)$. However, participants in the openness condition wrote substantially more than their counterparts in the control condition on the second (emotions vs control) and forth (introspection vs control) daily tasks $(d=.83 ; d=.36)$. Due to this variation I included word counts as a predictor in all statistical models. 


\begin{tabular}{lcccccccc}
\hline & \multicolumn{3}{c}{ Openness } & \multicolumn{3}{c}{ Control } & & \\
& $\mathrm{n}$ & $M$ & $S D$ & $\mathrm{n}$ & $M$ & $S D$ & $p$ & $d$ \\
\hline Daily Task 1 & 95 & 217.58 & 87.67 & 106 & 226.60 & 121.33 & .55 & .08 \\
Daily Task 2 & 99 & 270.27 & 115.75 & 102 & 176.24 & 115.24 & $<.001$ & .81 \\
Daily Task 3 & 93 & 158.47 & 84.95 & 99 & 168.10 & 117.59 & .52 & .09 \\
Daily Task 4 & 88 & 209.38 & 93.71 & 93 & 171.22 & 116.35 & .02 & .36 \\
Overall & 106 & 213.40 & 83.36 & 115 & 186.40 & 106.78 & .04 & .28 \\
\hline
\end{tabular}

Table 1. Word count descriptive statistics. Topics in the openness condition are aesthetics (Task1), emotions (Task 2), ideas (Task3) and introspection (Task4).

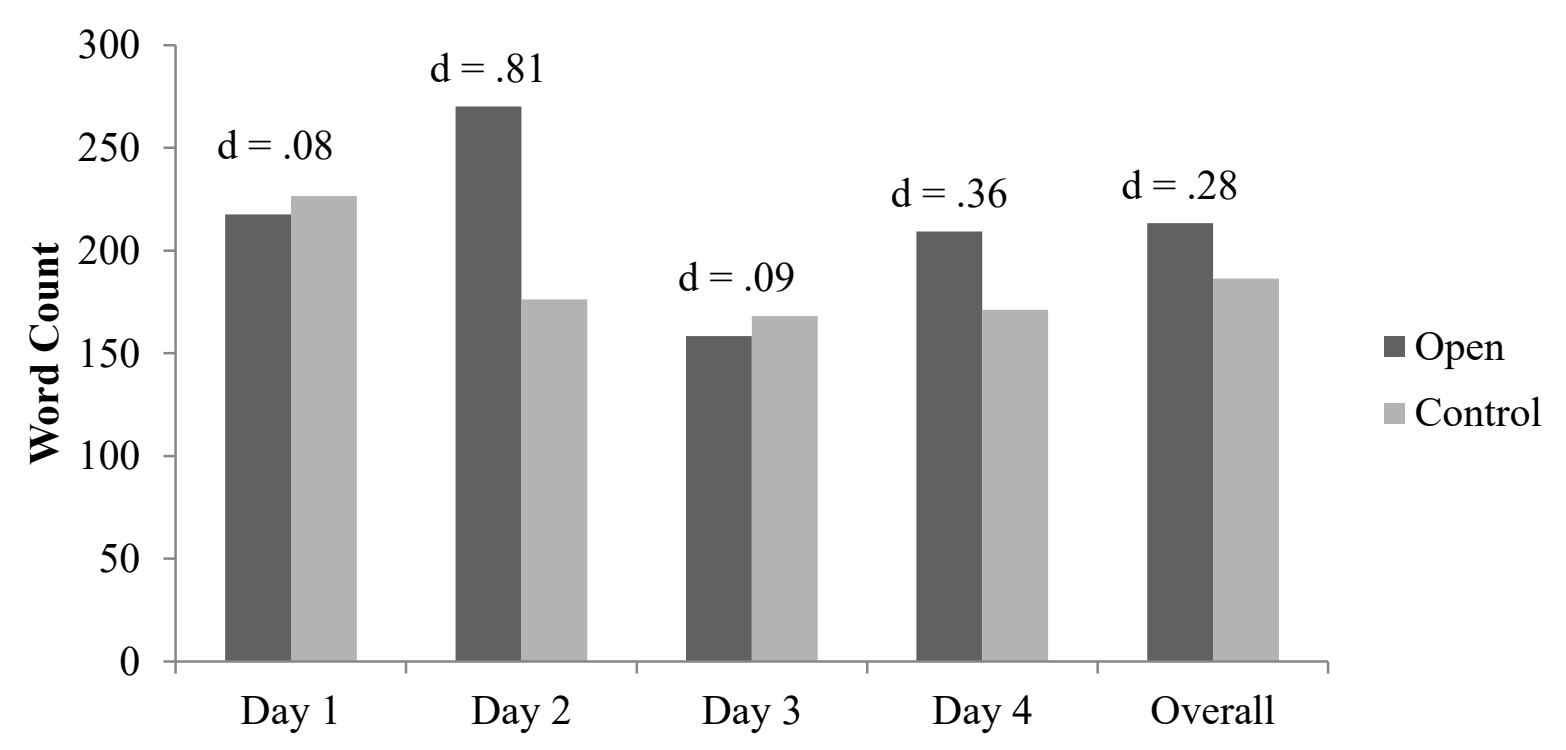

Figure 2. Mean word counts by condition over time. Topics in the openness condition are aesthetics (task 1), emotions (task 2), ideas (task 3) and introspection (task 4).

As a manipulation check of the curiosity task I compared the average rating of how curious participants were to see the trivia answers between the openness and control condition (see Figure 3). As expected those in the openness condition $(M=4.77, S D=1.10)$ were more curious to know the answers to the trivia items than were those in the control condition $(M=$ 3.20, $S D=1.39), t(184)=8.45, p<.001, d=1.25$. Consistent with this finding, participants in the openness condition $(M=3.07, S D=1.04)$ were less confident than participants in the control condition $(M=4.82, S D=1.04)$ that they knew the answers to the trivia questions $t(184)=$ 
$11.43, p<.001, d=1.68$. Thus, I can be relatively confident that the curiosity manipulation produced its intended effect.

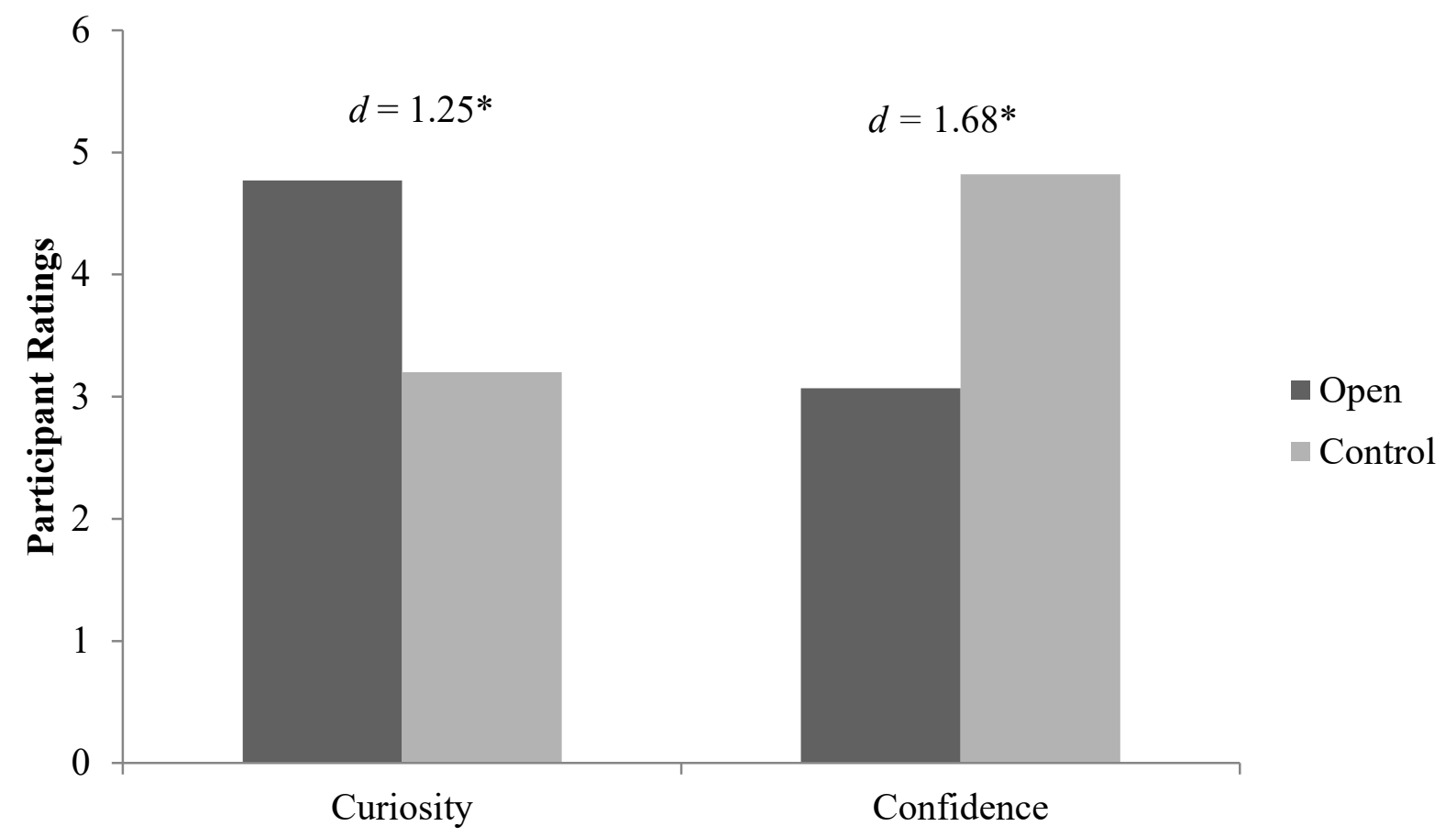

Figure 3. Mean curiosity and confidence ratings for the curiosity manipulation.

\section{Statistical Approach}

With one exception, I elected to test all hypotheses though a multi-level modelling (MLM) approach using SAS 9.4. MLM allows for analysis of between group and within-person differences across time points in longitudinal designs. Given the nature of my data, MLM confers a number of advantages over other statistical options such as t-tests, regression, or analysis of variance tests (ANOVA). First, the number of t-tests required to address my entire set of hypothesis would require steep p-value corrections to adjust for family-wise error; however, MLM arguably addresses this issue (Gelman, Hill, \& Yajima, 2012). Second, I am interested in trait by condition interactions. These categorical by condition interactions are normally testable with regression methods; however, because I am interested in these interactions across time 
points, MLM is required. Third, the unequal spacing between the pretest, posttest, and follow-up assessments violated an assumption of the general linear model. In contrast, MLM is not subject to this restriction (Singer, 1998).

In constructing models I used a series of additive steps that were consistent across hypothesis tests. Model A represents a random-intercept (or unconditional) model which will partition variance in the dependent variable into within person (level 1) and between person (level 2) variance.

\section{Model A: Random intercept (unconditional) model}

Level 1: $y_{t i}=\beta_{0 i}+r_{t i}$

Level 2: $\beta_{0 i}=\gamma_{00}+\mu_{0 i}$

Variance estimates from the unconditional model can also be used to calculate the intraclass correlation (ICC). The ICC is computed using the level 1 and level 2 variance estimates from the unconditional model and represents the proportion of the total variance accounted for by level 2 variance (West, Ryu, Kwok, \& Cham, 2011).

\section{Intraclass Correlation}

$$
\mathrm{ICC}=\frac{\tau 00}{\tau 00+\sigma 2}
$$

Model B is identical to Model A however the variable 'time' was allowed to vary randomly. The results from this model determine whether time should be considered a random 
effect in subsequent models, or in contrast, if a simpler model may provide a more reasonable fit (Singer, 1998).

Model C is a random coefficients model which adds the level 2 predictor of 'condition' and a condition by time interaction to test whether potential variation over time occurs at different rates depending upon condition.

Model C: Random coefficients model with 2 predictors (time and condition)

Level 1: $y_{t i}=\beta_{0 i}+\beta_{1 \mathrm{i}}(\text { time })_{\mathrm{ti}}+r_{t i}$

Level 2: $\beta_{0 i}=\gamma_{00}+\gamma_{01}(\text { condition })_{i}+\mu_{0 i}$

$$
\beta_{1 i}=\gamma_{00}+\gamma_{11}(\text { condition })_{i}+\mu_{0 i}
$$

Full model reduced Form:

$$
\begin{aligned}
y_{t i} & =\gamma_{00}+\gamma_{10}(\text { time })_{\mathrm{ti}}+\gamma_{01}(\text { condition })_{i}+\gamma_{11}(\text { time })_{\mathrm{ti}}(\text { condition })_{\mathrm{i}} \\
& +\mu_{0 i}+\mu_{1 i}(\mathrm{time})+r_{t i}
\end{aligned}
$$

In Model D I added the time-varying predictor variable of 'word count' (group centered) as a level 1 predictor and the time-invariant variable 'trait openness' (group centered) as a level 2 predictor.

Model D: Random coefficients model with 4 predictors

Level 1: $y_{t i}=\beta_{0 i}+\beta_{1 \mathrm{i}}(\text { time })_{\mathrm{ti}}+\beta_{2 \mathrm{i}}($ word count $)+r_{t i}$

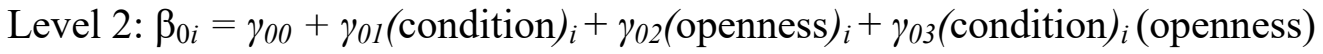

$$
+\mu_{0 i}
$$




$$
\begin{aligned}
\beta_{1 i} & =\gamma_{00}+\gamma_{11}(\text { condition })_{i}+\gamma_{12}(\text { openness })_{i}+\gamma_{13}(\text { condition })_{i}(\text { openness })_{i} \\
& +\mu_{0 i}
\end{aligned}
$$

Full model reduced Form:

$$
\begin{aligned}
& y_{t i}=\gamma_{00}+\gamma_{10}(\text { time })_{\mathrm{ti}}+\gamma_{20}(\text { word count })_{\mathrm{t}}+\gamma_{01}(\text { condition })_{i}+\gamma_{02}(\text { openness })_{i}+ \\
& \gamma_{03}(\text { condition })_{i}(\text { openness })_{i}+\gamma_{11}(\text { time })_{\mathrm{ti}}(\text { condition })_{\mathrm{i}}+\gamma_{12}(\text { word count })_{i} \\
& (\text { condition })+\gamma_{03}(\text { openness })_{i}(\text { condition })+\gamma_{12}(\text { time })_{i}(\text { openness })+\gamma_{30}(\text { time }) \\
& i(\text { word Count })+\mu_{0 i}+\mu_{1 i}(\text { time })+r_{t i}
\end{aligned}
$$

Finally, in all cases a Model E is presented. Because the presence of multiple nonsignificant interaction terms can unduly influence multilevel results, I employed a sequential testing strategy to remove non-significant interaction terms in order from largest to smallest $p$ values (see Aiken \& West, 1999, pp. 111-113).

\section{Hypothesis 1: Creativity}

Hypothesis 1a proposes that scores on the alternate uses task would be greater in the openness condition than the control condition following the condition specific tasks for each of the four components of the alternate uses task: originality, flexibility (number of response categories), fluency (total number of response), and elaboration. As shown in Table 2 and illustrated in Figure 4, participants provided the more original responses on average on the first alternate uses task, however, the differences between conditions on all originality scores were $\operatorname{trivial}(d=.00-.13)$. 


\begin{tabular}{lccccc}
\hline & \multicolumn{2}{c}{ Openness } & \multicolumn{2}{c}{ Control } & \\
& $M$ & $S D$ & $M$ & $S D$ & $d$ \\
\hline Day 1 (Brick) & 1.50 & .89 & 1.38 & .89 & .13 \\
Day 2 (Newspaper) & 0.89 & .35 & 0.90 & .37 & .03 \\
Day 3 (Paperclip) & 0.90 & .37 & 0.93 & .35 & .08 \\
Day 4 (Pillow) & 1.04 & .40 & 1.04 & .39 & .00 \\
Day 5 (Shoebox) & 0.99 & .41 & 0.97 & .40 & .05 \\
\hline
\end{tabular}

Table 2. Alternate uses task 'originality' descriptive statistics (daily assessments). Topics in the openness condition are aesthetics (task 1), emotions (task 2), ideas (task 3 ) and introspection (task 4); Task 5 is a curiosity manipulation.

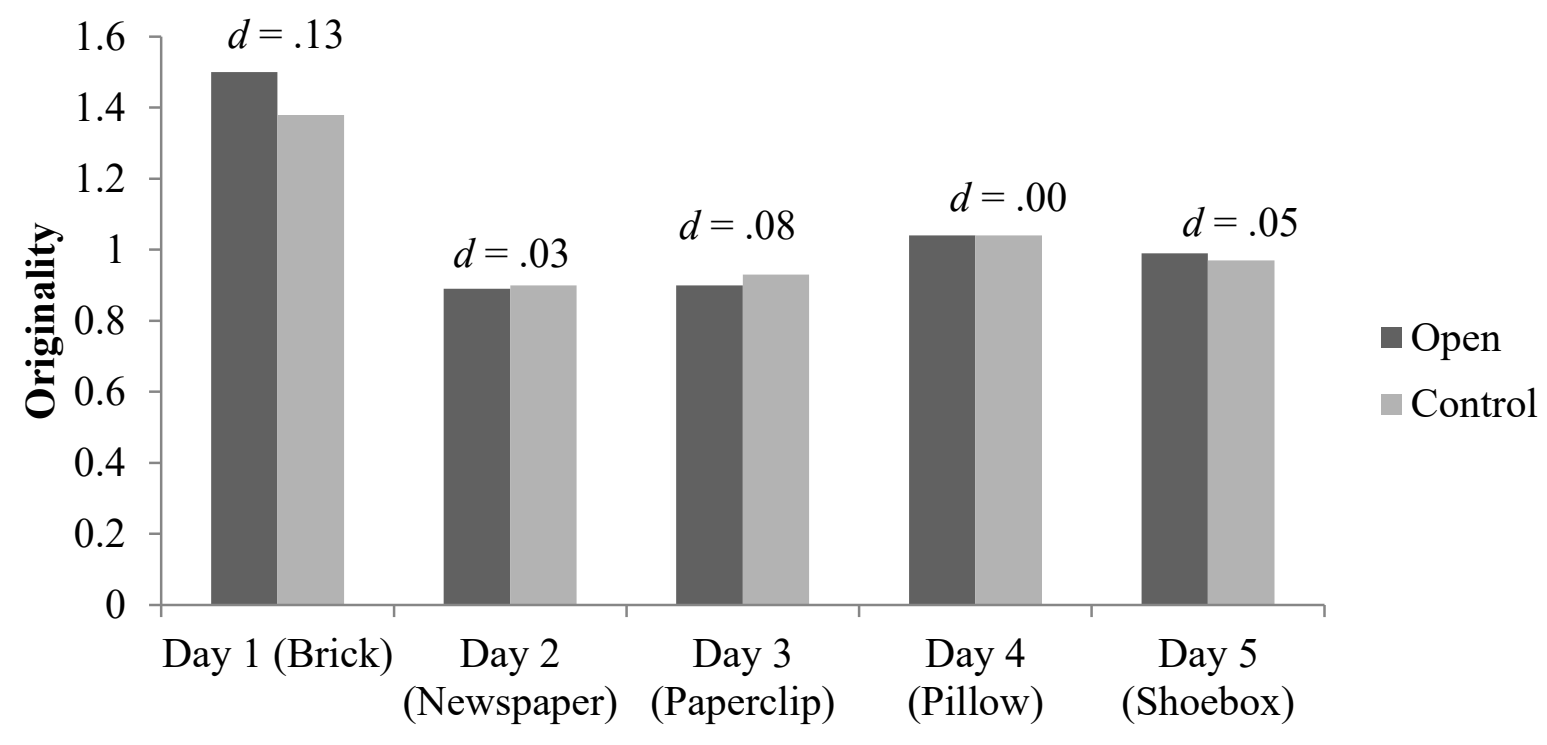

Figure 4. Mean alternate uses task 'originality' scores over time (daily assessments). Topics in the openness condition are aesthetics (task 1), emotions (task 2), ideas (task 3) and introspection (task 4).

Using parameter estimates from Model A, I calculated an intra class correlation (ICC) of .26 which suggests that $26 \%$ of the variance in originality scores was attributable to level 2 predictors. As illustrated in Table 3 the variable 'time' was not significant when included as randomly varying in Model B, and was therefore not included in subsequent models.

Consistent with previous research trait openness predicted originality scores on the alternate uses task averaging across assessments in the final model, $\beta=.11, S E=.04, t(208)=2.59, p=.01$. However, the originality of responses did not vary between conditions, $\beta=.04, S E=.04, t(206)$ 
$=0.96, p=.34$. Interestingly, a main effect of word count was observed suggesting that higher word counts in daily writing assignments, irrespective of condition, were associated with elevated scores of originality on the alternate uses task assessment, $\beta=.0004, S E=.00, t(206)=$ $2.29, p=.02$.

\begin{tabular}{|c|c|c|c|c|c|c|}
\hline Mode & & $\begin{array}{l}\text { Parameter } \\
\text { Estimates }\end{array}$ & $\begin{array}{c}\text { Standard } \\
\text { Error }\end{array}$ & $t$ & $z$ & $p$ \\
\hline \multirow[t]{4}{*}{ A } & Intercept $\left(\gamma_{00}\right)$ & 0.81 & .04 & 18.91 & & $<.001$ \\
\hline & Time $\left(\gamma_{10}\right)$ & 0.04 & .01 & 3.62 & & $<.001$ \\
\hline & Intercept $\left(\tau_{00}\right)$ & 0.04 & .01 & & 5.15 & $<.001$ \\
\hline & Residual $\left(\sigma^{2}\right)$ & 0.11 & .00 & & 15.76 & $<.001$ \\
\hline \multirow[t]{6}{*}{ B } & Intercept $\left(\gamma_{00}\right)$ & 0.81 & .04 & 19.33 & & $<.001$ \\
\hline & Time $\left(\gamma_{10}\right)$ & 0.04 & .01 & 3.48 & & $<.001$ \\
\hline & Intercept $\left(\tau_{00}\right)$ & 0.03 & .04 & & 0.73 & .234 \\
\hline & Time $\left(\tau_{11}\right)$ & 0.00 & .00 & & 0.61 & .272 \\
\hline & $\operatorname{Cov}\left(\tau_{10}\right)$ & -0.00 & .01 & & -0.20 & .839 \\
\hline & Residual $\left(\sigma^{2}\right)$ & 0.11 & .01 & & 12.72 & $<.001$ \\
\hline \multirow[t]{6}{*}{$\mathrm{C}$} & Intercept $\left(\gamma_{00}\right)$ & 0.73 & .14 & 5.32 & & $<.001$ \\
\hline & Time $\left(\gamma_{10}\right)$ & 0.06 & .04 & 1.70 & & .090 \\
\hline & Condition $\left(\gamma_{01}\right)$ & 0.05 & .09 & 0.60 & & .546 \\
\hline & Time*Condition $\left(\gamma_{11}\right)$ & -0.01 & .22 & -0.60 & & .548 \\
\hline & Intercept $\left(\tau_{00}\right)$ & 0.04 & .01 & & 5.16 & $<.001$ \\
\hline & Residual $\left(\sigma^{2}\right)$ & 0.11 & .01 & & 15.74 & $<.001$ \\
\hline \multirow[t]{12}{*}{$\mathrm{D}$} & Intercept $\left(\gamma_{00}\right)$ & 0.62 & .19 & 3.27 & & .001 \\
\hline & Time $\left(\gamma_{10}\right)$ & 0.09 & .06 & 1.53 & & .128 \\
\hline & Word Count $\left(\gamma_{20}\right)$ & -0.00 & .00 & -0.25 & & .799 \\
\hline & Condition $\left(\gamma_{01}\right)$ & 0.07 & .12 & 0.57 & & .571 \\
\hline & Trait Open $\left(\gamma_{02}\right)$ & 0.08 & .17 & 0.45 & & .650 \\
\hline & Trait Open*Condition $\left(\gamma_{03}\right)$ & -0.04 & .08 & -0.45 & & .655 \\
\hline & Trait Open*Time $\left(\gamma_{12}\right)$ & 0.03 & .04 & 0.73 & & .466 \\
\hline & Time*Condition $\left(\gamma_{11}\right)$ & -0.01 & .04 & -0.29 & & .771 \\
\hline & Time*Word Count $\left(\gamma_{30}\right)$ & 0.00 & .00 & 1.20 & & .229 \\
\hline & Condition*Word Count $\left(\gamma_{21}\right)$ & -0.00 & .00 & -0.06 & & .953 \\
\hline & Intercept $\left(\tau_{00}\right)$ & 0.03 & .01 & & 4.04 & $<.001$ \\
\hline & Residual $\left(\sigma^{2}\right)$ & 0.10 & .01 & & 12.64 & $<.001$ \\
\hline \multirow[t]{2}{*}{$\mathrm{E}$} & Intercept $\left(\gamma_{00}\right)$ & 0.66 & .08 & 8.10 & & $<.001$ \\
\hline & Time $\left(\gamma_{10}\right)$ & 0.08 & .02 & 4.39 & & $<.001$ \\
\hline
\end{tabular}




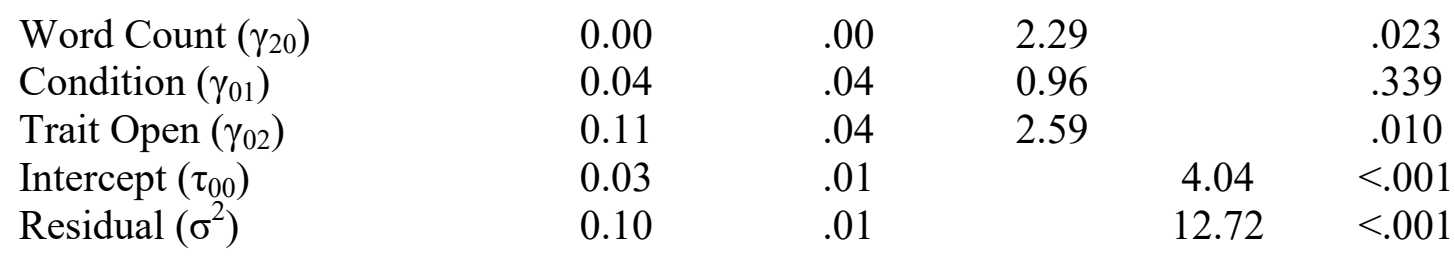

Table 3. MLM models for alternate uses task 'originality' (daily assessments). Topics in the openness condition are aesthetics (task 1), emotions (task 2), ideas (task 3) and introspection (task4).

Means and $S D$ 's for the number of response categories (flexibility) given by participants in each condition are presented in Table 4 and illustrated in Figure 5. Again, differences in flexibility of responses between conditions were negligible $(d=.06-.18)$.

\begin{tabular}{lccccc}
\hline & \multicolumn{2}{c}{ Openness } & \multicolumn{3}{c}{ Control } \\
& $M$ & $S D$ & $M$ & $S D$ & $d$ \\
\hline Day 1 (Brick) & 4.83 & 2.19 & 4.42 & 2.27 & .18 \\
Day 2 (Newspaper) & 5.82 & 2.37 & 5.99 & 2.69 & .07 \\
Day 3 (Paperclip) & 5.02 & 2.26 & 5.14 & 2.10 & .06 \\
Day 4 (Pillow) & 5.36 & 2.30 & 5.09 & 2.26 & .12 \\
Day 5 (Shoebox) & 4.23 & 1.96 & 4.01 & 2.04 & .11 \\
\hline
\end{tabular}

Table 4. Alternate uses task means and SDs for flexibility. Topics in the openness condition are aesthetics (task 1), emotions (task 2), ideas (task 3) and introspection (task 4); task 5 is the curiosity manipulation.

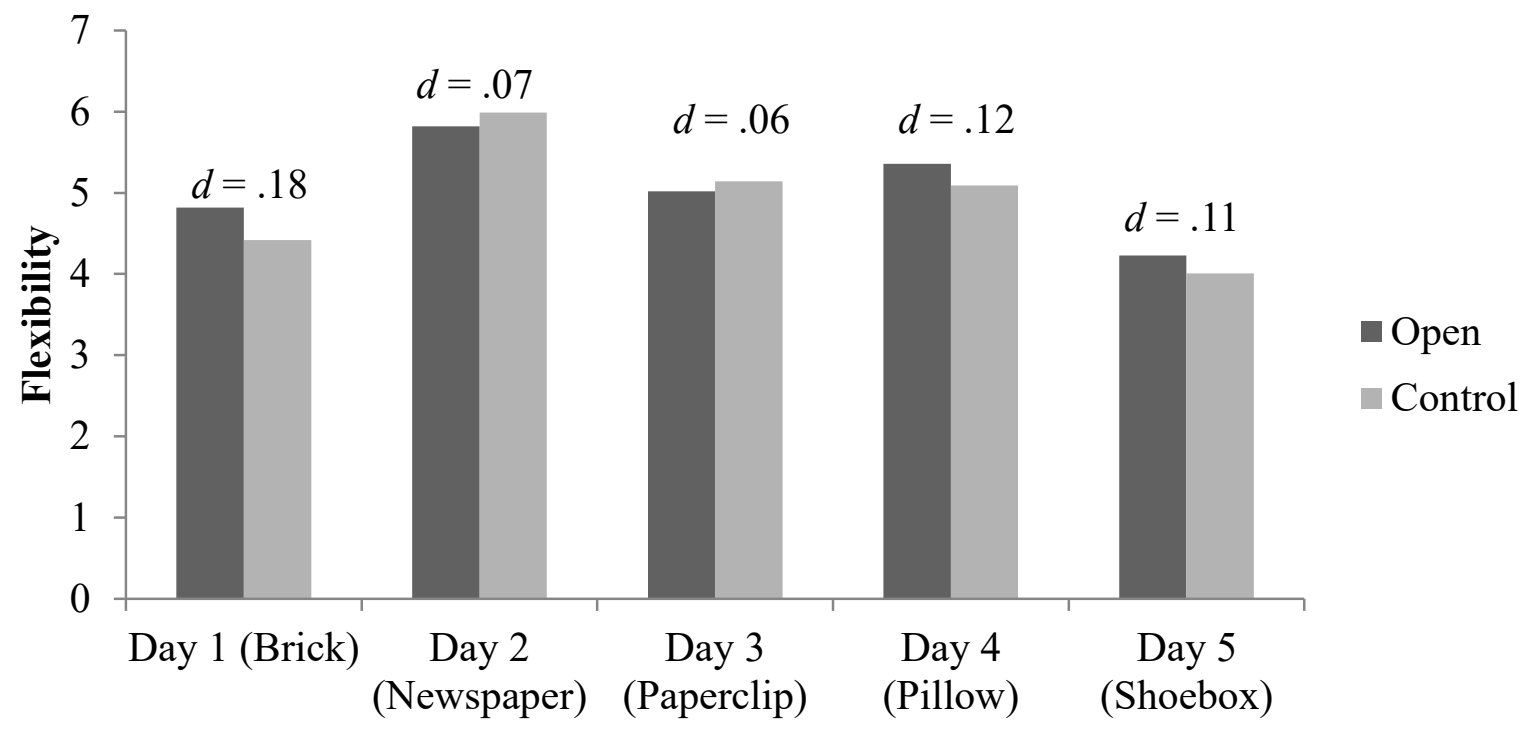


Figure 5. Mean alternate uses task 'flexibility' scores over time (daily assessments). Topics in the openness condition are aesthetics (task 1), emotions (task 2), ideas (task 3 ) and introspection (task 4).

Contrary to the hypothesis, no main effect of condition was observed in the final model, $\beta$ $=0.09, S E=.25, t(208)=0.36, p=.72$. Consistent with previous research and results from analyses on originality scores, trait openness predicted the flexibility of responses on the alternate uses task assessments in the final model, $\beta=1.36, S E=.27, t(208)=5.03, p<.001$. Flexibility scores also varied across time points such that individuals tended to provide more conceptual categories on their responses as the study progressed over time, $\beta=.13, S E=.19, t$ $(208)=2.25, p=.03$. Additionally, a time by word count interaction was detected, $\beta=0.002, S E$ $=.0005, t(208)=3.49, p<.001$. Following procedures developed by Aiken and West (1991) I used simple slopes analyses to probe this interaction (see Figure 6). Simple slopes analyses revealed that individuals' flexibility scores increased over time only for those who wrote $1 S D$ more words in their writing tasks than average, $\beta=0.37, S E=.08, t(495)=4.65, p<.001$. 


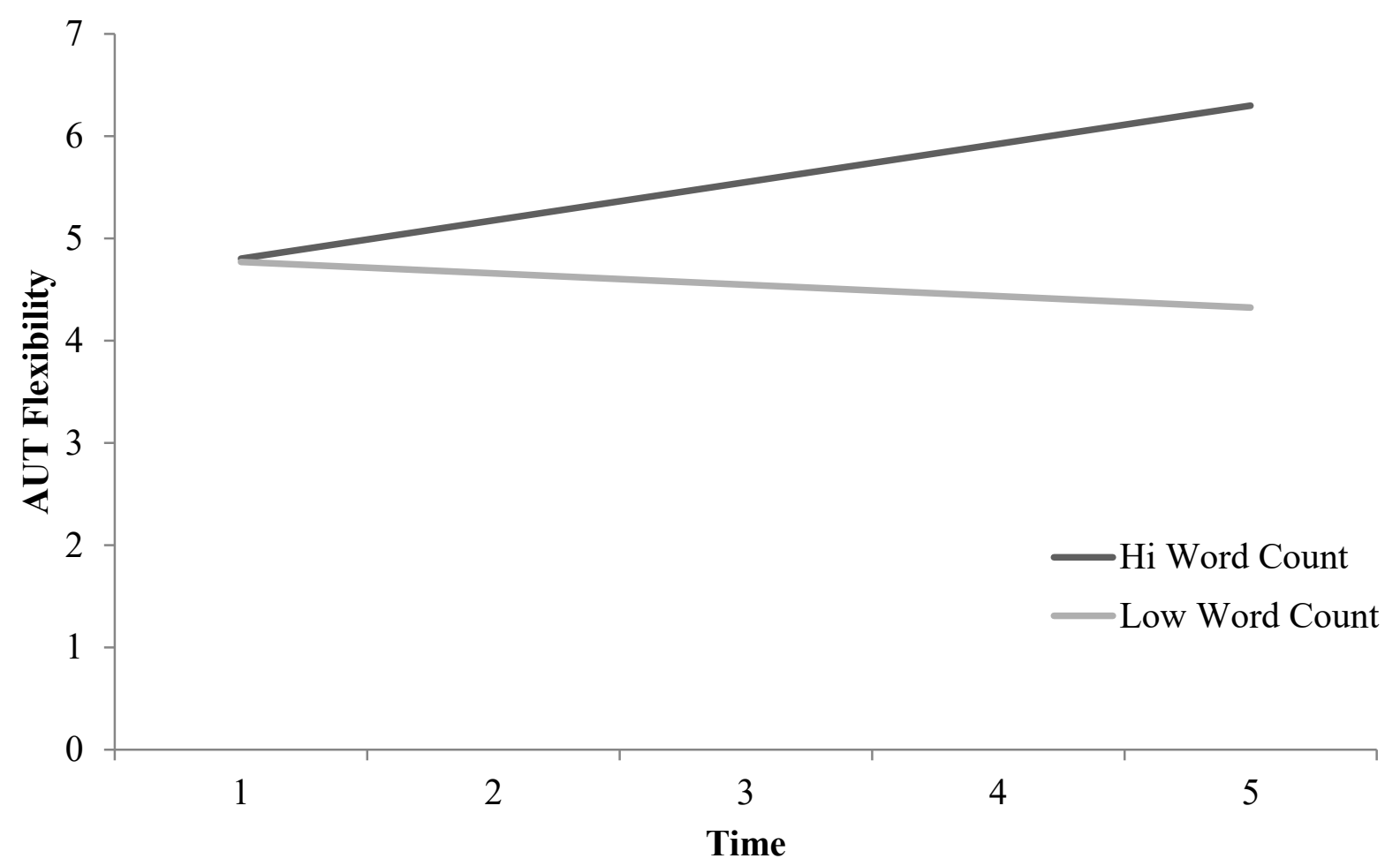

Figure 6. Simple slopes for time by word count interaction predicting alternate uses tasks 'flexibility' scores (daily assessments).

\begin{tabular}{|c|c|c|c|c|c|c|}
\hline \multicolumn{2}{|c|}{ Model } & $\begin{array}{l}\text { Parameter } \\
\text { Estimates }\end{array}$ & $\begin{array}{l}\text { Standard } \\
\text { Error }\end{array}$ & $t$ & $z$ & $p$ \\
\hline \multirow[t]{4}{*}{$\mathrm{A}$} & Intercept $\left(\gamma_{00}\right)$ & 5.40 & .17 & 31.27 & & $<.001$ \\
\hline & Time $\left(\gamma_{10}\right)$ & -0.17 & .04 & -4.25 & & $<.001$ \\
\hline & Intercept $\left(\tau_{00}\right)$ & 2.54 & .32 & & 7.91 & $<.001$ \\
\hline & Residual $\left(\sigma^{2}\right)$ & 2.86 & & & & \\
\hline \multirow[t]{6}{*}{ B } & Intercept $\left(\gamma_{00}\right)$ & 5.39 & .18 & 30.03 & & $<.001$ \\
\hline & Time $\left(\gamma_{10}\right)$ & -0.17 & .04 & -4.18 & & $<.001$ \\
\hline & Intercept $\left(\tau_{00}\right)$ & 3.04 & .57 & & 5.33 & $<.001$ \\
\hline & Time $\left(\tau_{11}\right)$ & - & - & & - & - \\
\hline & $\operatorname{Cov}\left(\tau_{10}\right)$ & -0.08 & .07 & & -1.14 & .253 \\
\hline & Residual $\left(\sigma^{2}\right)$ & 2.86 & .16 & & 18.38 & $<.001$ \\
\hline \multirow[t]{4}{*}{$\mathrm{C}$} & Intercept $\left(\gamma_{00}\right)$ & 5.49 & .56 & 9.82 & & $<.001$ \\
\hline & Time $\left(\gamma_{10}\right)$ & -0.15 & .13 & -1.16 & & .248 \\
\hline & Condition $\left(\gamma_{01}\right)$ & -0.06 & .35 & -0.18 & & .860 \\
\hline & Time*Condition $\left(\gamma_{11}\right)$ & -0.01 & .08 & -0.16 & & .870 \\
\hline
\end{tabular}




\begin{tabular}{|c|c|c|c|c|c|c|}
\hline & Intercept $\left(\tau_{00}\right)$ & 2.55 & .32 & & 7.90 & $<.001$ \\
\hline & Residual $\left(\sigma^{2}\right)$ & 2.87 & .16 & & 18.36 & $<.001$ \\
\hline \multirow[t]{12}{*}{$\mathrm{D}$} & Intercept $\left(\gamma_{00}\right)$ & 4.86 & .62 & 7.87 & & $<.001$ \\
\hline & Time $\left(\gamma_{10}\right)$ & 0.03 & .19 & 0.16 & & .872 \\
\hline & Word Count $\left(\gamma_{20}\right)$ & -0.05 & .38 & -0.13 & & .897 \\
\hline & Condition $\left(\gamma_{01}\right)$ & 0.06 & .11 & 0.54 & & .587 \\
\hline & Trait Open $\left(\gamma_{02}\right)$ & 1.72 & .92 & 1.87 & & .063 \\
\hline & Trait Open*Condition $\left(\gamma_{03}\right)$ & -0.34 & .54 & -0.63 & & .529 \\
\hline & Trait Open*Time $\left(\gamma_{12}\right)$ & 0.06 & .12 & 0.52 & & .601 \\
\hline & Time* Condition $\left(\gamma_{11}\right)$ & 0.06 & .12 & 0.54 & & .587 \\
\hline & Time*Word Count $\left(\gamma_{30}\right)$ & 0.00 & .00 & 3.75 & & $<.001$ \\
\hline & Condition*Word $\operatorname{Count}\left(\gamma_{21}\right)$ & -0.00 & .00 & -1.19 & & .234 \\
\hline & Intercept $\left(\tau_{00}\right)$ & 2.32 & .32 & & 7.35 & $<.001$ \\
\hline & Residual $\left(\sigma^{2}\right)$ & 2.66 & .17 & & 15.75 & $<.001$ \\
\hline \multirow[t]{8}{*}{$\mathrm{E}$} & Intercept $\left(\gamma_{00}\right)$ & 4.65 & .42 & 10.96 & & $<.001$ \\
\hline & Time $\left(\gamma_{10}\right)$ & 0.13 & .06 & 2.25 & & .025 \\
\hline & Word Count $\left(\gamma_{20}\right)$ & -0.00 & .00 & -1.31 & & .191 \\
\hline & Condition $\left(\gamma_{01}\right)$ & 0.09 & .25 & 0.36 & & .718 \\
\hline & Trait Open $\left(\gamma_{02}\right)$ & 1.36 & .27 & 5.03 & & $<.001$ \\
\hline & Time*Word Count $\left(\gamma_{30}\right)$ & 0.00 & .00 & 3.94 & & $<.001$ \\
\hline & Intercept $\left(\tau_{00}\right)$ & 2.29 & .31 & & 7.38 & $<.001$ \\
\hline & Residual $\left(\sigma^{2}\right)$ & 2.66 & .17 & & 15.82 & $<.001$ \\
\hline
\end{tabular}

Figure 7. MLM models for alternate uses task 'flexibility' scores (daily assessments).

Total responses provided (fluency) did not vary by condition $(\mathrm{d}=.00-.05$; see Table 5 and Figure 8).

\begin{tabular}{lccccc}
\hline & \multicolumn{2}{c}{ Openness } & \multicolumn{2}{c}{ Control } & \\
& $M$ & $S D$ & $M$ & $S D$ & .04 \\
\hline Day 1 (Brick) & 7.72 & 2.97 & 7.57 & 3.82 & .05 \\
Day 2 (Newspaper) & 8.37 & 3.20 & 8.56 & 3.86 & .03 \\
Day 3 (Paperclip) & 6.56 & 3.22 & 6.67 & 3.28 & .04 \\
Day 4 (Pillow) & 6.80 & 3.15 & 6.93 & 3.22 & .00 \\
Day 5 (Shoebox) & 6.81 & 3.16 & 6.82 & 3.20 & \\
\hline
\end{tabular}

Table 5. Alternate uses task 'fluency' descriptive statistics (daily assessments). Topics in the openness condition are aesthetics (task 1), emotions (task 2), ideas (task 3 ) and introspection (task 4); task 5 is the curiosity manipulation. 


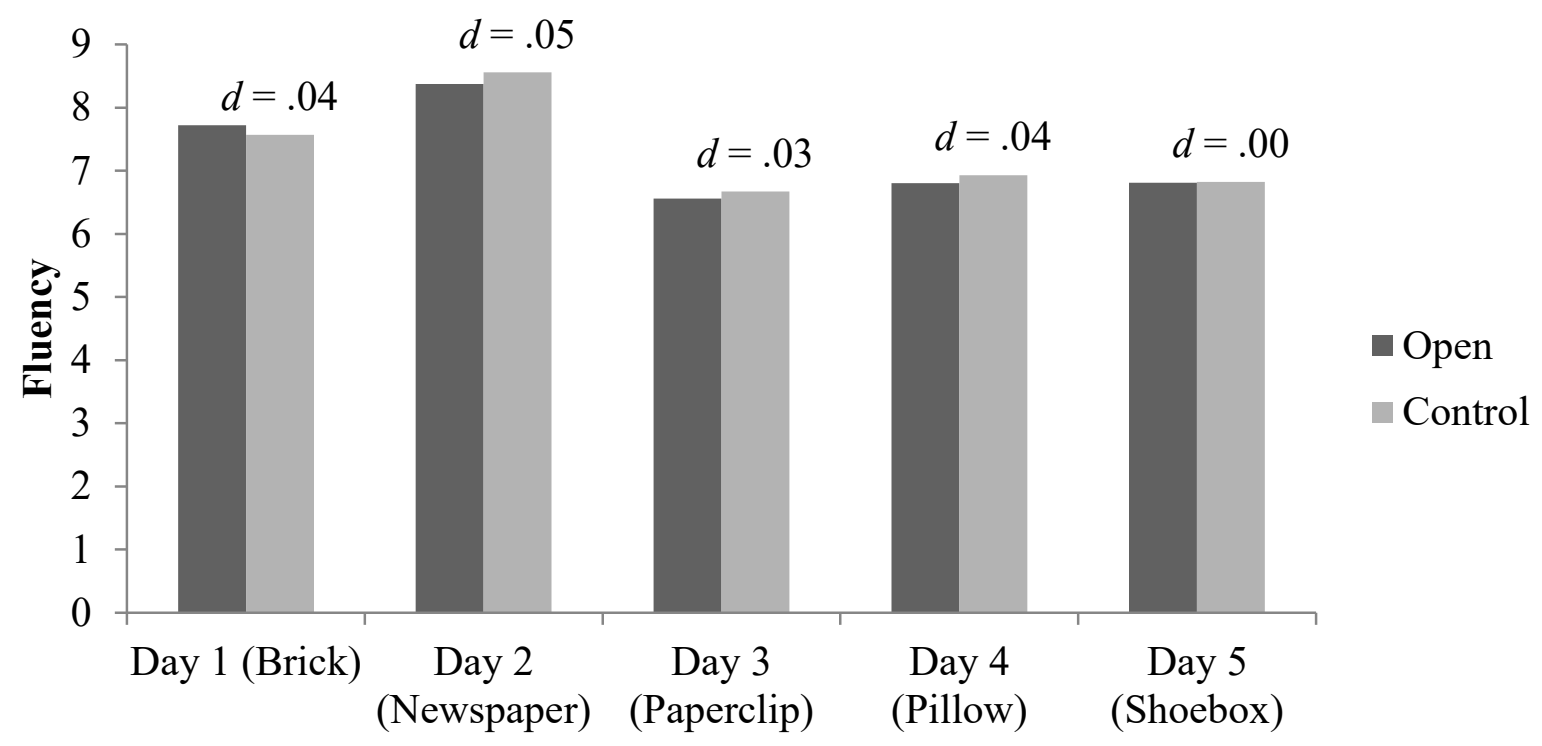

Figure 8. Mean alternate uses task 'fluency' scores over time (daily assessments). Topics in the openness condition are aesthetics (task 1), emotions (task 2), ideas (task 3 ) and introspection (task 4); task 5 is the curiosity manipulation.

A main effect of time was observed suggesting that the number of responses individual participants provided decreased over the duration of the study (see Table 6 ), $\beta=-0.36, S E=.08$, $t(495)=-4.84, p<.001$. Consistent with analysis of originality and flexibility, trait openness was a significant predictor of fluency in the final model, $\beta=.1 .67, S E=.42, t(208)=53.97, p<.001$, but was not influenced by condition, $\beta=0.26, S E=.38, t(208)=0.68, p=.84$. Similar to flexibility scores, variation in word count across time points accounted for a statistically significant proportion of variance in the fluency of response, $\beta=0.002, S E=.0007, t(208)=$ $2.61, p=.01$. When probed (see Figure 9), this interactions suggests that fluency decreased significantly over time for those $1 S D$ below the word count mean, $\beta=-0.63, S E=.27, t(495)=-$ $2.36, p=.02$, however, this was not the case for those $1 S D$ above the word count mean, $\beta=$ $0.18, S E=.25, t(495)=-0.73, p=.47$. 


\begin{tabular}{|c|c|c|c|c|c|c|}
\hline Model & & $\begin{array}{l}\text { Parameter } \\
\text { Estimates }\end{array}$ & $\begin{array}{c}\text { Standard } \\
\text { Error }\end{array}$ & $t$ & $z$ & $p$ \\
\hline \multirow[t]{4}{*}{ A } & Intercept $\left(\gamma_{00}\right)$ & 8.12 & .24 & 33.23 & & $<.001$ \\
\hline & Time $\left(\gamma_{10}\right)$ & -0.33 & .05 & -6.50 & & $<.001$ \\
\hline & Intercept $\left(\tau_{00}\right)$ & 6.95 & .79 & 8.83 & & $<.001$ \\
\hline & Residual $\left(\sigma^{2}\right)$ & 4.33 & .24 & 18.40 & & $<.001$ \\
\hline \multirow[t]{6}{*}{$\mathrm{B}$} & Intercept $\left(\gamma_{00}\right)$ & 8.11 & .27 & 30.50 & & $<.001$ \\
\hline & Time $\left(\gamma_{10}\right)$ & -0.32 & .05 & -5.99 & & $<.001$ \\
\hline & Intercept $\left(\tau_{00}\right)$ & 9.43 & 1.48 & & 6.36 & $<.001$ \\
\hline & Time $\left(\tau_{11}\right)$ & 0.09 & .06 & & 1.41 & .079 \\
\hline & $\operatorname{Cov}\left(\tau_{10}\right)$ & -0.54 & .26 & & -2.09 & .036 \\
\hline & Residual $\left(\sigma^{2}\right)$ & 4.11 & .26 & & 15.83 & $<.001$ \\
\hline \multirow[t]{6}{*}{$\mathrm{C}$} & Intercept $\left(\gamma_{00}\right)$ & 8.00 & .79 & 10.11 & & $<.001$ \\
\hline & Time $\left(\gamma_{10}\right)$ & -029 & .16 & -1.79 & & .074 \\
\hline & Condition $\left(\gamma_{01}\right)$ & 0.08 & .49 & 0.16 & & .870 \\
\hline & Time*Condition $\left(\gamma_{11}\right)$ & -0.02 & .10 & -0.23 & & .819 \\
\hline & Intercept $\left(\tau_{00}\right)$ & 6.99 & .79 & & 8.82 & $<.001$ \\
\hline & Residual $\left(\sigma^{2}\right)$ & 4.34 & .24 & & 18.38 & $<.001$ \\
\hline \multirow[t]{12}{*}{$\mathrm{D}$} & Intercept $\left(\gamma_{00}\right)$ & 7.85 & .87 & 9.07 & & $<.001$ \\
\hline & Time $\left(\gamma_{10}\right)$ & -0.40 & .24 & -1.66 & & .097 \\
\hline & Word Count $\left(\gamma_{20}\right)$ & 0.00 & .00 & 0.32 & & .751 \\
\hline & Condition $\left(\gamma_{01}\right)$ & 0.21 & .53 & 0.40 & & 692 \\
\hline & Trait Open $\left(\gamma_{02}\right)$ & 3.21 & 1.39 & 2.31 & & .022 \\
\hline & Trait Open*Condition $\left(\gamma_{03}\right)$ & -0.80 & .84 & -0.96 & & .340 \\
\hline & Trait Open*Time $\left(\gamma_{12}\right)$ & -0.14 & .16 & -0.86 & & .390 \\
\hline & Time*Condition $\left(\gamma_{11}\right)$ & 0.03 & .15 & 0.18 & & .859 \\
\hline & Time*Word Count $\left(\gamma_{30}\right)$ & 0.00 & .00 & 2.73 & & .007 \\
\hline & Condition*Word Count $\left(\gamma_{21}\right)$ & -0.00 & .00 & -0.36 & & .721 \\
\hline & Intercept $\left(\tau_{00}\right)$ & 6.22 & .75 & & 8.24 & $<.001$ \\
\hline & Residual $\left(\sigma^{2}\right)$ & 4.39 & .28 & & 15.77 & $<.001$ \\
\hline \multirow[t]{8}{*}{$\mathrm{E}$} & Intercept $\left(\gamma_{00}\right)$ & 7.79 & .65 & 12.07 & & $<.001$ \\
\hline & Time $\left(\gamma_{10}\right)$ & -0.36 & .08 & -4.84 & & $<.001$ \\
\hline & Word Count $\left(\gamma_{20}\right)$ & 0.00 & .00 & 0.20 & & .843 \\
\hline & Condition $\left(\gamma_{01}\right)$ & 0.26 & .38 & 0.68 & & .500 \\
\hline & Trait Open $\left(\gamma_{02}\right)$ & 1.67 & .42 & 3.97 & & $<.001$ \\
\hline & Time*Word Count $\left(\gamma_{30}\right)$ & 0.00 & .00 & 2.61 & & .009 \\
\hline & Intercept $\left(\tau_{00}\right)$ & 6.19 & .75 & & 8.30 & $<.001$ \\
\hline & Residual $\left(\sigma^{2}\right)$ & 4.38 & .28 & & 15.84 & $<.001$ \\
\hline
\end{tabular}

Table 6. MLM models for alternate uses task 'fluency' scores (daily assessments). 


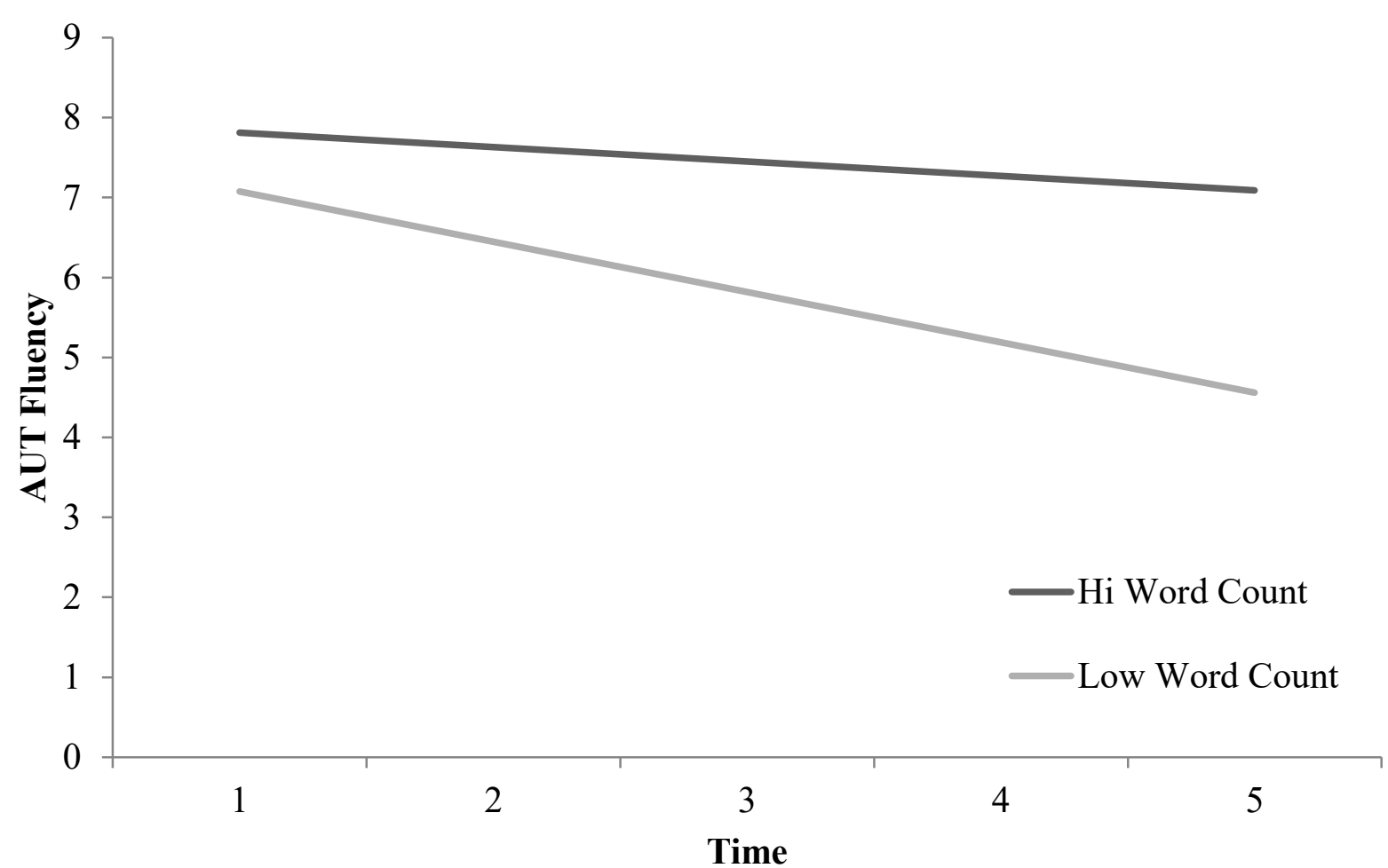

Figure 9. Probing time by word count interaction for alternate uses task fluency scores (daily assessments).

Finally, the degree of elaboration in alternate uses task responses was analyzed.

Descriptive statistics are presented and Table 7 and visualized in Figure 10. Upon visual inspection of Figure 10 two findings are evident. First, the degree of elaboration decreased over time points irrespective of condition. Second, those in the openness condition generally elaborated less than did those in the control condition. This between group difference was most evident on day 3 where a small effect was present $(d=.32)$.

\begin{tabular}{lccccc}
\hline & \multicolumn{2}{c}{ Openness } & \multicolumn{2}{c}{ Control } & \\
& $M$ & $S D$ & $M$ & $S D$ & $d$ \\
\hline Day 1 (Brick) & 4.53 & 4.10 & 4.75 & 5.03 & .05 \\
Day 2 (Newspaper) & 4.65 & 3.90 & 5.30 & 5.11 & .14 \\
Day 3 (Paperclip) & 3.05 & 2.92 & 4.11 & 3.74 & .32 \\
Day 4 (Pillow) & 1.87 & 2.25 & 2.27 & 3.39 & .14 \\
Day 5 (Shoebox) & 1.19 & 2.11 & 1.12 & 2.20 & .03 \\
\hline
\end{tabular}


Table 7. Alternate uses task 'elaboration' descriptive statistics (daily assessments). Topics in the openness condition are aesthetics (task 1), emotions (task 2), ideas (task 3 ) and introspection (task 4); task 5 is the curiosity manipulation.

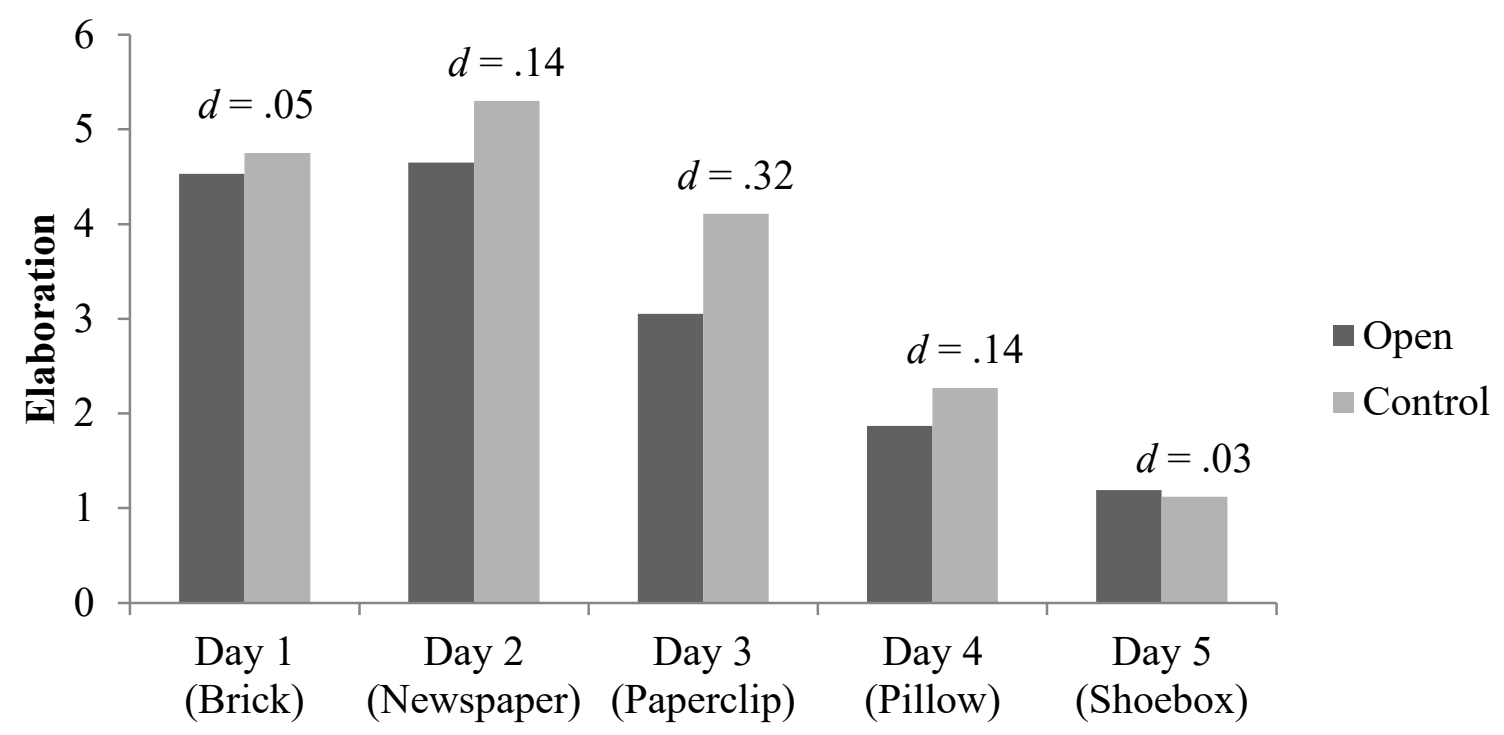

Figure 10. Mean alternate uses task 'elaboration' scores over time (daily assessments). Topics in the openness condition are aesthetics (task 1), emotions (task 2), ideas (task 3 ) and introspection (task 4); task 5 is the curiosity manipulation.

Consistent with the inferences drawn from the visual inspection of Figure 10, elaboration scores were found to decrease significantly over time (see Table 8), $\beta=-0.81, S E=.10, t(208)=$ $-7.75, p<.001$, and a main effect of condition was detected suggesting that participants in the control condition provided more elaborate answers on average, $\beta=0.78, S E=.39, t(208)=1.99$, $p=.05$. Furthermore, a main effect of word count suggests that individuals who wrote more on the daily writing activities also provided more elaborate responses to the alternate uses task assessments, $\beta=0.004, S E=.001, t(208)=3.09, p=.002$. Finally, trait openness was a significant predictor of elaboration pooling across assessments, $\beta=1.68, S E=.42, t(208)=$ $3.94, p<.001$. 


\begin{tabular}{|c|c|c|c|c|c|c|}
\hline Model & & $\begin{array}{l}\text { Parameter } \\
\text { Estimates }\end{array}$ & $\begin{array}{c}\text { Standard } \\
\text { Error }\end{array}$ & $t$ & $z$ & $p$ \\
\hline \multirow[t]{4}{*}{ A } & Intercept $\left(\gamma_{00}\right)$ & 6.16 & .27 & 22.57 & & $<.001$ \\
\hline & Time $\left(\gamma_{10}\right)$ & -0.99 & .06 & -15.79 & & $<.001$ \\
\hline & Intercept $\left(\tau_{00}\right)$ & 7.00 & .85 & & 8.27 & $<.001$ \\
\hline & Residual $\left(\sigma^{2}\right)$ & 6.68 & .36 & & 18.43 & $<.001$ \\
\hline \multirow[t]{6}{*}{$\mathrm{B}$} & Intercept $\left(\gamma_{00}\right)$ & 6.08 & .37 & 16.40 & & $<.001$ \\
\hline & Time $\left(\gamma_{10}\right)$ & -0.96 & .07 & -12.84 & & $<.001$ \\
\hline & Intercept $\left(\tau_{00}\right)$ & 21.61 & 2.78 & & 7.76 & $<.001$ \\
\hline & Time $\left(\tau_{11}\right)$ & 0.51 & .12 & & 4.35 & $<.001$ \\
\hline & $\operatorname{Cov}\left(\tau_{10}\right)$ & -3.22 & .54 & & -6.01 & $<.001$ \\
\hline & Residual $\left(\sigma^{2}\right)$ & 5.39 & .34 & & 15.91 & $<.001$ \\
\hline \multirow[t]{8}{*}{$\mathrm{C}$} & Intercept $\left(\gamma_{00}\right)$ & 5.03 & 1.20 & 4.21 & & $<.001$ \\
\hline & Time $\left(\gamma_{10}\right)$ & -0.81 & .24 & -3.33 & & $<.001$ \\
\hline & Condition $\left(\gamma_{01}\right)$ & 0.68 & .74 & 0.92 & & .361 \\
\hline & Time*Condition $\left(\gamma_{11}\right)$ & -0.10 & .15 & -0.67 & & .501 \\
\hline & Intercept $\left(\tau_{00}\right)$ & 21.64 & 2.79 & & 7.75 & $<.001$ \\
\hline & Time $\left(\tau_{11}\right)$ & 0.51 & .12 & & 4.36 & $<.001$ \\
\hline & $\operatorname{Cov}\left(\tau_{10}\right)$ & -3.23 & .54 & & -6.00 & $<.001$ \\
\hline & Residual $\left(\sigma^{2}\right)$ & & & & & \\
\hline \multirow[t]{14}{*}{$\mathrm{D}$} & Intercept $\left(\gamma_{00}\right)$ & 4.91 & 1.30 & 3.78 & & $<.001$ \\
\hline & Time $\left(\gamma_{10}\right)$ & -0.94 & .34 & -2.75 & & .006 \\
\hline & Word Count $\left(\gamma_{20}\right)$ & 0.00 & .00 & 0.86 & & .392 \\
\hline & Condition $\left(\gamma_{01}\right)$ & 0.50 & .80 & 0.63 & & .530 \\
\hline & Trait Open $\left(\gamma_{02}\right)$ & 3.65 & 1.56 & 2.34 & & .020 \\
\hline & Trait Open*Condition $\left(\gamma_{03}\right)$ & -0.93 & .85 & -1.09 & & .276 \\
\hline & Trait Open*Time $\left(\gamma_{12}\right)$ & -0.17 & .23 & -0.76 & & .450 \\
\hline & Time* Condition $\left(\gamma_{11}\right)$ & 0.09 & .21 & 0.41 & & .684 \\
\hline & Time*Word Count $\left(\gamma_{30}\right)$ & 0.00 & .00 & 0.08 & & .937 \\
\hline & Condition*Word Count $\left(\gamma_{21}\right)$ & -0.00 & .00 & -0.04 & & .967 \\
\hline & Intercept $\left(\tau_{00}\right)$ & 21.00 & 3.19 & & 6.57 & $<.001$ \\
\hline & Time $\left(\tau_{11}\right)$ & 0.64 & .23 & & 2.76 & .003 \\
\hline & $\operatorname{Cov}\left(\tau_{10}\right)$ & -3.49 & .80 & & -4.39 & $<.001$ \\
\hline & Residual $\left(\sigma^{2}\right)$ & 6.19 & .48 & & 12.93 & $<.001$ \\
\hline \multirow[t]{6}{*}{$\mathrm{E}$} & Intercept $\left(\gamma_{00}\right)$ & 4.51 & .72 & 6.25 & & $<.001$ \\
\hline & Time $\left(\gamma_{10}\right)$ & -0.81 & .10 & -7.75 & & $<.001$ \\
\hline & Word Count $\left(\gamma_{20}\right)$ & 0.00 & .00 & 3.09 & & .002 \\
\hline & Condition $\left(\gamma_{01}\right)$ & 0.78 & .39 & 1.99 & & .048 \\
\hline & Trait Open $\left(\gamma_{02}\right)$ & 1.68 & .42 & 3.94 & & $<.001$ \\
\hline & Intercept $\left(\tau_{00}\right)$ & 20.87 & 3.16 & & 6.60 & $<.001$ \\
\hline
\end{tabular}




$\begin{array}{lcccr}\text { Time }\left(\tau_{11}\right) & 0.62 & .23 & 2.72 & .003 \\ \text { Cov }\left(\tau_{10}\right) & -3.44 & .78 & -4.38 & <.001 \\ \text { Residual }\left(\sigma^{2}\right) & 6.18 & .48 & 12.95 & <.001\end{array}$

Table 8. MLM models for alternate uses task ‘elaboration' scores (daily assessments).

In summary, the hypothesis that creative thinking ability would be greater in the openness condition was not supported for any of the four components of the alternate uses task. However, across these components two findings were consistent (see Table 9 for an overview of results). First, consistent with previous work on personality and creativity, trait openness predicted scores on the alternate uses task irrespective of condition. Second, in each set of analyses the frequency of words written in the daily assessments predicted creativity scores (for originality and elaboration a main effect of word count was observed while a time by word count interaction was found for fluency and flexibility). This pattern of results will be explored in the discussion section. 


\begin{tabular}{|c|c|c|c|c|}
\hline Model E & Originality & Fluency & Elaboration & Flexibility \\
\hline Intercept $\left(\gamma_{00}\right)$ & $*$ & * & $*$ & $*$ \\
\hline Time $\left(\gamma_{10}\right)$ & $*$ & $*$ & $*$ & $*$ \\
\hline Condition $\left(\gamma_{01}\right)$ & & & $*$ & \\
\hline Trait Open & $*$ & $*$ & $*$ & $*$ \\
\hline Word Count $\left(\gamma_{20}\right)$ & $*$ & & $*$ & \\
\hline Time*Word Count $\left(\gamma_{12}\right)$ & $\mathrm{N} / \mathrm{A}$ & $*$ & $\mathrm{~N} / \mathrm{A}$ & * \\
\hline Intercept $\left(\tau_{00}\right)$ & $*$ & $*$ & $*$ & $*$ \\
\hline Time $\left(\tau_{11}\right)$ & $\mathrm{N} / \mathrm{A}$ & $\mathrm{N} / \mathrm{A}$ & $*$ & $\mathrm{~N} / \mathrm{A}$ \\
\hline $\operatorname{Cov}\left(\tau_{10}\right)$ & $\mathrm{N} / \mathrm{A}$ & N/A & $*$ & N/A \\
\hline Residual $\left(\sigma^{2}\right)$ & $*$ & $*$ & $*$ & $*$ \\
\hline $\begin{array}{l}\text { Inter Class Correlation } \\
\text { (ICC) }\end{array}$ & .26 & .61 & .51 & .47 \\
\hline
\end{tabular}

Table 9. Summary of statistically significant findings from Model E for alternate uses task subscales. *p <.05. N/A ( Not Applicable) denotes models where the variable time was not allowed to randomly vary or an interaction was not retained in the model. 
In order to test whether within and between subject differences in creative thinking ability were present from pretest to posttest assessments (hypothesis $1 \mathrm{~b}$ ) I conducted 2 (condition) x 2 (time) mixed-factors analysis of variance (ANOVA) with remote association task scores as the dependent variable. The subset of the sample included in this analysis included all participants who completed both remote association task assessments and who reported their English language skills were 'as proficient as a native speaker'. Descriptive statistics are presented below in Table 10 and visualized in Figure 11.

\begin{tabular}{lcccccc}
\hline & \multicolumn{3}{c}{ Openness } & \multicolumn{3}{c}{ Control } \\
& $\mathrm{n}$ & $M$ & $S D$ & $\mathrm{n}$ & $M$ & $S D$ \\
\hline Pretest & 66 & 14.45 & 5.44 & 70 & 13.96 & 4.23 \\
Posttest & 66 & 13.12 & 5.89 & 70 & 12.57 & 4.99 \\
\hline
\end{tabular}

Table 10. Remote association task descriptive statistics (pretest and posttest).

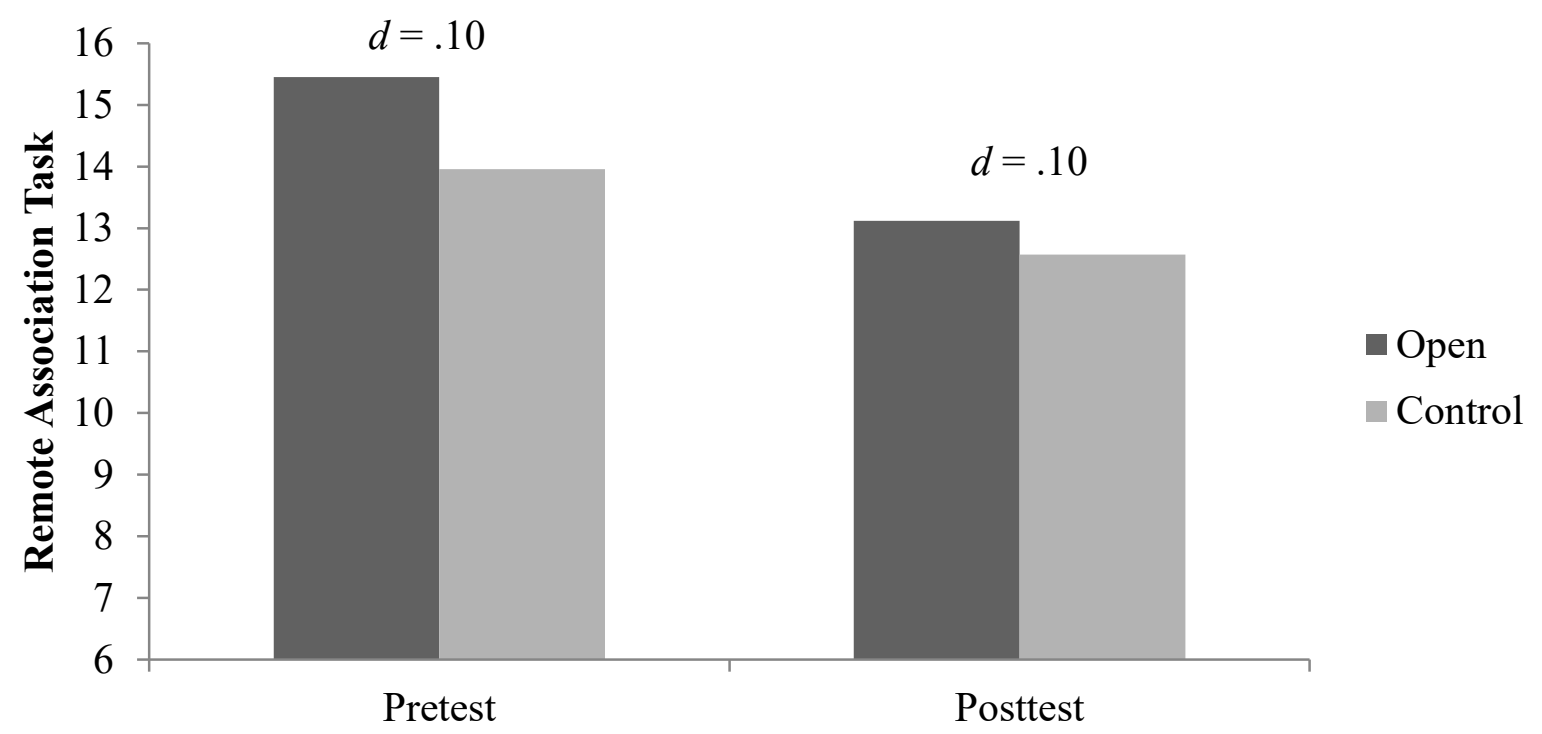

Figure 11. Mean remote association task over time (pretest and posttest).

A significant main effect of time on random association task scores was found across time points indicating that remote association task scores decreased across time, $F(1,134)=$ $14.35, p<.001$, partial $\eta^{2}=.10$. No main effect was observed for condition, $F(1,134)=.42, p=$ 
.52 , partial $\eta^{2}=.00$, and the condition by time interaction was not significant, $F(1,134)=.005, p$ $=.92$, partial $\eta^{2}=.00$. Thus, no evidence was found in support of hypothesis $1 \mathrm{~b}$.

\section{Hypothesis 2: Personal Growth}

Hypotheses $2 \mathrm{a}-\mathrm{b}$ predicts that individuals in the openness condition will report increases in self-reported personal growth across pretest, posttest, and follow-up assessments (2a) and that this effect will not be influenced by individual levels of trait openness (2b). As shown in Table 11 there was a failure of random assignment at the pretest assessment wherein scores on the personal growth scale were higher in the openness condition than the control condition $(d=.32)$. However, as Figure 12 illustrates, this difference was trivial at the posttest assessment $(d=.05)$ and at the follow up assessment the mean score of the control condition was higher than the openness condition $(d=.15)$. Surprisingly, and counter to my hypothesis, this pattern suggests linear growth in the control condition; however, multi-level analyses are required to test this proposition.

\begin{tabular}{lccccccc}
\hline & \multicolumn{3}{c}{ Openness } & \multicolumn{3}{c}{ Control } \\
& $\mathrm{n}$ & $M$ & $S D$ & $\mathrm{n}$ & $M$ & $S D$ & $d$ \\
\hline Pretest & 106 & 4.12 & .54 & 115 & 3.95 & .53 & .32 \\
Posttest & 86 & 4.11 & .57 & 93 & 4.14 & .57 & .05 \\
Follow up & 38 & 4.11 & .65 & 32 & 4.20 & .53 & .15 \\
\hline
\end{tabular}

Table 11. Personal growth descriptive statistics (pretest, posttest, and follow up assessments). 


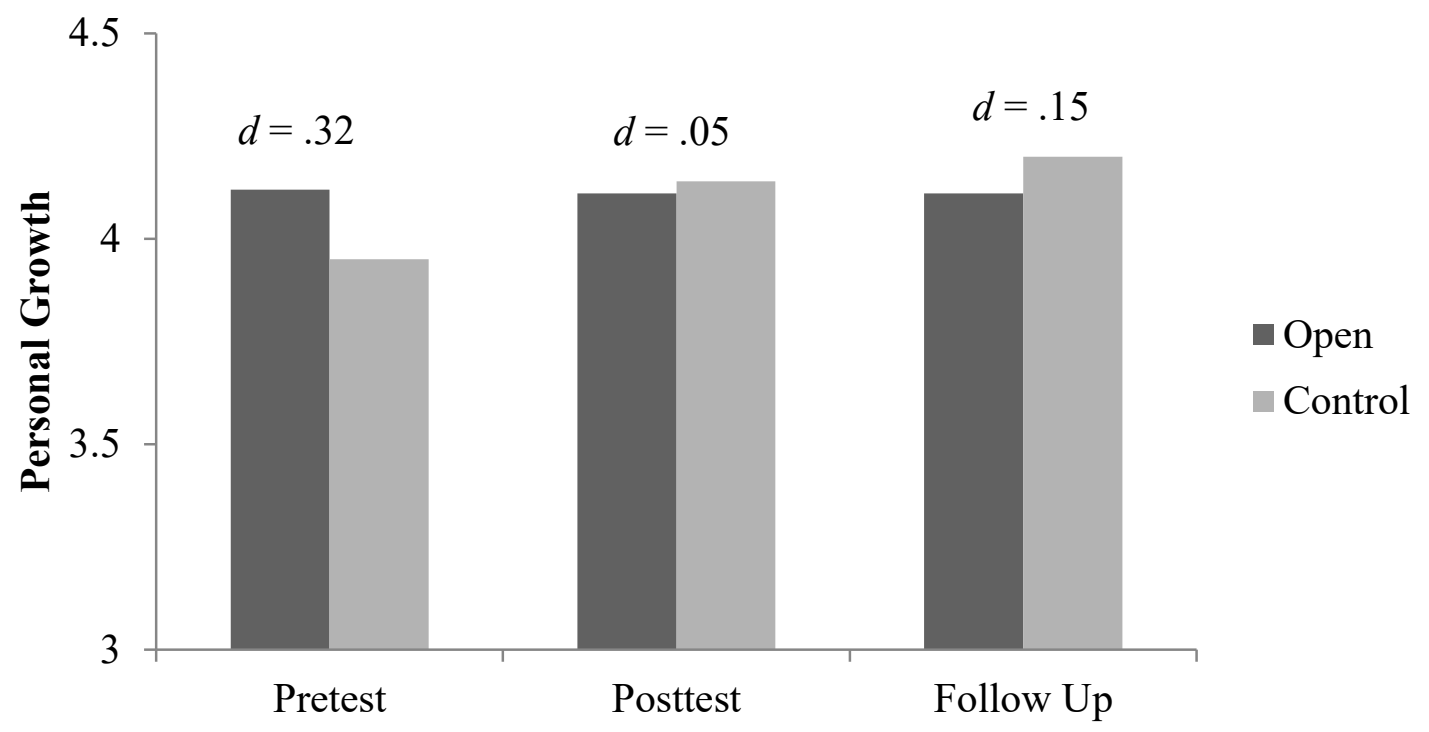

Figure 12. Mean personal growth scores over time (pretest, posttest, and follow-up assessments). As illustrated in Table 12 the variable 'time' was significant when included as randomly varying in Model B, and was therefore included as random in subsequent models. Results from Model C suggest that scores on the personal growth measure varied over time but not between conditions. However, when added to Model D the time by condition interaction was not significant, $\beta=-.06, S E=.04, t(206)=-1.45, p=.15$ suggesting the slight increase in personal growth scores over time did not vary significantly by condition. Thus, hypothesis $2 \mathrm{a}$--that personal growth scores would increase over time in the open condition--was not supported. 


\begin{tabular}{|c|c|c|c|c|c|c|}
\hline Model & & $\begin{array}{l}\text { Parameter } \\
\text { Estimates }\end{array}$ & $\begin{array}{c}\text { Standard } \\
\text { Error }\end{array}$ & $\mathrm{t}$ & $\mathrm{z}$ & $\mathrm{p}$ \\
\hline \multirow[t]{4}{*}{ A } & Intercept $\left(\gamma_{00}\right)$ & 4.12 & 0.04 & 109.14 & & $<.001$ \\
\hline & Time $\left(\gamma_{10}\right)$ & 0.05 & 0.02 & 2.69 & & .008 \\
\hline & Intercept $\left(\tau_{00}\right)$ & 0.19 & 0.02 & & 7.76 & $<.001$ \\
\hline & Residual $\left(\sigma^{2}\right)$ & 0.07 & 0.01 & & 10.16 & $<.001$ \\
\hline \multirow[t]{6}{*}{ B } & Intercept $\left(\gamma_{00}\right)$ & 4.11 & 0.04 & 110.75 & & $<.001$ \\
\hline & Time $\left(\gamma_{10}\right)$ & 0.06 & 0.02 & 2.61 & & .010 \\
\hline & Intercept $\left(\tau_{00}\right)$ & 0.19 & 0.03 & & 6.84 & $<.001$ \\
\hline & Time $\left(\tau_{11}\right)$ & 0.01 & 0.01 & & 0.85 & .197 \\
\hline & $\operatorname{Cov}\left(\tau_{10}\right)$ & 0.00 & 0.01 & & 0.10 & $<.001$ \\
\hline & Residual $\left(\sigma^{2}\right)$ & 0.06 & 0.01 & & 6.58 & $<.001$ \\
\hline \multirow[t]{6}{*}{$\mathrm{C}$} & Intercept $\left(\gamma_{00}\right)$ & 4.04 & 0.05 & 76.86 & & $<.001$ \\
\hline & Time $\left(\gamma_{10}\right)$ & 0.09 & 0.03 & 2.88 & & .004 \\
\hline & Condition $\left(\gamma_{01}\right)$ & 0.10 & 0.08 & 1.34 & & .180 \\
\hline & Time*Condition $\left(\gamma_{11}\right)$ & -0.06 & 0.04 & -1.43 & & .155 \\
\hline & Intercept $\left(\tau_{00}\right)$ & 0.19 & 0.02 & & 7.75 & $<.001$ \\
\hline & Residual $\left(\sigma^{2}\right)$ & 0.07 & 0.01 & & 10.15 & $<.001$ \\
\hline \multirow[t]{12}{*}{$\mathrm{D}$} & Intercept $\left(\gamma_{00}\right)$ & 4.08 & 0.05 & 84.85 & & $<.001$ \\
\hline & Time $\left(\gamma_{10}\right)$ & 0.08 & 0.03 & 2.79 & & .006 \\
\hline & Word Count $\left(\gamma_{20}\right)$ & 0.00 & 0.00 & 1.12 & & .266 \\
\hline & Condition $\left(\gamma_{01}\right)$ & 0.06 & 0.07 & 0.83 & & .406 \\
\hline & Trait Open $\left(\gamma_{02}\right)$ & 0.21 & 0.10 & 2.04 & & .043 \\
\hline & Trait Open*Condition $\left(\gamma_{03}\right)$ & 0.29 & 0.14 & 2.07 & & .040 \\
\hline & Trait Open*Time $\left(\gamma_{12}\right)$ & 0.02 & 0.04 & 0.48 & & .633 \\
\hline & Time*Condition $\left(\gamma_{11}\right)$ & -0.06 & 0.04 & -1.45 & & .149 \\
\hline & Time*Word Count $\left(\gamma_{30}\right)$ & 0.00 & 0.00 & -.05 & & .958 \\
\hline & Condition*WordCount $\left(\gamma_{21}\right)$ & 0.00 & 0.00 & 1.28 & & .202 \\
\hline & Intercept $\left(\tau_{00}\right)$ & 0.14 & 0.02 & & 7.24 & $<.001$ \\
\hline & Residual $\left(\sigma^{2}\right)$ & 0.07 & 0.01 & & 10.11 & $<.001$ \\
\hline \multirow[t]{8}{*}{$\mathrm{E}$} & Intercept $\left(\gamma_{00}\right)$ & 4.10 & .05 & 88.40 & & $<.001$ \\
\hline & Time $\left(\gamma_{10}\right)$ & 0.05 & .02 & 2.60 & & .010 \\
\hline & Word Count $\left(\gamma_{20}\right)$ & 0.00 & .00 & 2.38 & & .018 \\
\hline & Condition $\left(\gamma_{01}\right)$ & 0.03 & .06 & 0.39 & & .695 \\
\hline & Trait Open $\left(\gamma_{02}\right)$ & 0.21 & .10 & 2.09 & & .038 \\
\hline & Trait Open*Condition $\left(\gamma_{03}\right)$ & 0.33 & .14 & 2.44 & & .016 \\
\hline & Intercept $\left(\tau_{00}\right)$ & 0.14 & .02 & & 7.31 & $<.001$ \\
\hline & Residual $\left(\sigma^{2}\right)$ & 0.07 & .01 & & 10.19 & $<.001$ \\
\hline
\end{tabular}


Table 12. MLM models for personal growth (pretest, posttest, and follow-up assessments).

In the final model, a main effect of time was observed indicating that responses on the personal growth scale varied across time points, $\beta=.05, S E=.02, t(206)=2.60, p=.01$. A significant main effect of word count suggests that individuals who wrote more during the daily writing tasks reported increasing higher scores on the personal growth scale pooling across the three time points, $\beta=.0008, S E=.0003, t(206)=2.38, p=.02$. Consistent with previous findings (Schmutte \& Ryff, 1997), trait openness was a significant predictor of personal growth when averaging across assessments in the final model, $\beta=.21, S E=.10, t(171)=2.09, p=.04$. A trait openness by condition interaction was also observed, $\beta=.33, S E=.14, t(171)=2.44, p=$ .02. Simple slopes were significant for both the control, $\beta=.21, S E=.10, t(171)=2.04, p=.04$ and openness conditions, $\beta=.50, S E=.10, t(171)=4.88, p<.001$. Figure 13 illustrates the relationship between condition and personal growth at levels of trait openness $1 S D$ above and below the mean.

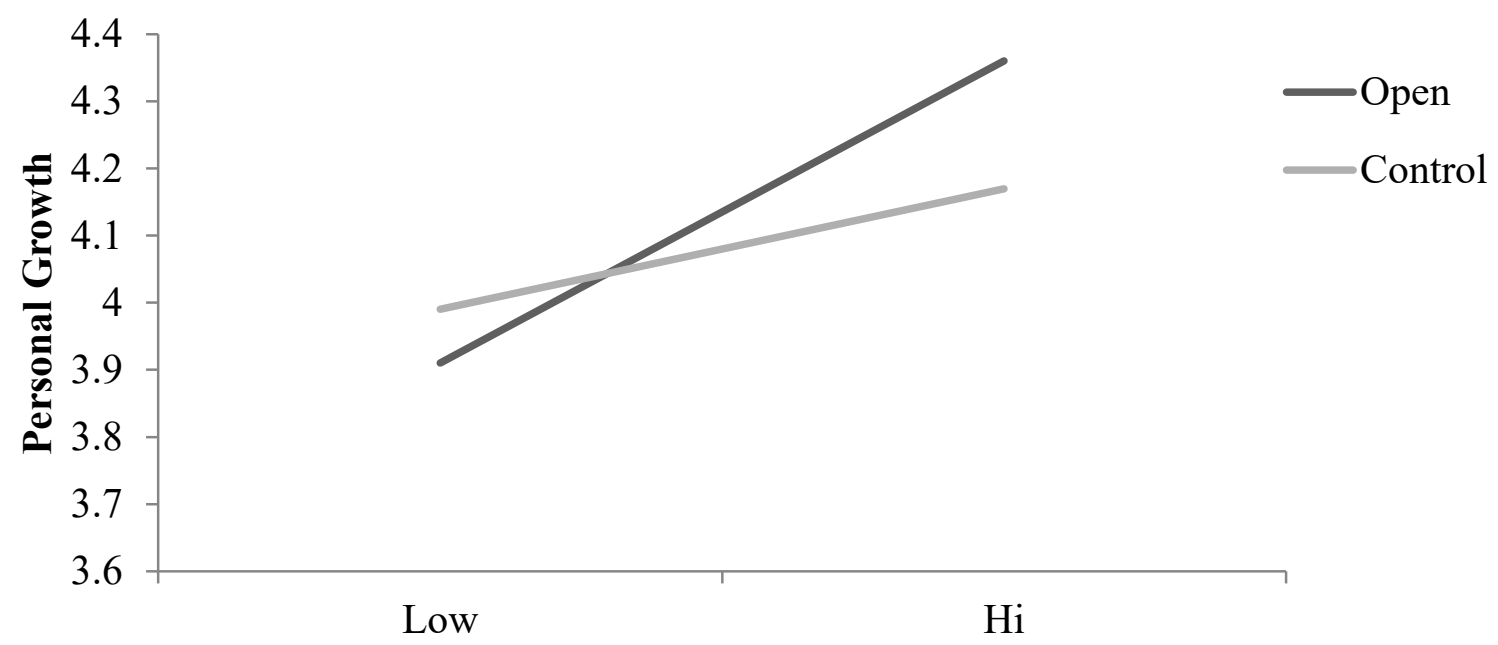

Trait Openness

Figure 13. Simple slopes for condition by trait openness interaction predicting personal growth (pretest, posttest, and follow-up assessments). 
As shown in figure 13, high levels of trait openness were positively related to scores on personal growth; however this effect was stronger for individuals in the openness condition. In other words, highly open people in the open condition reported the highest average score across personal growth measures.

\section{Hypothesis 3: Authenticity}

In hypothesis $3 \mathrm{a}$ I predicted that the tasks in the open condition would elicit elevated levels of state authenticity when compared to the control group. As shown in Table 13 and visualized in Figure 14, although there was some small variation in between conditions on authenticity across daily tasks $(d=.05-.17)$, the overall difference in authenticity was essentially zero $(d=.01)$

\begin{tabular}{lccccccc}
\hline & \multicolumn{3}{c}{ Openness } & \multicolumn{3}{c}{ Control } \\
& $\mathrm{n}$ & $M$ & $S D$ & $\mathrm{n}$ & $M$ & $S D$ & $d$ \\
\hline Daily Task 1 & 96 & 5.53 & 1.18 & 107 & 5.70 & 1.16 & .15 \\
Daily Task 2 & 99 & 5.76 & 1.35 & 104 & 5.54 & 1.31 & .17 \\
Daily Task 3 & 94 & 5.67 & 1.31 & 99 & 5.74 & 1.35 & .05 \\
Daily Task 4 & 89 & 5.79 & 1.26 & 93 & 5.66 & 1.47 & .09 \\
Daily Task 5 & 88 & 5.89 & 1.22 & 97 & 6.02 & 1.23 & .11 \\
Overall & 466 & 5.73 & 1.27 & 500 & 5.72 & 1.31 & .01 \\
\hline
\end{tabular}

Table 13. Authenticity descriptive statistics (daily assessments). Topics in the openness condition are aesthetics (task1), emotions (task 2), ideas (task3) and introspection (task 4); task 5 is the curiosity manipulation. 


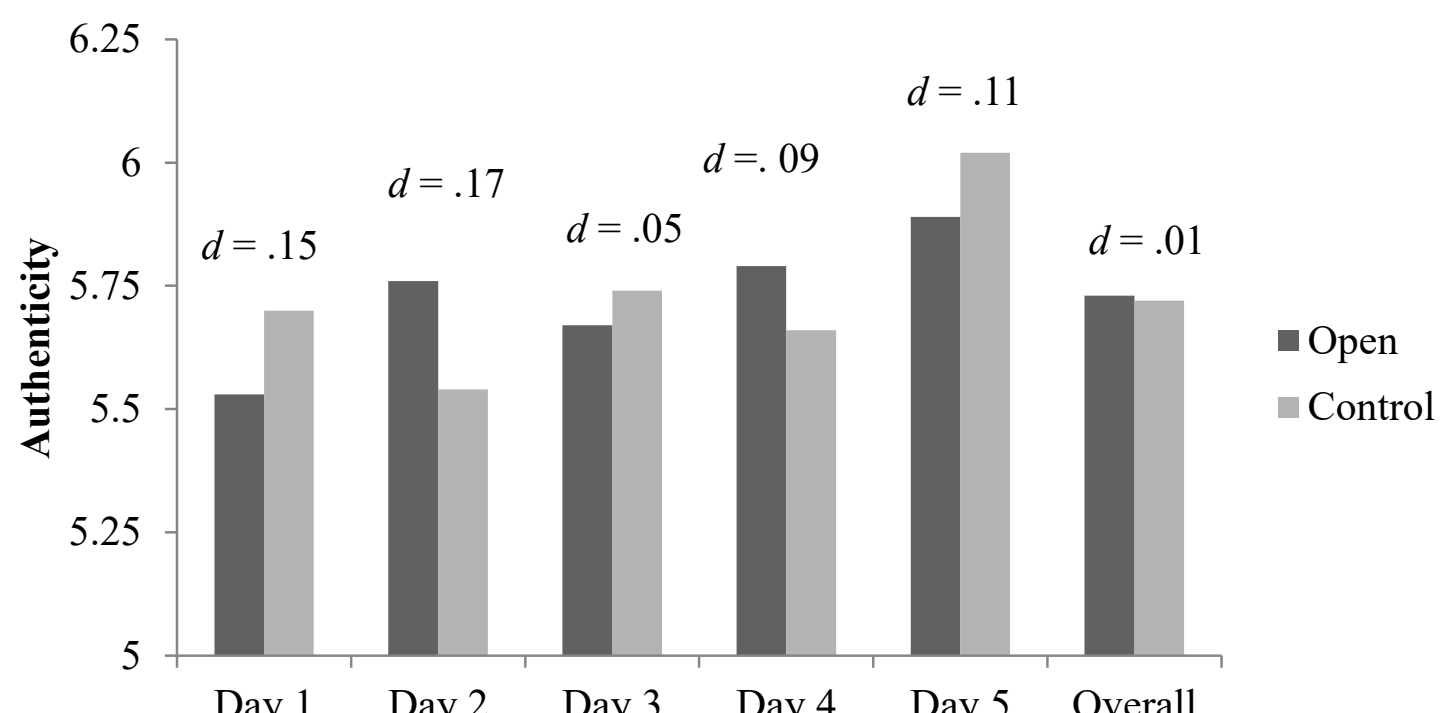

Figure 14. Mean authenticity scores over time (daily assessments). Topics in the openness condition are aesthetics (task 1), emotions (task 2), ideas (task 3) and introspection (task 4); task 5 is the curiosity manipulation.

As shown in Table 14 'time' was found to vary randomly in model B as was therefore retained in Models C-E. The main effect of condition in in the final model was not statistically significant, $\beta=.02, S E=.03, t(216)=1.40, p=.16$. Thus, hypothesis 3 a was not supported.

\begin{tabular}{|c|c|c|c|c|c|c|}
\hline \multicolumn{2}{|c|}{ Model } & $\begin{array}{l}\text { Parameter } \\
\text { Estimates }\end{array}$ & $\begin{array}{c}\text { Standard } \\
\text { Error }\end{array}$ & $t$ & $z$ & $p$ \\
\hline \multirow[t]{4}{*}{$\mathrm{A}$} & Intercept $\left(\gamma_{00}\right)$ & 5.49 & 0.09 & 59.85 & & $<.001$ \\
\hline & Time $\left(\gamma_{10}\right)$ & 0.07 & 0.02 & 3.91 & & $<.001$ \\
\hline & Intercept $\left(\tau_{00}\right)$ & 1.03 & 0.12 & & 8.94 & $<.001$ \\
\hline & Residual $\left(\sigma^{2}\right)$ & 0.66 & 0.03 & & 19.27 & $<.001$ \\
\hline \multirow[t]{6}{*}{$\mathrm{B}$} & Intercept $\left(\gamma_{00}\right)$ & 5.49 & 0.09 & 60.39 & & $<.001$ \\
\hline & Time $\left(\gamma_{10}\right)$ & 0.07 & 0.02 & 3.25 & & .001 \\
\hline & Intercept $\left(\tau_{00}\right)$ & 1.08 & 0.18 & & 5.90 & $<.001$ \\
\hline & Time $\left(\tau_{11}\right)$ & 0.03 & 0.01 & & 2.72 & .003 \\
\hline & $\operatorname{Cov}\left(\tau_{10}\right)$ & -0.05 & 0.04 & & -1.28 & .200 \\
\hline & Residual $\left(\sigma^{2}\right)$ & 0.59 & 0.04 & & 16.18 & $<.001$ \\
\hline \multirow[t]{5}{*}{$\mathrm{C}$} & Intercept $\left(\gamma_{00}\right)$ & 5.48 & 0.13 & 43.35 & & $<.001$ \\
\hline & Time $\left(\gamma_{10}\right)$ & 0.07 & 0.03 & 2.45 & & .015 \\
\hline & Condition $\left(\gamma_{01}\right)$ & 0.03 & 0.18 & 0.19 & & .850 \\
\hline & Time*Condition $\left(\gamma_{11}\right)$ & -0.01 & 0.04 & -0.17 & & .868 \\
\hline & Intercept $\left(\tau_{00}\right)$ & 1.09 & 0.18 & & 5.91 & $<.001$ \\
\hline
\end{tabular}




\begin{tabular}{|c|c|c|c|c|c|c|}
\hline & Time $\left(\tau_{11}\right)$ & 0.03 & 0.01 & & 2.75 & .003 \\
\hline & $\operatorname{Cov}\left(\tau_{10}\right)$ & -0.05 & 0.04 & & -1.31 & .190 \\
\hline & Residual $\left(\sigma^{2}\right)$ & 0.59 & 0.04 & & 16.18 & $<.001$ \\
\hline \multirow[t]{14}{*}{$\mathrm{D}$} & Intercept $\left(\gamma_{00}\right)$ & 5.59 & 0.14 & 42.68 & & $<.001$ \\
\hline & Time $\left(\gamma_{10}\right)$ & 0.01 & 0.05 & 0.27 & & .791 \\
\hline & Condition $\left(\gamma_{01}\right)$ & -0.14 & 0.19 & -0.75 & & .454 \\
\hline & Word Count $\left(\gamma_{20}\right)$ & 0.00 & 0.00 & 1.00 & & .319 \\
\hline & Trait Open $\left(\gamma_{02}\right)$ & -0.02 & 0.26 & -0.09 & & .925 \\
\hline & Time*Trait Open $\left(\gamma_{12}\right)$ & -0.07 & 0.07 & -1.03 & & .305 \\
\hline & Trait Open*Condition $\left(\gamma_{03}\right)$ & 1.21 & 0.32 & 3.79 & & $<.001$ \\
\hline & Time*Condition $\left(\gamma_{11}\right)$ & 0.07 & 0.07 & 1.05 & & .295 \\
\hline & Time*Word Count $\left(\gamma_{12}\right)$ & 0.00 & 0.00 & 0.30 & & .763 \\
\hline & Condition*Word Count $\left(\gamma_{21}\right)$ & 0.00 & 0.00 & 0.05 & & .961 \\
\hline & Intercept $\left(\tau_{00}\right)$ & 0.91 & 0.19 & & 4.88 & $<.001$ \\
\hline & Time $\left(\tau_{11}\right)$ & 0.09 & 0.02 & & 3.95 & $<.001$ \\
\hline & $\operatorname{Cov}\left(\tau_{10}\right)$ & -0.07 & 0.05 & & -1.37 & .017 \\
\hline & Residual $\left(\sigma^{2}\right)$ & 0.50 & 0.04 & & 13.14 & $<.001$ \\
\hline \multirow[t]{10}{*}{$\mathrm{E}$} & Intercept $\left(\gamma_{00}\right)$ & 5.49 & .24 & 23.12 & & $<.001$ \\
\hline & Time $\left(\gamma_{10}\right)$ & 0.05 & .03 & 1.40 & & .161 \\
\hline & Condition $\left(\gamma_{01}\right)$ & 0.02 & .14 & 0.13 & & .896 \\
\hline & Word Count $\left(\gamma_{20}\right)$ & 0.00 & .00 & 4.03 & & $<.001$ \\
\hline & Trait Open $\left(\gamma_{02}\right)$ & 2.27 & .50 & 4.52 & & $<.001$ \\
\hline & Trait Open*Condition $\left(\gamma_{03}\right)$ & -1.21 & .32 & -3.80 & & $<.001$ \\
\hline & Intercept $\left(\tau_{00}\right)$ & 0.90 & .18 & & 4.89 & $<.001$ \\
\hline & Time $\left(\tau_{11}\right)$ & 0.09 & .04 & & 3.95 & $<.001$ \\
\hline & $\operatorname{Cov}\left(\tau_{10}\right)$ & -0.07 & .05 & & -1.31 & .190 \\
\hline & Residual $\left(\sigma^{2}\right)$ & 0.50 & .04 & & 13.20 & $<.001$ \\
\hline
\end{tabular}

Table 14 MLM models for authenticity (daily assessments).

In Model E, 'time' ceased to be a significant predictor, $\beta=.05, S E=.03, t(548)=.14, p$

$=.16$. A main effect of word count was observed suggesting that individuals who wrote more on the writing tasks reported higher levels of authenticity, $\beta=.002, S E=.0005, t(206)=4.03, p<$ .001 . Additionally, both the main effect of openness, $\beta=2.27, S E=.50, t(206)=4.52, p<.001$, and the trait openness by condition interaction were significant, $\beta=1.21, S E=.32, t(216)=$ $3.79, p<.001$. Simple slopes analyses revealed that the relationship between condition and authenticity was influenced by trait levels of openness in the open condition, $\beta=1.18, S E=.25, t$ $(216)=4.64, p<.001$ but not the control condition, $\beta=-.02, S E=.26, t(216)=-.09, p=.92$. As 
shown in Figure 15, higher levels of trait openness were associated with elevated scores of daily authenticity in the open condition but not in the control condition.

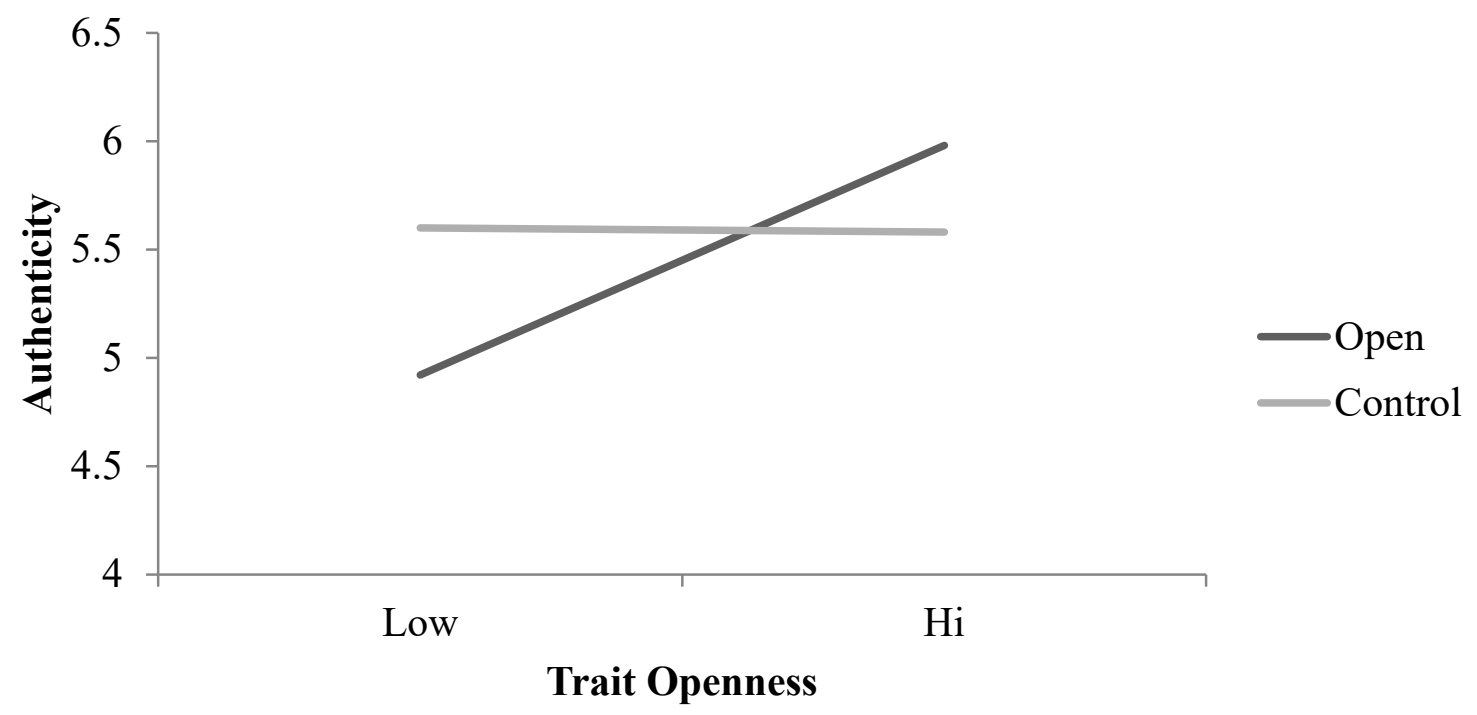

Figure 15. Simple slopes for condition by trait openness interaction predicting authenticity scores (daily assessments).

Hypothesis $3 \mathrm{~b}$ predicted that authenticity would vary across pretest, posttest, and followup assessments and that this variation would differ depending upon condition. As shown in Table 15 and Figure 16 little between group variations in authenticity was present across assessments

\begin{tabular}{lccccccc}
\hline & \multicolumn{3}{c}{ Openness } & \multicolumn{3}{c}{ Control } & \multicolumn{1}{c}{. } \\
& $\mathrm{n}$ & $M$ & $S D$ & $\mathrm{n}$ & $M$ & $S D$ & .08 \\
Pretest & 106 & 4.76 & 1.02 & 115 & 4.67 & 1.12 & .07 \\
Posttest & 84 & 5.16 & 1.07 & 92 & 5.24 & 1.16 & .03 \\
Follow up & 38 & 5.13 & 1.11 & 32 & 5.09 & 1.08 & .03 \\
\hline
\end{tabular}

Table 15. Authenticity descriptive statistics (pretest, posttest, and follow up assessments). 


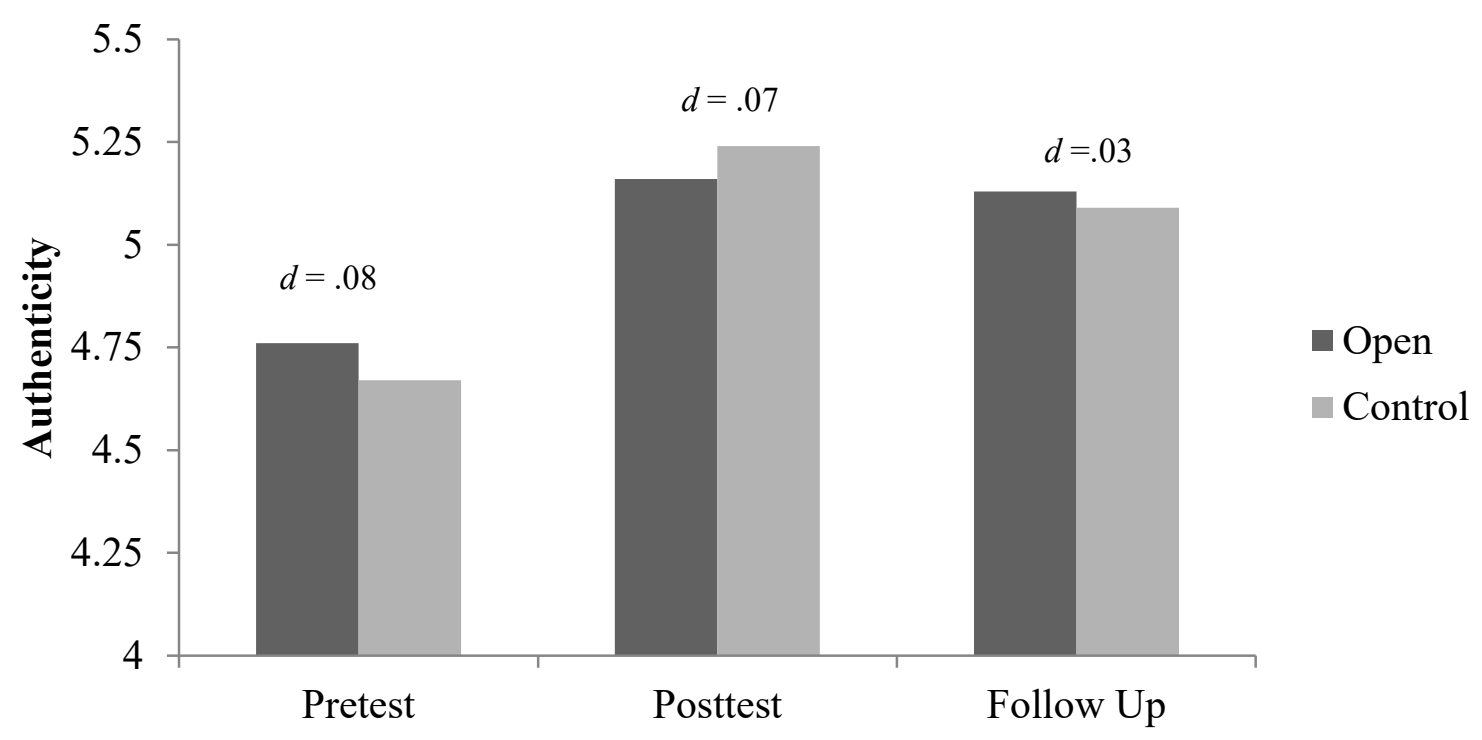

Figure 16. Mean authenticity scores over time (pretest, posttest, and follow up assessments).

In Model B time was not found to randomly vary to a significant degree and was excluded from subsequent analysis (see Table 16). Neither time nor condition were significant predictors of authenticity across pretest, posttest and follow-up assessment. Therefore, hypothesis $3 \mathrm{~b}$ was not supported. 


\begin{tabular}{|c|c|c|c|c|c|c|}
\hline Mode & & $\begin{array}{l}\text { Parameter } \\
\text { Estimates }\end{array}$ & $\begin{array}{c}\text { Standard } \\
\text { Error }\end{array}$ & $t$ & $z$ & $p$ \\
\hline \multirow[t]{4}{*}{$\mathrm{A}$} & Intercept $\left(\gamma_{00}\right)$ & 5.47 & 0.17 & 30.67 & & $<.001$ \\
\hline & Time $\left(\gamma_{10}\right)$ & -0.18 & 0.13 & -1.39 & & .170 \\
\hline & Intercept $\left(\tau_{00}\right)$ & 0.72 & 0.15 & & 4.76 & $<.001$ \\
\hline & Residual $\left(\sigma^{2}\right)$ & 0.52 & 0.10 & & 5.19 & $<.001$ \\
\hline \multirow[t]{6}{*}{$\mathrm{B}$} & Intercept $\left(\gamma_{00}\right)$ & 5.47 & 0.18 & 30.72 & & $<.001$ \\
\hline & Time $\left(\gamma_{10}\right)$ & -0.18 & 0.13 & -1.40 & & .168 \\
\hline & Intercept $\left(\tau_{00}\right)$ & 0.69 & 0.52 & & 1.32 & .094 \\
\hline & Time $\left(\tau_{11}\right)$ & 0.00 & 0.20 & & 0.00 & .500 \\
\hline & $\operatorname{Cov}\left(\tau_{10}\right)$ & 0.01 & 0.32 & & 0.05 & .963 \\
\hline & Residual $\left(\sigma^{2}\right)$ & & & & & \\
\hline \multirow[t]{6}{*}{$\mathrm{C}$} & Intercept $\left(\gamma_{00}\right)$ & 5.63 & 0.25 & 22.12 & & $<.001$ \\
\hline & Time $\left(\gamma_{10}\right)$ & -0.30 & 0.19 & -1.61 & & .114 \\
\hline & Condition $\left(\gamma_{01}\right)$ & -0.32 & 0.36 & -0.88 & & .378 \\
\hline & Time*Condition $\left(\gamma_{11}\right)$ & 0.23 & 0.25 & 0.90 & & .372 \\
\hline & Intercept $\left(\tau_{00}\right)$ & 0.74 & 0.15 & & 4.79 & $<.001$ \\
\hline & Residual $\left(\sigma^{2}\right)$ & 0.52 & 0.10 & & 5.15 & .001 \\
\hline \multirow[t]{12}{*}{$\mathrm{D}$} & Intercept $\left(\gamma_{00}\right)$ & 5.60 & 0.27 & 21.03 & & $<.001$ \\
\hline & Time $\left(\gamma_{10}\right)$ & -0.28 & 0.20 & -1.39 & & .171 \\
\hline & Word Count $\left(\gamma_{20}\right)$ & 0.00 & 0.00 & 0.42 & & .678 \\
\hline & Condition $\left(\gamma_{01}\right)$ & -0.34 & 0.36 & -0.94 & & .349 \\
\hline & Trait Open $\left(\gamma_{02}\right)$ & -0.44 & 0.41 & -1.08 & & .282 \\
\hline & Trait Open*Condition $\left(\gamma_{03}\right)$ & 0.56 & 0.37 & 1.52 & & .132 \\
\hline & Trait Open*Time $\left(\gamma_{12}\right)$ & 0.08 & 0.27 & 0.30 & & .768 \\
\hline & Time*Condition $\left(\gamma_{11}\right)$ & 0.19 & 0.26 & 0.73 & & .472 \\
\hline & Time*Word Count $\left(\gamma_{30}\right)$ & 0.00 & 0.00 & -0.27 & & .785 \\
\hline & Condition*Word Count $\left(\gamma_{21}\right)$ & 0.00 & 0.00 & 1.87 & & .064 \\
\hline & Intercept $\left(\tau_{00}\right)$ & 0.68 & 0.15 & & 4.51 & $<.001$ \\
\hline & Residual $\left(\sigma^{2}\right)$ & 0.53 & 0.10 & & 5.12 & $<.001$ \\
\hline \multirow[t]{8}{*}{$\mathrm{E}$} & Intercept $\left(\gamma_{00}\right)$ & 5.50 & .19 & 28.24 & & $<.001$ \\
\hline & Time $\left(\gamma_{10}\right)$ & -0.19 & .13 & -1.49 & & .147 \\
\hline & Word Count $\left(\gamma_{20}\right)$ & 0.00 & .00 & 0.04 & & .968 \\
\hline & Condition $\left(\gamma_{01}\right)$ & -0.19 & .17 & -0.71 & & .480 \\
\hline & Trait Open $\left(\gamma_{02}\right)$ & -0.06 & .18 & -0.33 & & .743 \\
\hline & Condition*Word Count $\left(\gamma_{21}\right)$ & 0.00 & .00 & 2.47 & & .015 \\
\hline & Intercept $\left(\tau_{00}\right)$ & 0.69 & .15 & & 4.61 & $<.001$ \\
\hline & Residual $\left(\sigma^{2}\right)$ & 0.52 & .10 & & 5.21 & $<.001$ \\
\hline
\end{tabular}

Table 16. MLM models for authenticity (pretest, posttest and follow-up assessments). 
In Model $\mathrm{E}$ a significant condition by word count interaction was observed, $\beta=.005, S E$ $=.002, t(147)=2.47, p=.02$. Simple slopes analyses revealed that there was a statistically significant positive relationship between word count and authenticity for the open condition, $\beta=$ $.005, S E=.002, t(147)=1.91, p=.06$ but not the control condition, $\beta=.0009, S E=.002, t(147)$ $=.42, p=.68$. The interaction is depicted in figure 18 .

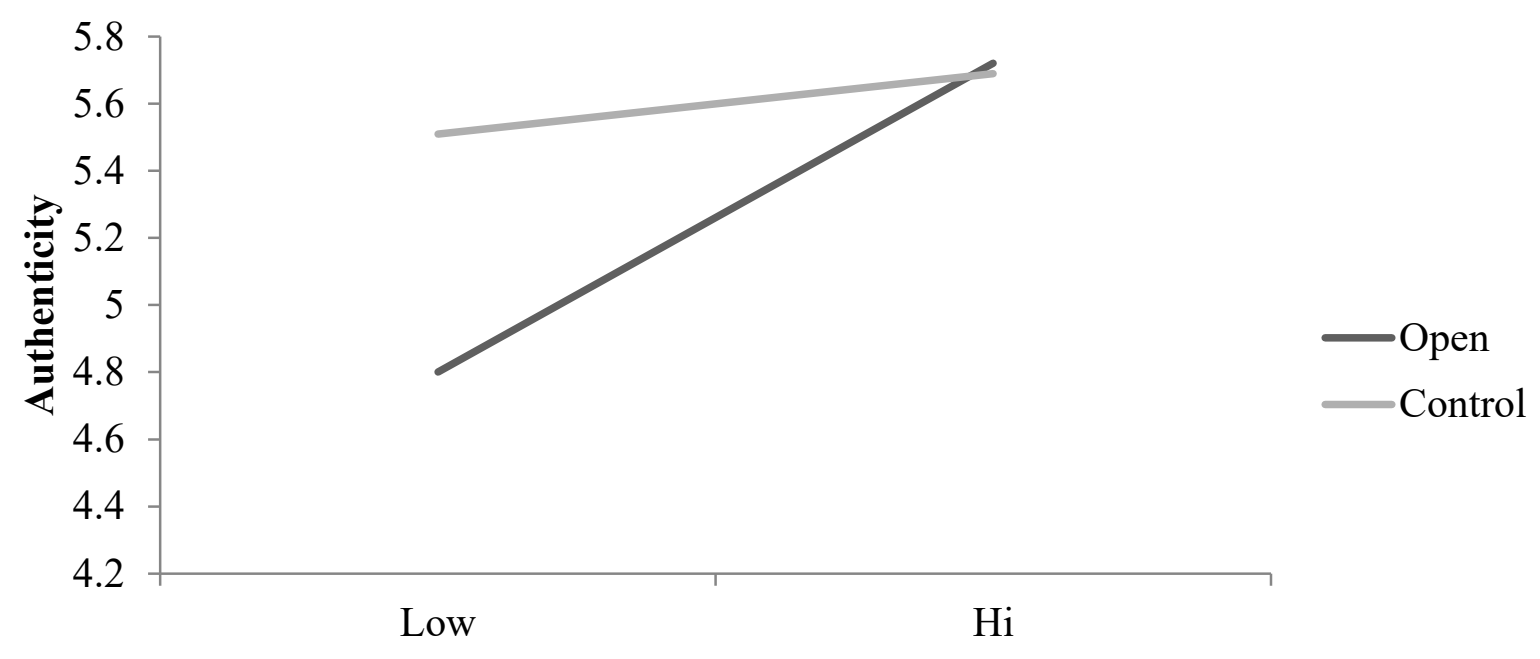

Word Count

Figure 17. Simple slopes for condition by trait openness interaction predicting authenticity (posttest, follow-up assessments).

Overall, hypotheses 2 and 3 were not supported. An overview of statistical findings from Model E is presented in Table 17. Table 17 displays findings for each set of hypothesis tests in addition to results from exploratory analyses. Due to the exploratory nature of this experiment the remaining variables assessed in the experiment that were not included in hypothesis tests were analyzed according to the same procedures as the hypothesis tests. Exploratory analyses for positive affect are presented below while the remainder of analyses can be found in Appendix $P$ $\& \mathrm{Q}$.

In models including daily assessment variables a main effect of word count was observed in each of the four dependent variables. Statistically significant findings were found across three 
of the four variables for both time and trait openness. No variables were predicted by the time by trait openness interaction or the time by condition interaction. Interestingly, five trait openness by condition interactions were observed across tests (see discussion section for a set of potential explanations).

Patterns across the five variables assessed across pretest, posttest and follow-up assessments were sparse. Variation across time points was observed in four of the five variables (effort, positive affect, negative affect, and personal growth) while a quadratic effect was observed across three variables (effort, positive affect, negative affect). 


\begin{tabular}{|c|c|c|c|c|c|c|c|c|c|}
\hline & Daily Logs & & & & Pretest, Postt & Follow & & & \\
\hline Model E & Authenticity & Effort & PA & NA & Authenticity & Effort & PA & NA & $\begin{array}{l}\text { Personal } \\
\text { Growth }\end{array}$ \\
\hline Intercept $\left(\gamma_{00}\right)$ & $*$ & $*$ & $*$ & $*$ & $*$ & * & $*$ & $*$ & $*$ \\
\hline Time $\left(\gamma_{10}\right)$ & & $*$ & $*$ & $*$ & & $*$ & $*$ & $*$ & $*$ \\
\hline Condition $\left(\gamma_{01}\right)$ & & & $*$ & & & & & & \\
\hline Word Count $\left(\gamma_{20}\right)$ & $*$ & $*$ & $*$ & $*$ & & & & & $*$ \\
\hline Trait Open & $*$ & $*$ & $*$ & & & & & $\dagger$ & $*$ \\
\hline Time*Trait Open & - & - & - & - & - & - & - & - & - \\
\hline Trait Open*Condition & $*$ & $*$ & $*$ & - & - & - & $*$ & - & $*$ \\
\hline Time*Condition $\left(\gamma_{11}\right)$ & - & - & - & $\dagger$ & - & - & & - & - \\
\hline Time*Word Count $\left(\gamma_{12}\right)$ & - & - & - & - & - & - & - & - & - \\
\hline $\begin{array}{l}\text { Condition*Word Count } \\
\left(\gamma_{21}\right)\end{array}$ & - & $*$ & - & $*$ & $*$ & $*$ & - & - & - \\
\hline Time*Time & - & - & - & - & - & $*$ & $*$ & $*$ & - \\
\hline Time*Time*Condition & - & - & - & - & - & & & & - \\
\hline Intercept $\left(\tau_{00}\right)$ & $*$ & $*$ & $*$ & $*$ & $*$ & $*$ & $*$ & $*$ & $*$ \\
\hline Time $\left(\tau_{11}\right)$ & $*$ & $*$ & $*$ & $*$ & - & - & $*$ & - & - \\
\hline $\operatorname{Cov}\left(\tau_{10}\right)$ & & & & & - & - & & - & - \\
\hline Residual $\left(\sigma^{2}\right)$ & * & $*$ & * & * & $*$ & $*$ & * & $*$ & $*$ \\
\hline $\begin{array}{l}\text { Inter Class Correlation } \\
\text { (ICC) }\end{array}$ & .61 & .62 & .59 & .71 & .58 & & .54 & .60 & .73 \\
\hline
\end{tabular}




\section{Exploratory Analyses: Positive Affect}

Due to the exploratory nature of this experiment I have opted to conduct exploratory analyses. I conducted exploratory analyses by applying the series of models used previous analysis beginning with positive affect reported immediately following the daily activities. As shown in Table 18 and illustrated in Figure 19 participants in the open condition reported more positive affect following daily tasks than did participants in the control condition. Effect sizes ranged from trivial (task $5 ; d=.04$ ) to small (tasks $1-4 ; d=.26-.36$ ). The overall effect size was small in magnitude $(d=.24)$.

\begin{tabular}{lccccccc}
\hline & \multicolumn{3}{c}{ Openness } & \multicolumn{3}{c}{ Control } \\
& $\mathrm{n}$ & $M$ & $S D$ & $\mathrm{n}$ & $M$ & $S D$ & $d$ \\
\hline Daily Task 1 & 96 & 2.86 & .80 & 107 & 2.64 & .87 & .26 \\
Daily Task 2 & 99 & 2.77 & .95 & 104 & 2.48 & .93 & .31 \\
Daily Task 3 & 94 & 2.70 & .83 & 99 & 2.38 & .95 & .36 \\
Daily Task 4 & 89 & 2.52 & .91 & 93 & 2.28 & .88 & .27 \\
Daily Task 5 & 88 & 2.60 & .86 & 97 & 2.57 & .82 & .04 \\
Overall & 466 & 2.69 & .88 & 500 & 2.48 & .90 & .24 \\
\hline
\end{tabular}

Table 18 Positive affect descriptive statistics (daily assessments). Topics in the openness condition are aesthetics (task 1), emotions (task 2), ideas (task 3) and introspection (task 4); task 5 is the curiosity manipulation.

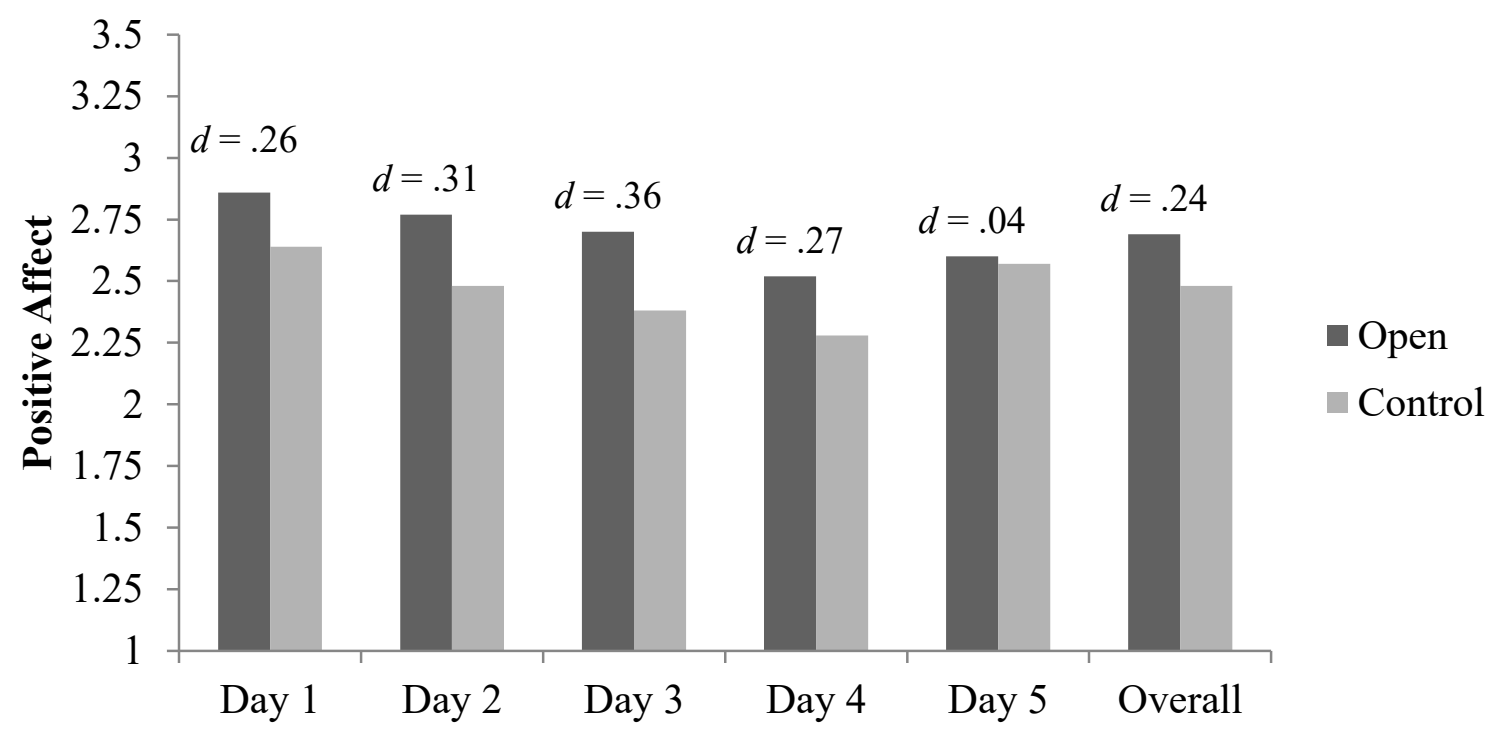


Figure 18. Mean positive affect scores across time (daily assessments). Topics in the openness condition are aesthetics (task 1), emotions (task 2), ideas (task 3) and introspection (task 4); task 5 is the curiosity manipulation.

In Model E (see Table 19), positive affect was found to vary across time points $\beta=-.11$, $S E=.02, t(548)=-5.52, p<.001$, such that individual reported less positive affect as the study progressed. A main effect of condition was also found, $\beta=-.23, S E=.10, t(216)=-2.12, p=$ .03 , indicating that the participants reported more positive affect immediately following the open condition activities then the control condition activities. A main effect of trait openness was observed suggesting that higher levels of trait openness were associated with more positive affect averaging across assessments, $\beta=1.29, S E=.36, t(216)=3.58, p<.001$. A statistically significant condition by trait openness interaction was found, $\beta=.79, S E=.23, t(216)=3.50, p$ $<.001$.

\begin{tabular}{|c|c|c|c|c|c|c|}
\hline Mode & & $\begin{array}{l}\text { Parameter } \\
\text { Estimates }\end{array}$ & $\begin{array}{c}\text { Standard } \\
\text { Error }\end{array}$ & $t$ & $z$ & $p$ \\
\hline \multirow[t]{4}{*}{$\mathrm{A}$} & Intercept $\left(\gamma_{00}\right)$ & 2.76 & 0.06 & 43.66 & & $<.001$ \\
\hline & Time $\left(\gamma_{10}\right)$ & -0.06 & 0.01 & -4.78 & & $<.001$ \\
\hline & Intercept $\left(\tau_{00}\right)$ & 0.47 & 0.05 & & 8.86 & $<.001$ \\
\hline & Residual $\left(\sigma^{2}\right)$ & 0.33 & 0.02 & & 19.28 & $<.001$ \\
\hline \multirow[t]{6}{*}{ B } & Intercept $\left(\gamma_{00}\right)$ & 276 & 0.07 & 40.25 & & $<.001$ \\
\hline & Time $\left(\gamma_{10}\right)$ & -0.06 & 0.02 & -4.19 & & $<.001$ \\
\hline & Intercept $\left(\tau_{00}\right)$ & 0.67 & 0.10 & & 6.58 & $<.001$ \\
\hline & Time $\left(\tau_{11}\right)$ & 0.02 & 0.01 & & 3.03 & .001 \\
\hline & $\operatorname{Cov}\left(\tau_{10}\right)$ & -0.05 & 0.02 & & -2.80 & .005 \\
\hline & Residual $\left(\sigma^{2}\right)$ & 0.29 & 0.02 & & 16.60 & $<.001$ \\
\hline \multirow[t]{8}{*}{$\mathrm{C}$} & Intercept $\left(\gamma_{00}\right)$ & 2.62 & 0.09 & 27.77 & & $<.001$ \\
\hline & Time $\left(\gamma_{10}\right)$ & -0.04 & 0.02 & -2.09 & & .037 \\
\hline & Condition $\left(\gamma_{01}\right)$ & 0.31 & 0.14 & 2.29 & & .023 \\
\hline & Time*Condition $\left(\gamma_{11}\right)$ & -0.04 & 0.03 & -1.36 & & .175 \\
\hline & Intercept $\left(\tau_{00}\right)$ & 0.64 & 0.10 & & 648 & $<.001$ \\
\hline & Time $\left(\tau_{11}\right)$ & 0.02 & 0.01 & & 2.99 & .001 \\
\hline & $\operatorname{Cov}\left(\tau_{10}\right)$ & -0.05 & 0.02 & & -2.69 & .007 \\
\hline & Residual $\left(\sigma^{2}\right)$ & 0.29 & 0.02 & & 16.59 & $<.001$ \\
\hline $\mathrm{D}$ & Intercept $\left(\gamma_{00}\right)$ & 2.69 & 0.09 & 28.82 & & $<.001$ \\
\hline
\end{tabular}




\begin{tabular}{|c|c|c|c|c|c|}
\hline Time $\left(\gamma_{10}\right)$ & -0.09 & 0.03 & -3.37 & & $<.001$ \\
\hline Condition $\left(\gamma_{01}\right)$ & 0.27 & 0.13 & 2.02 & & .045 \\
\hline Word Count $\left(\gamma_{20}\right)$ & 0.00 & 0.00 & 1.03 & & .305 \\
\hline Trait Open $\left(\gamma_{02}\right)$ & -0.37 & 0.18 & -2.01 & & .045 \\
\hline Time*Trait Open $\left(\gamma_{12}\right)$ & 0.03 & 0.04 & 0.67 & & .501 \\
\hline Condition*Trait Open $\left(\gamma_{03}\right)$ & 0.79 & 0.23 & 3.50 & & $<.001$ \\
\hline Time*Condition $\left(\gamma_{11}\right)$ & -0.02 & 0.04 & -0.48 & & .631 \\
\hline Time*Word Count $\left(\gamma_{12}\right)$ & 0.00 & 0.00 & 1.00 & & .319 \\
\hline Condition*Word Count $\left(\gamma_{21}\right)$ & 0.00 & 0.00 & -1.74 & & .082 \\
\hline Intercept $\left(\tau_{00}\right)$ & 0.47 & 0.09 & & 4.96 & $<.001$ \\
\hline Time $\left(\tau_{11}\right)$ & 0.01 & 0.01 & & 1.43 & .076 \\
\hline $\operatorname{Cov}\left(\tau_{10}\right)$ & -0.01 & 0.02 & & -0.32 & .748 \\
\hline Residual $\left(\sigma^{2}\right)$ & 0.26 & 0.02 & & 13.39 & $<.001$ \\
\hline Intercept $\left(\gamma_{00}\right)$ & 3.16 & .17 & 18.68 & & $<.001$ \\
\hline Time $\left(\gamma_{10}\right)$ & -0.11 & .02 & -5.52 & & $<.001$ \\
\hline Condition $\left(\gamma_{01}\right)$ & -0.23 & .10 & -2.19 & & .030 \\
\hline Word Count $\left(\gamma_{20}\right)$ & 0.00 & .00 & 3.64 & & $<.001$ \\
\hline Trait Open $\left(\gamma_{02}\right)$ & 1.29 & .36 & 3.58 & & $<.001$ \\
\hline Condition*Trait Open $\left(\gamma_{03}\right)$ & -0.80 & .23 & -3.52 & & $<.001$ \\
\hline Intercept $\left(\tau_{00}\right)$ & 0.45 & .09 & & 4.89 & $<.001$ \\
\hline Time $\left(\tau_{11}\right)$ & 0.01 & .01 & & 1.25 & .100 \\
\hline $\operatorname{Cov}\left(\tau_{10}\right)$ & -0.00 & .02 & & -0.12 & .906 \\
\hline Residual $\left(\sigma^{2}\right)$ & 0.26 & .02 & & 13.43 & $<.001$ \\
\hline
\end{tabular}

Table 19. MLM models for positive affect (daily assessments).

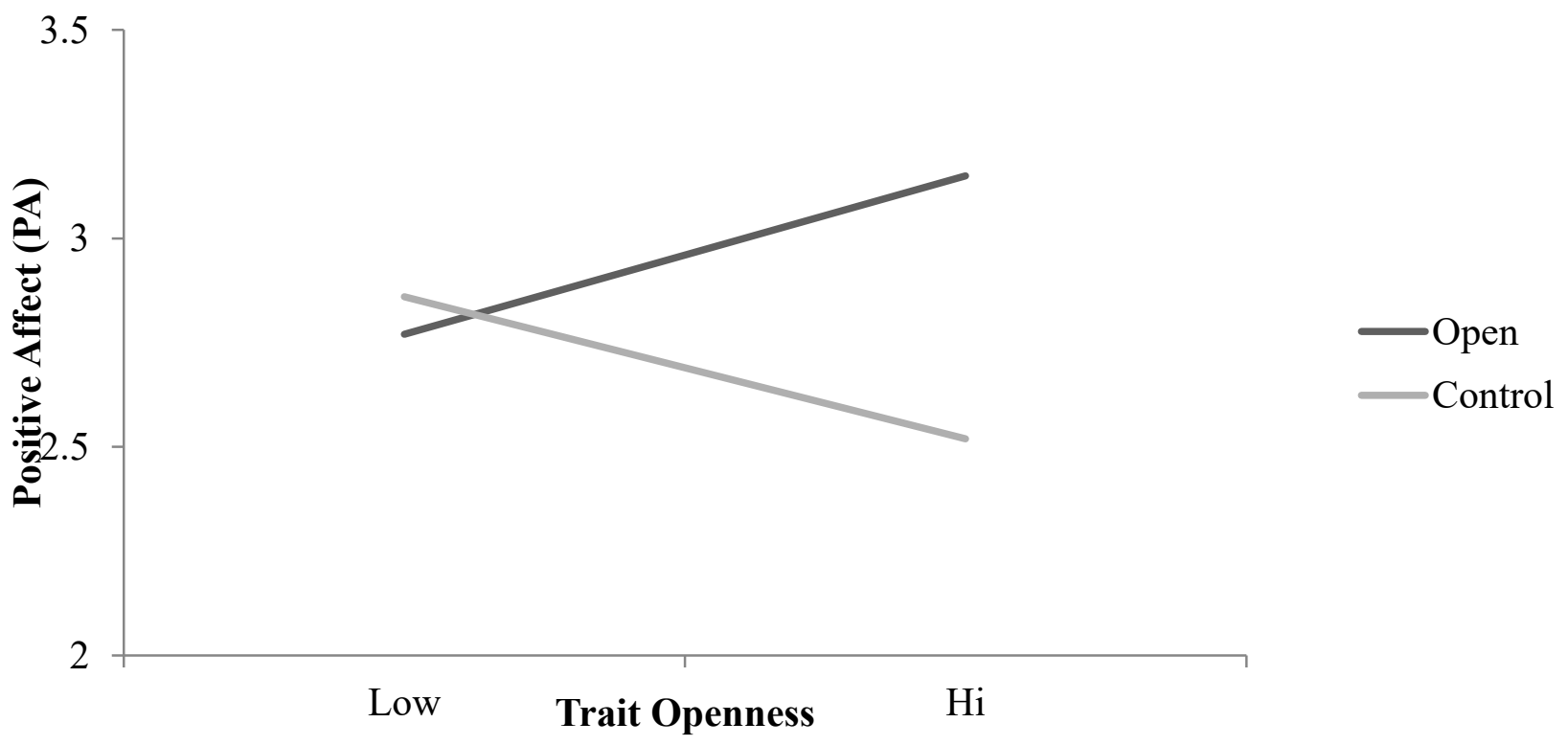


Figure 19. Simple slopes for condition by trait openness interaction predicting positive affect (daily assessments).

As illustrated in Figure 20, the relationship between condition and positive affect varied depending upon individual levels of trait openness. The simple slope for the open condition, $\beta=$ $.43, S E=.18, t(216)=2.34, p=.02$, and the control condition, $\beta=-.37, S E=.18, t(216)=-$ $2.01, p=.05$, were both statistically significant.

As illustrated in Table 20 and depicted in Figure 21, self-reported positive affect did not differ by any meaningful magnitude during the pretest and posttest assessments $(d=.04-.09)$. A small effect size was present at the follow-up assessment; however, the sample size at this assessment is sub-optimal.

\begin{tabular}{lccccccc}
\hline & \multicolumn{3}{c}{ Openness } & \multicolumn{3}{c}{ Control } \\
& $\mathrm{n}$ & $\mathrm{M}$ & $\mathrm{SD}$ & $\mathrm{n}$ & $\mathrm{M}$ & $\mathrm{SD}$ & $d$ \\
\hline Pretest & 106 & 3.18 & .64 & 115 & 3.21 & .88 & .04 \\
Posttest & 86 & 2.93 & .69 & 95 & 2.86 & .79 & .09 \\
Follow Up & 38 & 3.04 & .77 & 34 & 2.84 & .94 & .23 \\
\hline
\end{tabular}

Table 20. Positive affect descriptive statistics (pretest, posttest and follow up assessments).

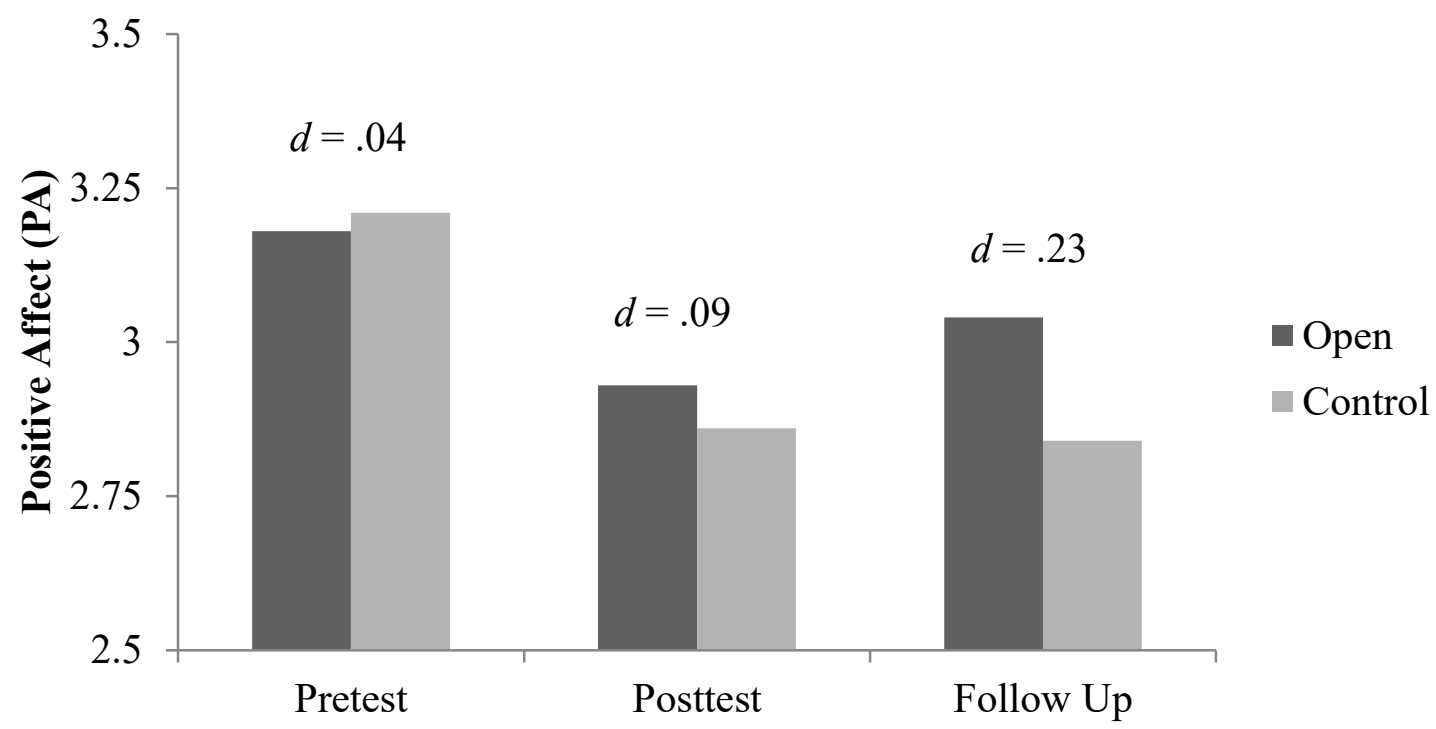

Figure 20.Mean positive affect scores across time (pretest, posttest, and follow up assessments). 
In Model E (see Table 21) a main effect of time, $\beta=-0.60, S E=.14, t(210)=-4.42, p<$ .001 , and a condition by trait openness interaction were observed, $\beta=.41, S E=.21, t(171)=$ $1.95, p=.05$.

\begin{tabular}{|c|c|c|c|c|c|c|}
\hline Mode & & $\begin{array}{l}\text { Parameter } \\
\text { Estimates }\end{array}$ & $\begin{array}{c}\text { Standard } \\
\text { Error }\end{array}$ & $t$ & $z$ & $p$ \\
\hline \multirow[t]{4}{*}{ A } & Intercept $\left(\gamma_{00}\right)$ & 3.17 & 0.06 & 56.71 & & $<.001$ \\
\hline & Time $\left(\gamma_{10}\right)$ & -0.18 & 0.04 & -4.70 & & $<.001$ \\
\hline & Intercept $\left(\tau_{00}\right)$ & 0.31 & 0.05 & & 6.29 & $<.001$ \\
\hline & Residual $\left(\sigma^{2}\right)$ & 0.27 & 0.03 & & 10.21 & $<.001$ \\
\hline \multirow[t]{6}{*}{$\mathrm{B}$} & Intercept $\left(\gamma_{00}\right)$ & 3.17 & 0.05 & 57.96 & & $<.001$ \\
\hline & Time $\left(\gamma_{10}\right)$ & -0.21 & 0.04 & -4.72 & & $<.001$ \\
\hline & Intercept $\left(\tau_{00}\right)$ & 0.35 & 0.07 & & 5.39 & $<.001$ \\
\hline & Time $\left(\tau_{11}\right)$ & 0.09 & 0.04 & & 2.07 & .019 \\
\hline & $\operatorname{Cov}\left(\tau_{10}\right)$ & -0.04 & 0.04 & & -1.01 & .313 \\
\hline & Residual $\left(\sigma^{2}\right)$ & 0.20 & 0.03 & & 6.06 & $<.001$ \\
\hline \multirow[t]{8}{*}{$\mathrm{C}$} & Intercept $\left(\gamma_{00}\right)$ & 3.20 & 0.08 & 41.57 & & $<.001$ \\
\hline & Time $\left(\gamma_{10}\right)$ & -0.30 & 0.06 & -4.80 & & $<.001$ \\
\hline & Condition $\left(\gamma_{01}\right)$ & -0.04 & 0.11 & -0.39 & & .697 \\
\hline & Time*Condition $\left(\gamma_{11}\right)$ & 0.17 & 0.09 & 2.04 & & .043 \\
\hline & Intercept $\left(\tau_{00}\right)$ & 0.35 & 0.06 & & 5.41 & $<.001$ \\
\hline & Time $\left(\tau_{11}\right)$ & 0.09 & 0.04 & & 1.95 & .025 \\
\hline & $\operatorname{Cov}\left(\tau_{10}\right)$ & -0.04 & 0.04 & & -0.83 & .404 \\
\hline & Residual $\left(\sigma^{2}\right)$ & 0.20 & 0.03 & & 6.11 & $<.001$ \\
\hline \multirow[t]{14}{*}{$\mathrm{D}$} & Intercept $\left(\gamma_{00}\right)$ & 3.20 & 0.08 & 41.21 & & $<.001$ \\
\hline & Time $\left(\gamma_{10}\right)$ & -0.30 & 0.06 & -4.81 & & $<.001$ \\
\hline & Condition $\left(\gamma_{01}\right)$ & -0.05 & 0.11 & -0.45 & & .656 \\
\hline & Word Count $\left(\gamma_{20}\right)$ & 0.00 & 0.00 & 0.56 & & .578 \\
\hline & Trait Open $\left(\gamma_{02}\right)$ & -0.17 & 0.16 & -1.06 & & .293 \\
\hline & Time*Trait Open $\left(\gamma_{02}\right)$ & 0.14 & 0.09 & 1.56 & & .120 \\
\hline & Condition*Trait Open $\left(\gamma_{03}\right)$ & 0.43 & 0.22 & 1.96 & & .052 \\
\hline & Time*Condition $\left(\gamma_{11}\right)$ & 0.17 & 0.09 & 1.99 & & .048 \\
\hline & Time*Word Count $\left(\gamma_{12}\right)$ & 0.00 & 0.00 & 0.41 & & .683 \\
\hline & Condition*Word Count $\left(\gamma_{21}\right)$ & 0.00 & 0.00 & -0.37 & & .710 \\
\hline & Intercept $\left(\tau_{00}\right)$ & 0.36 & 0.07 & & 5.39 & $<.001$ \\
\hline & Time $\left(\tau_{11}\right)$ & 0.08 & 0.04 & & 1.91 & .028 \\
\hline & $\operatorname{Cov}\left(\tau_{10}\right)$ & -0.04 & 0.04 & & -0.99 & .324 \\
\hline & Residual $\left(\sigma^{2}\right)$ & 0.197 & 0.03 & & 6.11 & $<.001$ \\
\hline $\mathrm{E}$ & Intercept $\left(\gamma_{00}\right)$ & 3.23 & 0.08 & 41.13 & & $<.001$ \\
\hline
\end{tabular}




\begin{tabular}{|c|c|c|c|c|c|}
\hline Time $\left(\gamma_{10}\right)$ & -0.60 & 0.14 & -4.42 & & $<.001$ \\
\hline Condition $\left(\gamma_{01}\right)$ & -0.06 & 0.11 & -0.55 & & .585 \\
\hline Word Count $\left(\gamma_{20}\right)$ & 0.00 & 0.00 & 0.60 & & .552 \\
\hline Trait Open $\left(\gamma_{02}\right)$ & -0.09 & 0.15 & -0.55 & & .580 \\
\hline Trait Open*Condition $\left(\gamma_{03}\right)$ & 0.41 & 0.21 & 1.95 & & .053 \\
\hline Time*Time $\left(\gamma_{40}\right)$ & 0.19 & 0.08 & 2.50 & & .013 \\
\hline Time*Time*Condition $\left(\gamma_{41}\right)$ & -0.04 & 0.11 & -0.33 & & .745 \\
\hline Intercept $\left(\tau_{00}\right)$ & 0.37 & 0.07 & & 5.62 & $<.001$ \\
\hline Time $\left(\tau_{11}\right)$ & 0.09 & 0.04 & & 2.08 & .019 \\
\hline $\operatorname{Cov}\left(\tau_{10}\right)$ & -0.05 & 0.04 & & -1.18 & .236 \\
\hline Residual $\left(\sigma^{2}\right)$ & 0.19 & 0.03 & & 6.05 & $<.001$ \\
\hline
\end{tabular}

Table 21. MLM models for positive affect (pretest, posttest, and follow-up assessments).

When probed the condition by trait openness interaction revealed that high levels of openness were associated with low levels of positive affect in both conditions (see Figure 22), however this effect was slightly more pronounced in the control condition $\beta=-0.60, S E=.13, t$ $(171)=-4.42, p<.001$, when compared to the open condition, $\beta=-.38, S E=.14, t(171)=-2.76$, $p=.006$

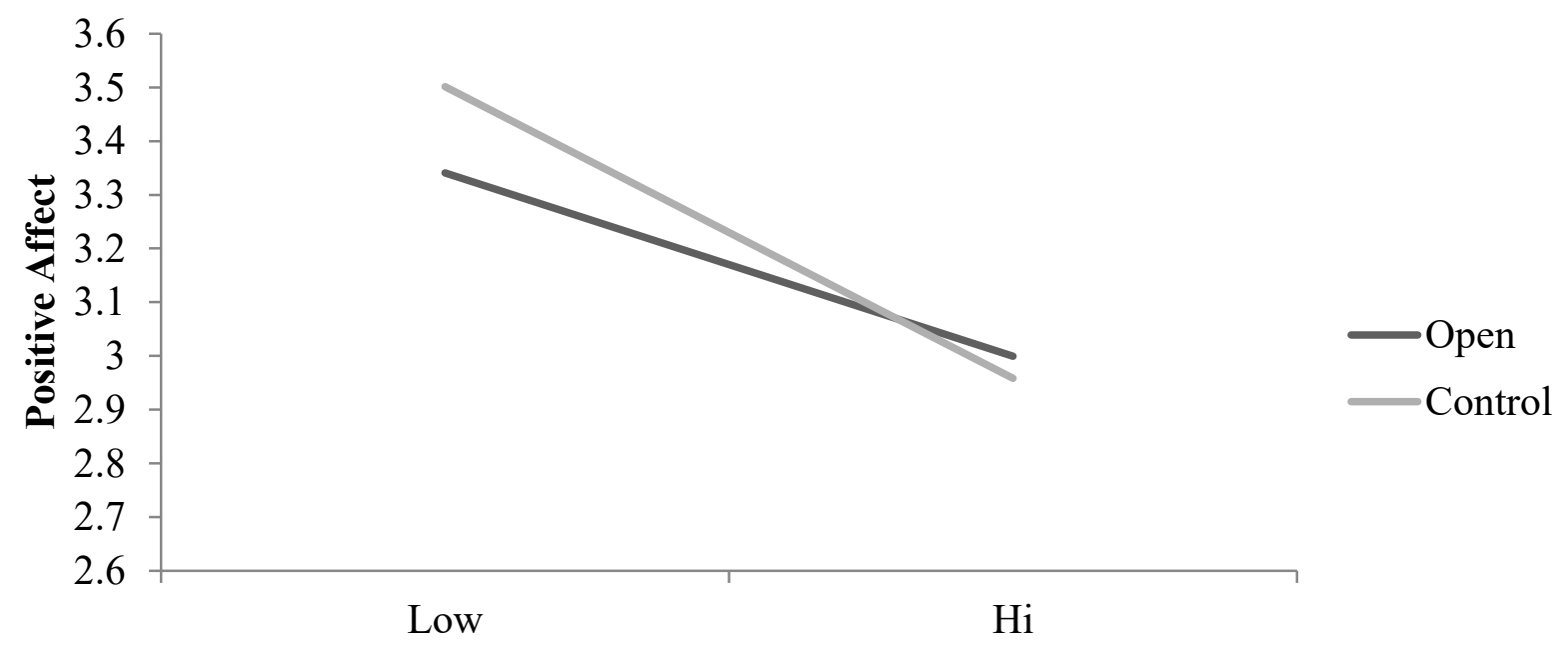

Trait Openness

Figure 21. Simple slopes for condition by trait openness interaction predicting positive affect (pretest, posttest, and follow up assessments).

Lastly, a quadratic term was found to be significant suggesting that individuals' positive affect decreased from pretest to posttest and then increased from posttest to the follow-up 
assessment, $\beta=.19, S E=.08, t(171)=2.50, p=.01$. Despite the between group trend seemingly apparent in Figure 21, the quadratic by condition interaction was not significant in Model E, $\beta=$ $-.04, S E=.11, t(171)=-0.33, p=.75$.

\section{Discussion}

This experiment investigated the outcomes of behaviour associated with the personality trait of openness to experience. Guided by previous enacted trait research (e.g., Zelenski et al., 2012; Zelenski et al., 2013) and the trait-state isomorphism hypothesis (Fleeson, 2001), three hypotheses regarding the outcomes of open states were proposed. Specifically, I hypothesized that engaging in open behaviour would 1) enhance creative thinking ability in the moment and over time, 2) elevate levels of authenticity in the moment and over time, and 3) facilitate personal growth over time; interestingly, these hypotheses were not supported. This lack of support for the trait-state isomorphism of openness contrasts with cases where traits and states are characterized in part by similar outcomes (e.g., extraversion and positive affect; neuroticism and negative affect). Despite null results, this initial exploration of manipulating open states yielded several findings which require further study and provides a template for further enacted open research.

\section{Creativity}

I predicted that open states would be associated with elevated scores on the alternate uses task relative to a control condition. This test of the trait-state isomorphism hypothesis was not supported. Results supported typical findings in the literature suggesting that trait openness is a significant predictor of creative thinking ability (e.g., Feist, 1998). However, open behaviours did not influence creativity significantly. 
Main effects of time were observed across each of the four components of the alternate uses task. The contrasting directions of trends over time provide insight into potential shortcomings of the experimental design. For example, the fluency and elaboration components of the alternate uses task reflect the frequency of responses provided and the level of detail provided in each response. Both fluency and elaboration scores were found to decrease over the five time points. In that these components are more quantitative rather than qualitative (cf. the originality and flexibility components), the decrease in elaboration and fluency over time may best be accounted for by motivational effects. That is, it is likely that participants gave more effort to the first assessments than the fifth. Potential changes to experimental design elements may counteract this motivational effect (see 'limitations and future research' section).

Motivational accounts may also explain the unexpected decrease in remote association task scores from pretest to posttest. This pre-post assessment was included to assess any residual effect of creative thinking ability resulting from the openness manipulation, should such an effect exist (hypothesis 1b). Given that no effect of open states on creativity were observed, the lack of a within-person increase on remote association task scores over time is not surprising. However, a decrease over time is unexpected. This effect is consistent with the decrease in alternate uses task elaboration and fluency scores over time and could conceivably also be accounted for by motivational effects. That is, participants may have been less motivated to contribute their full effort on the seventh day of the experiment than the first. However, while this explanation accounts for the observed effect and is consistent with the trend observed with alternate uses scores scores an alternative, an equally plausible causal factor is that the two versions of the remote association task were not exactly equivalent. The two versions of the remote association task were constructed using normative data from Bowden and Jung-Beeman (2003). Although 
items were compiled with the intension of creating two assessments of equal difficulty the assessments used different sets of items; thus, it is possible these tests were not equivalent.

Interestingly, individuals provided more conceptual categories in their responses across time points. Although potential order or item effects cannot be ruled out, the most probable explanation of this effect is that repeated exposure to creative thinking tasks facilitated enhanced performance over time. A main effect of time was also observed for the originality component. The beta indicated an upward trend across time; however, the non-linear nature of the data [see Figure 4] undermines confidence in the direction of the effect. Therefore, although practice effects seem likely to account for the linear increase in flexibility scores across time the results do not speak strongly to the directionality of the originality scores across time points.

An unexpected finding was the influence of word count in predicting scores on each of four alternate use task components. In that word counts in writing exercises can be interpreted as a proxy for effort (e.g., Layous \& Lyubomirsky, 2012), the set of findings observed in this experiment may simply suggest that individuals who put forth a greater effort in the daily tasks also put more effort into the creative thinking assessment and subsequently scored higher on the alternate uses task. Alternatively, it is conceivable that the writing process itself is conducive to creative thinking. This rationale is often used to promote the use of 'free-writing' or 'wet-ink' exercises. Although a literature review did not reveal empirical support for the link between freewriting and creative thinking ability, it is often believed that the process of continuous writing is associated with creative thinking ability (e.g., Bonk \& Smith, 1998).

In summary, although evidence supported the relationship between trait openness and creative thinking ability this experiment failed to find support for the notion that the behaviours and cognitions associated with trait openness facilitate creative thinking ability. 


\section{Personal Growth}

Hypothesis 2 made predictions regarding personal growth. Because openness is a strong predictor of personal growth I hypothesized that engaging in more open behaviour over a period of one week would lead to increases in personal growth. Although I found trait openness to predict personal growth, the differences in personal growth scores across pretest and posttest assessments was essentially zero.

Given the strong relationship between trait openness and personal growth, the lack of support for this hypothesis is likely due to elements of the experimental design. Behavioural intervention studies often consider factors such as timing and dosage when assessing an experimental design (Layous \& Lyubomirsky, 2012). In this experiment, timing refers to when participants were asked to complete their condition-specific activities (i.e., daily) while dosage refers to the length of the activities (approximately 15 minutes). The dosage of the condition specific activities were selected based on the typical procedures of laboratory based enacted trait research. For example, enacted extraversion studies typically use 10-15 minute manipulations of extraverted behaviour in a laboratory setting to induce states of extraversion (e.g., Zelenski et al., 2013). Thus, it is reasonable to expect that 15 minutes of open activities would be sufficient to induce open states. The timing of the activities, i.e., daily activities, is consistent with some previous psychological interventions (e.g., Seligman, Steen, Park, \& Peterson, 2005), however this decision was not based on an explicitly established relationships between the frequency of open behaviour and outcomes associated with trait openness; it is not well established how often, and to what degree, one must engage in open behaviours in order to cause detectable changes in personal growth.

Although it is plausible that timing and dosage were not sufficient to produce measurable 
differences in personal growth over time, it is also possible that the manipulation was effective, but not detectable with the two week follow-up assessment. For example, a study conducted by Huta \& Ryan (2010) investigated the benefits of engaging in eudaimonic vs. hedonic behaviours for 10 consecutive days and found that differences in positive affect were only detectable three months following the intervention. Given the close conceptual relationships between openness and aspects of eudaimonia (e.g., Vitterso, 2004; Ryff, 2014) a similar delayed manifestation of results is possible in this experiment. That is, any insight gained from reflecting on beauty, ideas, or one's behaviour may take longer than two weeks to influence behaviour in a manner conducive to personal growth.

Another potential issue is the personal growth measure itself. The personal growth subscale of the psychological well being inventory is a well-validated measure commonly employed in psychological research. However, with items such as "I am the kind of person who likes to give new things a try" and "For me, life has been a continuous process of learning, changing, and growth" this measure assesses a trait-like inclination towards personal growth. In retrospect, this measure of personal growth may not have been well suited to the purposed of this experiment. Future attempts to investigate the relationship between open behaviour and personal growth should consider alternative assessments better suited to assessing changes in personal growth. One potential method of assessment is to track daily growth-oriented behaviour. In an investigation of how trait and state curiosity relate to well-being and meaning in life, Kashdan and Steger (2007) asked participants to complete a daily checklist of growth-oriented and hedonistic behaviours. Growth items were validated by a panel of experts and reflect proactive social behaviors and sustaining goal-directed efforts. Through the assessment of actual growth oriented behaviour, future research may be better able to study the relationship between open 
behaviour and personal growth.

Finally, an additional consideration is that factors other than openness predict personal growth. Together the distinct but related traits of openness and extraversion form a higher-order meta-trait, referred to as plasticity (DeYoung, Peterson, \& Higgins, 2002), engagement (Olson, 2005) and even personal growth (Digman, 1997). This meta trait is thought to represent a general exploratory tendency manifested in its partially overlapping concrete/behavioural (extraversion) and abstract/ intellectual (openness) manifestations (DeYoung et al., 2002). Based on Ryff's suggestion that these traits facilitate personal growth through providing an inclination (through openness) and the energy (through extraversion) to pursue growth opportunities, it is likely that the combination of open and extraverted behaviour would better facilitate personal growth. However, open behaviour alone should be sufficient to cultivate growth based on the relationship between trait openness and personal growth. As previously discussed, this lack of support for the relationship between open behaviour and personal growth in this experiment is likely due to experimental design elements such as the dosage and timing of the manipulation and the temporal spacing between posttest assessments.

\section{Authenticity}

I predicted that states of openness would be associated with ratings of authenticity i.e., the evaluation that one's behaviour is in line with their sense of 'true self'. This hypothesis was informed by experience sampling research which has demonstrated the link between open states and authenticity (Fleeson et al., 2010). Given that open states have been found to covary with assessments of authentic behaviour, one would expect to find that open states in the present study would also show this relationship with authenticity. 
Authenticity scores did not differ significantly between conditions; however, this lack of effect is likely due to ill-suited control condition activities. Although the control group was a reasonable comparison for the majority of the variables of interest, it is likely that writing about one's day also feels authentic. Thus, it seems plausible that the expected between group condition was due, in part, to the authentic nature of the control activities.

Interestingly, trait openness was associated with feeling authentic while completing the daily tasks in general; however, the trait openness by condition interaction suggests that this effect was much stronger in the open condition. The role of trait openness will be discussed in the context of multiple hypotheses below.

\section{Influence of Trait Openness}

In three notable instances, trait openness by condition interactions were observed; these interactions predicted personal growth, authenticity (daily assessments), and positive affect (daily assessments). In each case, open individuals in the open condition reported more positive/desirable outcomes than their less open peers. There are at least two plausible explanations that account for this pattern of results.

First, trait openness is often considered an 'enhancing' or 'amplifying' factor. For example, individuals high on trait openness typically report the greatest benefit in positive psychology interventions (Senf \& Liau, 2012). Openness has also been found to amplify the association between extraversion and well-being, although openness similarly amplifies the relationship between neuroticism and distress (Bardi \& Ryff, 2007).Thus, it seems plausible that trait openness likewise played an amplifying role for participants in the open condition. That is, the open condition consisted of a number of cognitively engaging activities and participants high on trait openness were more sensitive to the potential positive benefits of these activities. 
Second, it seems equally plausible that acting in accordance with one's trait would lead to desirable outcomes. The idea that trait-consistent behaviour produces more enjoyment is consistent with the behavioural concordance model (Mosokowitz \& Cote, 1995). Despite the intuitive appeal of behavioural concordance model, findings from the enacted trait literature suggest that behaving in a manner which is out of character can in fact be enjoyable.

Specifically, findings from experience sampling studies and laboratory experiments demonstrate that acting in an extraverted manner is enjoyable even for dispositional introverts. However, in contrast with enacted trait research on extraversion, the results of this experiment arguably support the notion that engaging in trait congruent behaviour is enjoyable for open individuals but not their less open counterparts. Potential support for this proposition is particularly evident with the positive affect results (see Figure 20). Higher levels of trait openness were associated with higher levels of positive affect experienced during the condition-specific activities, while lower levels of trait openness predicted lower levels of positive affect. Thus, it is possible that acting in accordance with one's disposition, when considering trait openness, is enjoyable and beneficial while acting counter to one's trait is markedly less enjoyable and beneficial.

The interactions between levels of trait openness and experimental condition in this study can arguably be explained by two competing interpretations. That is, it is possible that open individuals responds more strongly to positive activities and it is also possible that engaging in trait congruent behaviour leads to beneficial/enjoyable outcomes. Future research is needed to further assess these competing explanations in relation to trait openness.

\section{Trait-State Isomorphism}

This experiment tested a set of hypotheses predicted by the notion of trait-state isomorphism. Experiencing sampling studies and experimental manipulation have demonstrated 
that both extraversion and neuroticism are at least partially isomorphic. That is, extraversion is associated with positive affect at both the trait and state level and neuroticism is likewise associated with negative affect. Interestingly, with the exception of positive affect, no evidence of isomorphism was observed with openness and creative thinking ability or personal growth.

One salient pattern of results across isomorphism studies is that affective outcomes appear to be subject to isomorphism while there is no evidence thus far for more cognitive outcomes such as creativity or personal growth are isomorphic. That is, the relationship between openness and positive affect observed at the trait level was also observed at the state level in the present experiment. This isomorphism with an affective outcome is consistent with the established findings concerning state extraversion and neuroticism. However, the relationship between trait openness and creative thinking ability was not observed at the state level. Future research is needed to understand this apparent pattern of results.

\section{Limitations and Future Research}

This research project represents the first (known) empirical attempt to manipulate states of openness to experience as a means of further testing the trait-state isomorphism hypothesis. However, this initial exploratory study is subject to a number of limitations.

First and foremost, the lack of precision surrounding the exact composition of behaviours which comprise openness complicates any attempt to manipulate open states. Although each of the components of openness in this experiment (aesthetics, ideas, emotions, introspection, and curiosity) are all considered to be facets of openness in some taxonomies, this exact composition was not derived from a single taxonomy but rather was assembled from various taxonomies in order to address conceptual issues with the most popular personality inventory, the NEO-IP-R (Costa \& McCrea, 1992). Even among well-validated personality taxonomies, there is little 
consensus on a precise assortment of open facets. This is all to say that, if ten researchers independently sought to manipulate open states, it would be unlikely to find an exact match between their selections of openness facets and their choices in experimental manipulations. This lack of clarity is, of course, problematic. Although recent attempts to arrive at a comprehensive list of open facets (Connelly et al., 2015) have contributed much, there remains a lack of consensus regarding openness not seen with the other big five traits. Until this issue is resolved enacted trait research with openness will continue to be subject to this limitation.

With this limitation in mind, this experiment consisted of five activities designed to elicit states of aesthetic appreciation, emotional exploration, abstract conceptual exploration, introspection, and curiosity. With the exception of the exploration of ideas activity, all activities were successfully employed in the literature previous to their use in this experiment. Upon reflection on these activities, I would recommend one alteration for future research. The introspection activity, which was adapted from the self-affirmation literature (Cohen et al., 2000), asked participants to select a personal characteristic from a list that best described themselves and then write about a time when this characteristic was important in their lives. This activity requires reflection upon personal characteristics (through selecting the most relevant characteristic from the list) as well as behaviour (through contemplating when this characteristic played a role in their lives). Based on these qualities, this task was thought a suitable introspective activity. However, given its original use in the self-affirmation literature, the task encourages self-affirming introspection and leaves little room to introspection on less positive features of one's person. This bias is problematic in that introspection can be both self-affirming and non-affirming. Future research should address this issue and select a more appropriate introspective activity. 
Future research may also benefit from conducting enacted openness studies in a laboratory setting. Results from the creativity assessments strongly suggest that participants' motivation to fully engage in the study decreased as time progressed. Because research has demonstrated that the perception of being observed significantly enhances cooperative behaviour (e.g., Ernest-Jones, Nettle, \& Bateson, 2011; Bateson, Nettle, \& Roberts, 2006), one potential method of counteracting motivational effects may be to conduct in-lab experiments.

The present study sought to enhance individuals' engagement with abstract and sensory information through 'open' behaviour. However, the factors that may inhibit individuals from exploring their internal environment were not considered. For example, individuals may be reluctant to engage in introspection or the exploration of ideas or emotions if they perceive such activities may threaten their sense of self or worldview. This tension between exploration and inhibition can be observed at the interpersonal level. For example, an individual high on both behavioural approach and avoidance motivation may wish to engage with their environment but ultimately withdrawal (e.g.,Nikitin \& Freund, 2008). Internal inhibiting factors such as avoidance motivation may also contribute to a reluctance to explore abstract/sensory information. Another factor likely to inhibit such exploration is a perceived threat to self. For example, at the intergroup level recent research suggests that 'cognitive freezing', or the reluctance to be open to information regarding an outgroup, can be counteracted by reducing the sense of threat towards one's in-group (Whol, Porat, \& Halperin, in press). It seems plausible that a similar process would take place at the individual level, i.e., wherein a reduced threat to one's sense of self would facilitate or 'unfreeze' the exploration of information. Thus, the role of inhibition in abstract/sensory inhibition may be an interesting avenue for future research. 


\section{Conclusion}

This experiment sought to test the degree to which the outcomes of trait and state openness to experience are isomorphic. Contrary to the isomorphism hypothesis, open behaviours did not influence creative thinking ability. Thus, the promise of enacted openness as a method of facilitating creative thinking was not supported. Additionally, results did not support the link between open behaviour and personal growth, and open states were not found to be associated with higher levels of authenticity relative to a control.

This study represents the first empirical attempt to manipulate states of openness to experience and presents preliminary evidence for the relative lack trait-state isomorphism for openness. However, this study was limited by a number of factors. For example, the lack of precision regarding the key characteristics of openness in the literature makes any manipulation of openness inexact. Furthermore, certain elements of the experimental design may have not been conducive to an optimal test of isomorphism (e.g., the seven day intervention format, the follow-up assessment taking place at the two-week mark, and choices regarding measurements of dependent variables).

Despite these methodological shortcomings, this experiment should have revealed at least some evidence of isomorphism for creative thinking ability should an effect exist. That is, across five manipulations of open states no concrete, or even modestly suggestive, evidence was observed to indicate that state openness was associated with creative thinking ability. Positive affect was observed to be partially isomorphic; however, this could conceivably be due to either trait-state isomorphism or differences in the inherent pleasantness of condition specific tasks. When these findings are compared to the existing literature it becomes apparent that only affective outcomes have been found to be isomorphic while cognitive characteristics such as 
creativity do not appear to be isomorphic. Thus, results from this experiment tentatively suggest trait-state isomorphism may not extend to cognitive outcomes. More research is needed to understand the underlying mechanisms and processes which renders some traits (e.g., extraversion and neuroticism) to be partially isomorphic and others seemingly less isomorphic (e.g, openness). 


\section{References}

Aiken, L., \& West, S. G. (1991). Multiple regression: Testing and interpreting interactions. Newbury Park, CA: Sage

Aron, E. N., \& Aron, A. (1997). Sensory-processing sensitivity and its relation to introversion and emotionality. Journal of Personality and Social Psychology, 73, 345-368.

Ashton, M. C., Lee, K., Vernon, P. A., \& Jang, K. L. (2000). Fluid intelligence, crystallized intelligence, and the Openness/Intellect factor. Journal of Research in Personality, 34, $197-207$.

Ashton, M. C., \& Lee, K. (2001). A theoretical basis for the major dimensions of personality. European Journal of Personality, 15, 327-353.

Baas, M., De Dreu C. K. W, \& Nijstad, B. A. 2008. A meta-analysis of 25 years of moodcreativity research: Hedonic tone, activation, or regulatory focus? Psychological Bulletin, $134,779-806$.

Bardi A., Ryff, C. D. (2007). Interactive effects of traits on adjustment to a life transition. Journal of Personality, 75, 955-984.

Bateson, M., Nettle, D., \& Roberts, G. 2006. Cues of being watched enhance cooperation in a real-world setting. Biology Letters, 2, 412-414.

Blackie, L. E., Roepke, A. M., Forgeard, M. J., Jayawickreme, E., \& Fleeson, W. (2014). Act well to be well. In Parks, A. C., \& Schueller S. M (Eds.), Handbook of Positive Psychology Interventions.

Bonk, C. J., \& Smith, G. S. (1998). Alternative instructional strategies for creative and critical thinking in the accounting curriculum. Journal of Accounting Education, 16, 261-293. 
Bowden, E. M., \& Jung-Beeman, M. (2003). Normative data for 144 compound remote associate problems. Behaviour Research Methods, Instruments, \& Computers, 35, 634-639.

Burch, G., Hemsley, D. R., Corr, P. J., \& Pavelis, C. (2005). Personality, creativity and latent inhibition. European Journal of Personality, 19, 1-16.

Christensen, P. A., Guilford, J. P., Merrifield, P. R., \& Wilson, R. C. (1960). Alternate uses. Beverly Hills: Sheridan Psychological Services.

Carney, D., Jost, J., Gosling, S., \& Potter, J. (2008). The secret lives of liberals and conservatives: Personality profiles, interaction styles, and the things they leave behind. Political Psychology, 29(6), 807-840.

Carson, S. H., Peterson, J. B., \& Higgins, D. M. (2003). Decreased latent inhibition is associated with increased creative achievement in high-functioning individuals. Journal of Personality and Social Psychology, 85, 499-506.

Cohen, J. (1988). Statistical power analysis for the behavioral sciences (2nd ed.). Hillsdale, NJ: Lawrence Earlbaum Associates.

Cohen, G. L., Aronson. J., \& Steele, C. M. (2000). When beliefs yield to evidence: reducing biased evaluation by affirming the self. Personality and Social Psychology Bulletin, 26, 1151-1164.

Costa, P. T., \& McCrae, R. R. (1992). Revised NEO Personality Inventory (NEO PI-R) and NEO Five-Factor Inventory professional manual. Odessa, FL: Psychological Assessment Resources.

Connelly, B. S., Ones, D. S.., Davies, S. E., \& Birkland, B irkland, A. (2014). Opening up openness: A theoretical sort following critical incidents methodology and a meta-analytic investigation of the trait family measure. Journal of Personality Assessment, 17-28. 
DeNeve, K. M., \& Cooper, H. (1998). The happy personality: A meta-analysis of 137 personality traits and subjective well-being. Psychological Bulletin, 124, 197-229.

DeYoung, C. G. (2010). Personality neuroscience and the biology of traits. Social and Personality Psychology Compass, 4, 1165-1180.

DeYoung, C. G. (2014). Openness/Intellect: A dimension of personality reflecting cognitive exploration. In M. L. Cooper and R. J. Larsen (Eds.), APA handbook of personality and social psychology: Personality processes and individual differences (Vol 4, pp. 369 399). Washington, DC: American Psychological Association.

DeYoung, C. G., Peterson, J. B., \& Higgins, D. M. (2002). Higher-order factors of the Big Five predict conformity: Are there neuroses of health? Personality and Individual Differences, $33,533-552$.

DeYoung, C. G., Peterson, J. B., \& Higgins, D. M. (2005). Sources of Openness/Intellect: Cognitive and neuropsychological correlates of the fifth factor of personality. Journal of Personality, 73, 825-858.

DeYoung, C. G., Quilty, L. C., \& Peterson, J. B. (2007). Between facets and domains: 10 aspects of the Big Five. Journal of Personality and Social Psychology, 93, 880-896.

Diener, E., Emmons, R. A., Larsen, R. J., \& Griffin, S. (1985). The satisfaction with life scale. Journal of Personality Assessment, 49, 71-75.

Diessner, R., Rust, T., Solom, R. C., Frost, N., \& Parsons, L. (2006). Beauty and hope: a moral beauty intervention. Journal of Moral Education, 33, 301-317.

Digman, J. M. (1997). Higher-order factors of the big five. American Psychologists, 73, 12461256. 
Evans, D. E., \& Rothbart, M. L. (2008). Temperamental sensitivity: Two constructs or one? Personality and Individual Differences, 44, 108-118.

Ernest-Jones, M., Netlle, DD., \&Bateson, M. (2011). Effects of eye images on everyday cooperative behaviour: A field experiment. Evolution and Human Behaviour, 32, $172-$ 178.

Feist, G. J. (1998). A meta-analysis of personality in scientific and artistic creativity. Personality \& Social Psychology Review, 2, 290-309.

Fleeson, W. (2001). Toward a structure and process integrated view of personality: Traits as density distributions of states. Journal of Personality and Social Psychology, 80, 10111027.

Fleeson, W., Malanos, A. B., \& Achille, N. M. (2002). An intraindividual process approach to the relation between extraversion and positive affect: Is acting extraverted as good as being extraverted? Journal of Personality and Social Psychology, 83, 1409-1422.

Fleeson, W., \& Wilt, J. (2010). The relevance of big five trait content in behaviour to subjective authenticity: Do high levels of within-person behavioural variability undermine or enable authenticity achievement? Journal of Personality, 78, 1353-1382.

Gagolewski M., Tartanus B. (2015). R package stringi: Character string processing facilities. http://stringi.rexamine.com/.

Goldberg, L. R. (1990). An alternative 'description of personality’: The big-five factor structure. Personality Processes and Individual Differences, 59, 1216-1229.

Goldberg, L. R. (1999). A broad-bandwidth, public domain, personality inventory measuring the lower-level facets of several five-factor models. In I. Mervielde, I. Deary, F. De Fruyt, \& 
F. Ostendorf (Eds.), Personality Psychology in Europe, Vol. 7 (pp. 7-28). Tilburg, The Netherlands: Tilburg University Press.

Goldberg, L. R., Johnson, J. A., Eber, H. W., Hogan, R., Ashton, M. C., Cloninger, C. R., \& Gough, H. C. (2006). The International Personality Item Pool and the future of publicdomain personality measures. Journal of Research in Personality, 40, 84-96.

Haris, J. A. (2004). Measured intelligence, achievement, openness to experience and creativity. Personality and Individual Differences, 36, 913-929. doi:10.1016/S0191-8869(03)001612

Hirsh, J. B., DeYoung, C. G., Xu, X., \& Peterson, J. B. (2010). Compassionate liberals and polite conservatives: Associations of Agreeableness with political ideology and values. Personality and Social Psychology Bulletin, 36, 655-664.

Huta, V., \& Ryan, R. M. (2010). Pursuing pleasure or virtue: The differential and overlapping well-being benefits of hedonic and eudaimonic motives. Journal of Happiness Studies, $11,735-762$.

Isen, A. M. (1999). On the relationship between affect and creative problem solving. In S. W. Russ (Ed.), Affect, creative experience and psychological adjustment (pp. 3-17). Philadelphia: Brunner/Mazel.

Isen, A. M., Daubman, K. A., \& Nowicki, G. P. (1987). Positive affect facilitates creative problem solving. Journal of Personality and Social Psychology, 52, 1122-1131.

Jackson, J. J., Hill, P. L., Payne, B. R., Roberts, B. W., \& Stine-Morrow, E. A. L. (2012). Can an old dog learn (and want to experience) new tricks? Cognitive training increases openness to experience in older adults. Psychology and Aging, 27(2), 286-292. DOI:

10.1037/a0025918 
Johnson, J. A. (1994). Clarification of factor five with the help of the AB5C model. European Journal of Personality, 8, 311-334.

Johnson, J. A. (2014). Measuring thirty facets of the five factor model with a 120 -item public domain inventory: Development of the IPIP-NEO-120. Journal of Research in Personality, 51, 78-89.

Kashdan, T. B., \& Silva, P. J. (2008). Curiosity and interest: The benefits of thriving on novelty and challenge. In The Oxford Handbook of Positive Psychology (pp.367-374). New York: Oxford University Press, Inc.

Kashdan, T. B., \& Steger, M. F. (2007). Curiosity and pathways to well-being and meaning in life: Traits, states, and everyday behaviour. Motivation and Emotion. 31, 159-173.

Kaufmann, G., \& Vosburg, S. K. 2010. The effects of mood on early and late idea production. Creativity Research Journal, 14, 317-330.

Kang, M. J., Hsu, M., Krajbich, I. M., Loewenstein, G., McClure, S. M, Wang, J. T., \& Camerer, C. F. (2009). The wick in the candle of learning: Epistemic curiosity activates reward circuitry and enhances memory. Psychological Science, 20, 963-973.

King, L. A., Walker, L. M., \& Broyles, S. J. (1996). Creativity and the Five-Factor Model. Journal of Research in Personality, 30, 189-203.

Lee, K., \& Ashton, M. C. (2004). Psychometric Properties of the HEXACO Personality Inventory. Multivariate Behavioral Research, 39, 329-358

Lention, A. P., Slabu, L., Sedikides, C., \& Power, K. (2013). I feel good, therefore I am real: Testing the causal influence of mood on state authenticity. Cognition and Emotion, 27, 1202-1224. 
Letzring, T. D., \& Adamcik, L. A. (2015). Personality traits and affective states: Relationships with and without affect induction. Personality and Individual Differences, 75, 114-120.

Li, W., Li, X., Huang, L., Kong, X., Yang, W., Wei, D., . . Liu, J. (2014). Brain structures link traits creativity to openness to experience. Social Cognitive and Affective Neuroscience

Lucas, R. E., \& Fujita, F. (2000). Factors influencing the relation between extraversion and peasant affect. Journal of Personality and Social Psychology, 79, 1039-1056.

Layous, K., \& Lyubomirsky, S. (2012). The how, why, what, when, and who of happiness: Mechanisms underlying the success of positive interventions. In J. Gruber \& J. Moscowitz (Eds.), The light and dark side of positive emotions. New York: Oxford University Press

Lyubomirsky, S., Sousa, L., \& Dickerhoof, R. (2006). The costs and benefits of writing, talking, and thinking about life's triumphs and defeats. Journal of Personality and Social Psychology, 90, 692-708.

MacLean, K. A., Johnson, M. W., \& Griffiths, R. R. (2011). Mystical experiences occasioned by the hallucinogen psilocybin lead to increases in the personality domain of Openness. Journal of Psychopharmacology, 25, 1453-1461.

McCrae, R. R. (2007). Aesthetic chills as a universal marker of openness to experience. Motivation and Emotion, 31, 5-11.

McCrae, R. R., \& Sutin, A. R. (2007). Openness to Experience. In Leary, M. R., \& Hoyle, R. H. (Eds), Handbook of Individual Differences in Social Behaviour (pp. 257-271). Guilford Press. 
McNiel, J. M., \& Fleeson, W. (2006). The causal effects of extraversion on positive affect and neuroticism on negative affect: Manipulating state extraversion and state neuroticism in an experimental approach. Journal of Research in Personality, 40, 529-550.

Mednick, S. (1962). The associative basis of the creative process. Psychological Review, 69(3), $220-232$.

Mitte, K., \& Kampfe, N. (2008). Personality and the four faces of positive affect: A multitraitmultimethod analysis using self and peer report. Journal of Research in Personality, 42, $1370-1375$.

Moskowitz, D. S., \& Cote', S. (1995). Do interpersonal traits predict affect? A comparison of three models. Journal of Personality and Social Psychology, 69, 915-924.

Nikitin, J., \& Freund, A. M. (2008). The role of social approach and avoidance motives for subjective well-being and the successful transition to adulthood. Applied Psychology, 57, 90-111.

Noftle, E. E., Schnitker, S. A., \& Robins, R. W. (2011). Character and personality: Connections between positive psychology and personality psychology. In K. Sheldon, T. Kashdan, \& M. Steger, (Eds.), Designing the future of positive psychology: Taking stock and moving forward (pp. 207-227). New York: Oxford University Press.

Nusbaum, E. C., \& Silva, P. J. (2011). Are openness and intellect distinct aspects of openness to experience? A test of the I/O model. Personality and Individual Difference, 51(5), 571 574.

Olson, K. R. (2005). Engagement and self-control: Superordinate dimensions of Big Five traits. Personality and Individual Differences, 38, 1689-1700. 
Park, N., Peterson, C., \& Seligman, M. E. P. (2004). Strengths of character and wellbeing. Journal of Social and Clinical Psychology, 23, 603-619

Pennebaker, J. W., \& Francis, M. E. (1996). Cognitive, emotional, and language processes in disclosure. Cognition \& Emotion, 10, 601-626.

Peterson, C., \& Seligman, M. E. P. (2004). Character strengths and virtues: A handbook and classification. Washington, DC: American Psychological Association.

Peterson, J. B., \& Carson, S. (2000). Latent inhibition and openness to experience in a highachieving student population. Personality and Individual Differences, 28, 323-332.

Peterson, J. B., Smith, K. W., \& Carson, S. (2002). Openness and extraversion are associated with reduced latent inhibition: replication and commentary. Personality and Individual Difference, 33, 1137-1147.

R Core Team (2014). R: A language and environment for statistical computing. R Foundation for Statistical Computing, Vienna, Austria

Ryan, R. M., \& Frederick, C. M. (1997). On energy, personality and health: Subjective vitality as a dynamic reflection of well-being. Journal of Personality, 65, 529-565.

Ryff, C. D. (2014). Psychological well-being revisited: Advances in the science and practice of eudaimonia. Psychotherapy and Psychosomatics, 83, 10-28

Ryff, C. D. (1989). Happiness is everything, or is it? Explanations on the meaning of psychological well-being. Journal of Personality and Social Psychology, 57, 1069-1081.

Ryff, C. D., \& Keyes, C. L. (1995). The structure of psychological well-being revisited. Journal of Personality and Social Psychology, 69, 712-727.

Saucier, G. (1992). Openness versus intellect: Much ado about nothing? European Journal of Personality, 6, 381-386. 
Saucier, G. (2003). Factor structure of English-language personality type-nouns.Journal of Personality and Social Psychology, 85, 695-708.

Saucier, G., \& Ostendorf, F. (1999). Hierarchical subcomponents of the Big Five personality factors: A cross-language replication. Journal of Personality and Social Psychology, 76, $613-627$.

Seligman, M. E. P., Steen, T. A., Park, N., \& Peterson, C. (2005) Positive psychology progress: Empirical validation of interventions. American Psychologist, 60, 410-421.

Senf, K., \& Liau, A. K. (2012). The effects of positive interventions on happiness and depressive symptoms, with an examination of personality as a moderator. Journal of Happiness Studies.

Sheldon, K. M., Ryan, R. M., Rawsthorne, L., \& Ilardi, B. (1997). Trait self and true self: Crossrole variation in the Big Five traits and its relations with authenticity and subjective wellbeing. Journal of Personality and Social Psychology, 73, 1380-1393.

Schmutte, P. S., \& Ryff, C. D. (1997). Personality and well-being: re-examining methods and meanings. Journal of Personality and Social Personality, 73, 549-559.

Schiota, M. N., Keltner, D., \& John, O. P. (2006). Positive emotion dispositions differentially associated with big five personality and attachment style, The Journal of Positive Psychology, 2, 61-71.

Silvia, P. J., Nusbaum, E. C., Berg, C., Martin, C., \& O'Conner, A. (2009). Openness to experience, plasticity, and creativity: Exploring lower-order, higher-order, and interactive effects. Journal of Research in Personality.

Smillie, L. D. (2013). Why does it feel good to act like an extravert? Social and Personality Psychology Compass, 7, 878-887. 
Steel, P., Schmidt, J., \& Shultz, J. (2008). Refining the relationship between personality and subjective well-being. Psychological Bulletin, 134, 138-161.

Steger, M. F., Frazier, P., Oishi, S., \& Kaler, M. (2006). The meaning in life questionnaire: Assessing the presence of and search for meaning in life. Journal of Counseling Psychology, 53, 80.

Stephan, Y. (2009). Openness to experience and active older adults' life satisfaction: A trait and facet-level analysis. Personality and Individual Differences. 47, 637-641.

Sung, S. Y., \& Choi, J. N. (2009). Do big five personality factors affect individual creativity? The moderating role of extrinsic motivation. Social Behaviour and Personality, 37, 941956.

Tellegen, A. (1982). Brief manual for the multidimensional personality questionnaire. Unpublished manuscript, University of Minnesota, Minneapolis, 10311010.

Vittersø, J. (2004). Subjective well-being versus self-actualization: Using the flow-simplex to promote a conceptual, clarification of subjective quality of life. Social Indicators Research, 65, 299-331

Watson, D., \& Clark, L.A. (1994). The PANAS-X: Manual for the positive and negative affect schedule-expanded form. Iowa: The University of Iowa.

Whelan, D. C. (2014). Extraversion and counter-dispositional behaviour: exploring consequences and the impact of situation-behaviour congruence (Unpublished doctoral dissertation). Carleton University. 
Whol, M.J.A., Porat, R., \& Halperin, E. (in press). Unfreezing cognitions during an intractable conflict: Does an external incentive for negotiating peace and (low levels of) collective angst increase information seeking? British Journal of Social Psychology,

Williams, P. G., Rau, H. K., Cribbet, M. R., \& Gunn, H. E. (2009). Openness to Experience and stress regulation. Journal of Research in Personality, 43, 777-784.

Wilson, T. D., Reinhard, D. A., Westgate, E. C., Gilbert, D. T., Ellerbeck, N., Hahn, C ... \& Shaked, A. (2014). Just think: The challenges of the disengaged mind. Science, 345, 7579.

Woo, S. E., Chernyshenko, O. S., Longley, A., Zhang, Z.-X., Chiu, C., \& Stark, S. E. (in press). Openness to Experience: Its lower-level structure, measurement, and cross-cultural equivalence. Journal of Personality Assessment.

Zelenski, J. M., Santoro, M. S., \& Whelan, D. C. (2012). Would introverts be better off if they acted more like extraverts? Exploring emotional and cognitive consequences of counter dispositional behavior. Emotion, 12, 290-303.

Zelenski, J. M., Whelan, D. C., Nealis, L. J., Besner, C. M., Santoro, M. S., \& Wynn, J. E. (2013). Personality and affective forecasting: Trait introverts underpredict the hedonic benefits of acting extraverted. Journal of Personality and Social Psychology, 104(6), 1092-1108.

Zillig, L. M. P., Hemenover, S. H., \& Dienstbier, R. A. 2002. What do we assess when we assess a big five trait? A content analysis of the affective, behavioural and cognitive processes represented in big five personality inventories. Personality and Social Psychology Bulletin, 28, 847-858 


\section{Appendices}

\section{Appendix A - IPIP-NEO-120}

On the following page, there are phrases describing people's behaviors. Please use the rating scale below to describe how accurately each statement describes you. Describe yourself as you generally are now, not as you wish to be in the future. Describe yourself as you honestly see yourself, in relation to other people you know of the same sex as you are, and roughly your same age. So that you can describe yourself in an honest manner, your responses will be kept in absolute confidence. Please read each statement carefully, and then fill in the bubble that corresponds to the number on the scale.

Response Options

$\begin{array}{ccccc}1 & 2 & 3 & 4 & 5 \\ \text { Very } & \text { Moderately } & \text { Neither } & \text { Moderately } & \text { Very } \\ \text { Inaccurate } & \text { Inaccurate } & \begin{array}{c}\text { Accurate } \\ \text { Accurate }\end{array} & \begin{array}{c}\text { Accurate } \\ \text { Accurate }\end{array}\end{array}$

1 Worry about things

2 Makes friends easily

3 Have a vivid imagination

4 Trust others

5 Complete tasks successfully

6 Get angry easily

7 Love large parties

8 Believe in the importance of art

9 Use others for my own ends

10 Like to tidy up

11 Often feel blue

12 Take charge

13 Experience my emotions intensely

14 Love to help others

15 Keep my promises

16 Find it difficult to approach
41 Dislike myself

42 Try to lead others

43 Feel others' emotions

44 Am concerned about others

45 Tell the truth

46 Am afraid to draw attention to myself

47 Am always on the go

48 Prefer to stick with things I know

49 Yell at people

50 Do more than what's expected of me 51 Rarely overindulge

52 Seek adventure

53 Avoid philosophical discussions

54 Think highly of myself

55 Carry out my plans

56 Become overwhelmed by
81 Easily resist temptations

82 Enjoy being reckless

83 Have difficulty understanding abstract ideas 84 Have a high opinion of myself

85 Waste my time

86 Feel that I'm unable to deal with things

87 Love life

88 Tend to vote for conservative political candidates

89 Am not interested in other people's problems

90 Rush into things

91 Get stressed out easily

92 Keep others at a distance

93 Like to get lost in thought

94 Distrust people

95 Know how to get things done

96 Am not easily annoyed 
others

17 Am always busy

18 Prefer variety to routine

19 Love a good fight

20 Work hard

21 Go on binges

22 Love excitement

23 Love to read challenging material

24 Believe that I am better than others

25 Am always prepared

26 Panic easily

27 Radiate joy

28 Tend to vote for liberal

political candidates

29 Sympathize with the homeless

30 Jump into things without thinking

31 Fear the worst

32 Feel comfortable around

people

33 Enjoy wild flights of fantasy

34 Believe that others have good intentions

35 Excel in what I do

36 Get irritated easily

37 Talk to a lot of different

people at parties

38 See beauty in the things that others might not notice

39 Cheat to get ahead

40 Often forget to put things back in their proper place

events

57 Have a lot of fun

58 Believe that there is no absolute right or wrong 59 Feel sympathy for those who are worse off than myself 60 Make rash decisions

61 Am afraid of many things

62 Avoid contacts with others

63 Love to daydream

64 Trust what people say

65 Handle tasks smoothly

66 Lose my temper

67 Prefer to be alone

68 Do not like poetry

69 Take advantage of others

70 Leave a mess in my room

71 Am often down in the dumps

72 Take control of things

73 Rarely notice my emotional reactions

74 Am indifferent to the feelings of others

75 Break rules

76 Only feel comfortable with my friends

77 Do a lot in my spare time

78 Dislike change

79 Insult people

80 Do just enough work to get by
97 Avoid crowds

98 Do not enjoy going to art museums

99 Obstruct others' plans

100 Leave my belongings around

101 Feel comfortable with myself

102 Wait for others to lead the way

103 Don't understand people who get emotional

104 Take no time for others

105 Break my promises

106 Am not bothered by

difficult social situations

107 Like to take it easy

108 Am attached to

conventional ways

109 Get back at others

110 Put little time and effort into my work

111 Am able to control my

cravings

112 Act wild and crazy

113 Am not interested in theoretical discussion 114 Boast about my virtues

115 Have difficulty starting tasks

116 Remain calm under pressure

117 Look at the bright side of life

118 Believe that we should be tough on crime

119 Try not to think about the needy

120 Act without thinking 


\section{Appendix B - Remote Association Test (pretest)}

Below you will find a series of three stimulus words (example: age/ mile/ sand). Your task is to generate a forth word which, when combined with each of the stimulus words, results in word pairs that make up a common compound word or phrase (example: Stone [stoneage/milestone/sandstone]).

1. Cottage/swiss/cake

2. Loser/throat/spot

3. Night/wrist/stop

4. Rocking/wheel/high

5. Fountain/baking/pop

6. Aid/rubber/wagon

7. Cracker/fly/fighter

8. Cane/daddy/plum

9. Fish/mine/rush

10. Measure/worm/video

11. Sense/courtesy/place

12. Piece/mind/dating

13. River/note/account

14. Pie/luck/belly

15. Opera/hand/dish

16. Fur/rack/tail

17. Hound/pressure/shot

18. Sleeping/bean/trash

19. Light/birthday/stick

20. Shine/beam/struck

21. Water/mine/shaker

22. Basket/eight/snow

23. Right/cat/carbon

24. Nuclear/feud/album

25. Cross/rain/tie 


\section{Appendix C - Remote Association Test (posttest)}

Below you will find a series of three stimulus words (example: age/ mile/ sand). Your task is to generate a forth word which, when combined with each of the stimulus words, results in word pairs that make up a common compound word or phrase (example: Stone [stoneage/milestone/sandstone]).

1. Cream/swiss/cake

2. Show/life/row

3. Duck/fold/dollar

4. Dew/comb/bee

5. Reserve/ranger/tropical

6. Flake/mobile/cone

7. Safety/cushion/point

8. Dream/break/light

9. Political/surprise/line

10. High/district/house

11. Worm/shelf/end

12. Flower/friend/scout

13. Print/berry/bird

14. Date/alley/fold

15. Cadet/capsule/ship

16. Stick/make/point

17. Fox/man/peep

18. Dust/cereal/fish

19. Food/forward/break

20. Peach/arm/tar

21. Palm/shoe/house

22. Wheel/hand/shopping

23. Home/sea/bed

24. Sandwhich/golf/house

25. Sage/paint/hair 


\section{Appendix D - The Meaning in Life Questionnaire}

Please take a moment to think about what makes your life feel important to you. Please respond to the following statements as truthfully and accurately as you can, and also please remember that these are very subjective questions and that there are no right or wrong answers. Please answer according to the scale below:

\begin{tabular}{|c|c|c|c|c|c|c|}
\hline $\begin{array}{c}\text { Absolutely } \\
\text { False }\end{array}$ & $\begin{array}{c}\text { Mostly } \\
\text { False }\end{array}$ & $\begin{array}{c}\text { Somewhat } \\
\text { False }\end{array}$ & $\begin{array}{c}\text { Can't } \\
\text { Say }\end{array}$ & $\begin{array}{c}\text { Somewhat } \\
\text { True }\end{array}$ & $\begin{array}{c}\text { Mostly } \\
\text { True }\end{array}$ & $\begin{array}{c}\text { Absolutely } \\
\text { True }\end{array}$ \\
\hline 1 & 2 & 3 & 4 & 5 & 6 & 7 \\
\hline
\end{tabular}

I understand my life's meaning.

I am looking for something that makes my life feel meaningful.

I am always looking to find my life's purpose.

My life has a clear sense of purpose.

Leave this item blank

I have a good sense of what makes my life meaningful.

I have discovered a satisfying life purpose.

I am always searching for something that makes my life feel significant.

I am seeking a purpose or mission for my life.

My life has no clear purpose.

I am searching for meaning in my life. 


\section{Appendix E - Satisfaction with Life Scale}

Below are five statements that you may agree or disagree with. Using the 1 - 7 scale below, indicate your agreement with each item by placing the appropriate number on the line preceding that item. Please be open and honest in your responding.

\begin{tabular}{|c|c|c|c|c|c|c|}
\hline $\operatorname{tr}$ & Disagree & $\begin{array}{c}\text { Slightly } \\
\text { disagree }\end{array}$ & $\begin{array}{c}\text { Neither } \\
\text { agree not } \\
\text { disagree }\end{array}$ & $\begin{array}{c}\text { Slightly } \\
\text { agree }\end{array}$ & Agree & $\begin{array}{c}\text { Strongly } \\
\text { agree }\end{array}$ \\
\hline 1 & 2 & 3 & 4 & 5 & 6 & 7 \\
\hline
\end{tabular}

__ In most ways my life is close to my ideal.

The conditions of my life are excellent.

_ I am satisfied with my life.

I excel at leaving this space blank

So far I have gotten the important things I want in life.

If I could live my life over, I would change almost nothing. 


\section{Appendix F - Alternate Uses Test}

Alternate Uses Test Day 1: In the following task you will be asked to list as many possible uses as you can for a common household object. Specifically, please list all the uses you can think of for $a$ brick in the next five minutes.

Alternate Uses Test Day 2: In the following task you will be asked to list as many possible uses as you can for a common household object. Specifically, please list all the uses you can think of for a newspaper in the next five minutes.

Alternate Uses Test Day 3: In the following task you will be asked to list as many possible uses as you can for a common household object. Specifically, please list all the uses you can think of for a paperclip in the next five minutes.

Alternate Uses Test Day 4: In the following task you will be asked to list as many possible uses as you can for a common household object. Specifically, please list all the uses you can think of for a pillow in the next five minutes

Alternate Uses Test Day 5: In the following task you will be asked to list as many possible uses as you can for a common household object. Specifically, please list all the uses you can think of for a shoebox in the next five minutes. 


\section{Appendix G - Personal Growth}

Please indicate the degree to which you agree with the following statements. Use the scale below to record your answers.

\begin{tabular}{|l|l|l|l|l|l|}
\hline 1 & 2 & 3 & 4 & 5 & 6 \\
\hline $\begin{array}{l}\text { Strongly } \\
\text { disagree }\end{array}$ & $\begin{array}{l}\text { Moderately } \\
\text { disagree }\end{array}$ & $\begin{array}{l}\text { Slightly } \\
\text { disagree }\end{array}$ & Slightly agree & $\begin{array}{l}\text { Moderately } \\
\text { agree }\end{array}$ & $\begin{array}{l}\text { Strongly } \\
\text { agree }\end{array}$ \\
\hline
\end{tabular}

1. I am not interested in activities that will expand my horizons.

2. In general, I feel that I continue to learn more about myself as time goes by.

3. I am the kind of person who likes to give new things a try.

4. I don't want to try new ways of doing things--my life is fine the way it is.

5. I think it is important to have new experiences that challenge how you think about yourself and the world.

6. When I think about it, I haven't really improved much as a person over the years.

7. In my view, people of every age are able to continue growing and developing.

8. With time, I have gained a lot of insight about life that has made me a stronger, more capable person.

9. I have the sense that I have developed a lot as a person over time.

10. I do not enjoy being in new situations that require me to change my old familiar ways of doing things.

11. For me, life has been a continuous process of learning, changing, and growth.

12. I enjoy seeing how my views have changed and matured over the years.

13. I gave up trying to make big improvements or changes in my life a long time ago.

14. There is truth to the saying you can't teach an old dog new tricks. 


\section{Appendix H - Authenticity and Effort Questionnaire}

Please answer the following questions regarding how you felt over the course of the last week.

Strongly

Disagree

1

2

3

4

5

6

Strongly

Agree

7

1. The way I behaved made me tired and fatigued.

2. I was my true self during the last week.

3. I felt authentic in the way I behaved during the last week.

4. It was effortful to behave the way I did during the last week.

5. I actively attempted to behave appropriately.

6. I felt like I was really being me during the last week.

7. It feels like I have less energy to concentrate this week, compared to the week before.

8. I was putting on an "image" during the last week.

9. I did what I wanted to during the last week.

10. It was very easy to behave the way I did during the last week.

11. During the last week, my behaviour represented who I really am.

12. I pretended to enjoy the situation more than I truly did.

13. It took a lot of effort to behave the way I did.

14. I felt like I was putting on a "false face" during the past week.

15. If someone was observing me for the past week, they would have an accurate impression of the real me. 


\section{Appendix I - Authenticity and Effort (Daily Log)}

Please answer the following questions regarding how you felt over the course of the assigned activity.

Strongly

Disagree

1

2

3

4

5

6

Strongly

Agree

7

1. It was very easy to behave the way I did during the activity.

2. I felt authentic in the way I behaved during the activity.

3. I felt like I was really being me during the activity.

4. I was my true self during the activity.

5. During the activity, my behaviour represented who I really am.

6. It took a lot of effort to behave the way I did.

7. I felt like I was putting on a "false face" during the activity.

8. If someone was observing me during the activity, they would have an accurate impression of the real me. 


\section{Appendix J - PANAS}

This scale consists of a number of words and phrases that describe different feelings and emotions. Read each item and then mark the appropriate answer in the space next to that word. Indicate to what extent you have felt this way during the past week. Use the following scale to record your answers:

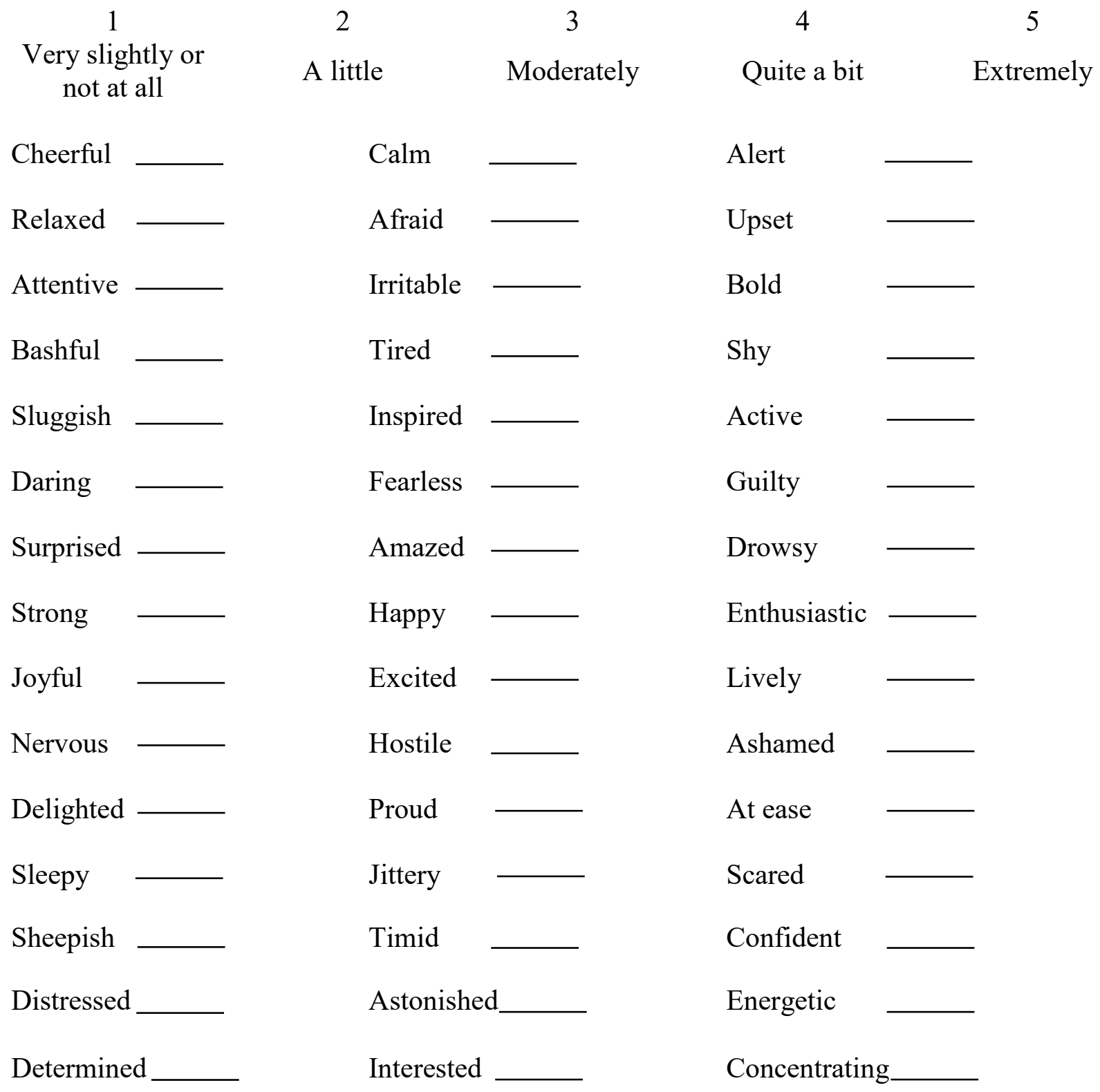




\section{Appendix K- PANAS (Daily Log)}

This scale consists of a number of words and phrases that describe different feelings and emotions. Read each item and then mark the appropriate answer in the space next to that word. Indicate to what extent you have felt this way during your assigned activity. Use the following scale to record your answers:

1

Very slightly or not at all

Afraid
Active -
Scared -
Nervous -
Alert -
Jittery -
Attentive

2

A little 3

Moderately

Relaxed

Guilty

Excited

Sluggish

At ease

Drowsy

Ashamed

Irritable

Sleepy

Calm

Hostile

Enthusiastic

Tired
4

5

Quite a bit Extremely
Inspired

Upset

Distressed

Interested

Proud

Strong 


\section{Appendix L - Experimental Condition Daily Log Instructions}

Over the next five days you will be asked to complete a series of fifteen minute free-style writing assignments. Today, you will be asked to think about and specify your intended writing topics. Please follow the guidelines below and provide a few words to describe your intended writing topic.

1. Tomorrow (Day 1) - On day 1 you will be asked to spend fifteen minutes (total) writing about three aspects of beauty that you have observed in your life. Specifically, you are asked to: 1) Describe something you feel is beautiful from nature; 2: Describe something you feel is beautiful that is human-made. 3) Describe something you feel is beautiful in human behavior.

Please spend some time thinking about what your 3 topics may be and provide tentative writing topics below.

2. The next day (Day2) - On day 2 you will be asked to write about two emotionally meaningful events in your life. In your writing, I'd like you to really let go and explore your deepest emotions and thoughts. You might tie your topic to your relationships with others including parents, significant others, friends, or relatives, to your past, your present, or your future, or to who you have been, who you would like to be, or who you are now. Don't worry about using complete sentences or being logical. Just write whatever comes to your mind about this experience. Please take a few moments to reflect. Once you have decided on your two writing topics please list them below.

1. Day 3 - On day 3 you will be asked to write about one or two of the most interesting ideas/concepts you have come across during your time in university. You will be asked to describe the concept briefly and elaborate on why you find it to be particularly interesting. Please take some time to reflect, and then list your two writing topics below.

2. Day 4 - Please take a few moments to look over the following list of commonly held values and personal characteristics.

[Artistic skills/aesthetic appreciation; sense of humor/ relations with friends/family; spontaneity/living life in the moment; social skills; musical ability/appreciation; physical attractiveness; creativity; business/managerial skills; romantic values]

Which two characteristics/values are most important to you? On day 4 you will be asked to describe why these two characteristics/values are important to you, and specify a time in your life when they were particularly important. 
Please reflect on, and list below, the two characteristics/values you intend to be your writing topics.

3. Day 5 - On day five you will be presented with a series of trivia questions contained within the daily survey.

Please make a separate copy of your writing topics for your own record.

For the next five days you will be emailed daily surveys. These surveys will contain a number of brief questionnaires that should take approximately 10 minutes to complete. Additionally, space will be provided for you to complete your writing assignments. We ask that you spend approximately fifteen minutes on your writing assignments.

$\square$ I acknowledge that I have made a separate copy of my writing topics.

\section{Review}

You have produced a series of writing topics which adhere to specific parameters. Over the next five days you will receive links to daily surveys. These short questionnaires will include space for you to complete your writing assignments or, on Day 5 , will include a trivia task.

Completion of these five daily surveys is worth up to a $1.25 \%$ grade increase (.25 for each). Additionally, for each completed daily survey you will be entered in a draw for a chance to win $\$ 250$.

Following the five daily surveys you will be asked to complete a final follow-up survey. The follow-up survey will be administered one day after the last daily survey and is worth a $.5 \%$ grade increase. 


\section{Appendix M - Experimental Condition Daily Log Tasks}

\section{Task specific instructions for each daily log:}

Instructions for Day 1: Please spend approximately 15 minutes writing on your chosen topic for today in the space below. As a reminder, here are the instructions for today's assignment:

Today you are asked to write about three aspects of beauty that you have observed in your life. Specifically, you are asked to: 1) Describe something you feel is beautiful from nature; 2 :

Describe something you feel is beautiful that is human-made. 3) Describe something you feel is beautiful in human behavior

Instructions for Day 2: Please spend approximately 15 minutes writing on your chosen topic for today in the space below. As a reminder, here are the instructions for today's assignment:

Today you are asked to write about two emotionally meaningful events in your life. Specifically, please write about one positive emotional event and one negative emotional event. In your writing, I'd like you to really let go and explore your deepest emotions and thoughts. You might tie your topic to your relationships with others including parents, significant others, friends, or relatives, to your past, your present, or your future, or to who you have been, who you would like to be, or who you are now. Don't worry about using complete sentences or being logical. Just write whatever comes to your mind about this experience.

Instructions for Day 3: Please spend approximately 15 minutes writing on your chosen topic for today in the space below. As a reminder, here are the instructions for today's assignment:

Today you are asked to write about one or two of the most interesting ideas/concepts you have come across during your time in university. You will be asked to describe the concept briefly and elaborate on why you find it to be particularly interesting.

Instructions for Day 4: Please spend approximately 15 minutes writing on your chosen topic for today in the space below. As a reminder, here are the instructions for today's assignment:

Please take a few moments to look over the following list of commonly held values and personal characteristics.

[Artistic skills/aesthetic appreciation; sense of humor/relations with friends/family; spontaneity/living life in the moment; social skills; musical ability/appreciation; physical attractiveness; creativity; business/managerial skills; romantic values]

Which two characteristics/values are most important to you? Today you will be asked to describe why these two characteristics/values are important to you, and specify a time in your life when they were particularly important.

\section{Instructions for Day 5:}


Today you will be presented with a series of trivia questions. Before the answers are presented each question you will be asked to rate how curious you are to know the answer, and how confident you are you know the answer. Please take a few moments to think about the answers to each question.

Please indicate your response using the following scale:

Not at all

1

2

3

4

5

6

Very

7

Question: What is the only country in the world where women dominate the government?

How curious are you to know the answer?

How confident are you that you know the answer?

Answer: Belgium

Question: What instrument was invented to sound like a human singing?

How curious are you to know the answer?

How confident are you that you know the answer?

Answer: Violin

Question: What snack food is an ingredient in the explosive dynamite?

How curious are you to know the answer?

How confident are you that you know the answer?

Answer: Peanuts

Question: What is the only type of animal besides a human that can get a sunburn?

How curious are you to know the answer?

How confident are you that you know the answer?

Answer: Pig

Question: What is the most abundant mineral in the human body?

How curious are you to know the answer?

How confident are you that you know the answer?

Answer: Calcium

Question: What is the most sober school according to The Princeton Review?

How curious are you to know the answer?

How confident are you that you know the answer? 
Answer: Brigham Young University

Question: What book is the most shoplifted book in the world?

How curious are you to know the answer?

How confident are you that you know the answer?

Answer: The Bible

Question: What invention should make Ts'ai Lun, a 2nd century inventor, a household name?

How curious are you to know the answer?

How confident are you that you know the answer?

Answer: Paper

Question: What Beatles song lasted the longest on the American charts?

How curious are you to know the answer?

How confident are you that you know the answer?

Answer: Hey Jude

Question: What breed of dog is the only animal whose evidence is admissible in American courts?

How curious are you to know the answer?

How confident are you that you know the answer?

Answer: Bloodhound

Question: What animal's excrements are consumed as luxury food?

How curious are you to know the answer?

How confident are you that you know the answer?

Answer: Bats

Question: What industry uses $20 \%$ of China's harvested plants?

How curious are you to know the answer?

How confident are you that you know the answer?

Answer: Medicine

Question: What unfortunate handicap did Thomas Edison suffer from?

How curious are you to know the answer?

How confident are you that you know the answer?

Answer: Deafness

Question: What secular philosopher's teaching influenced life in his country for 2000 years?

How curious are you to know the answer? 
How confident are you that you know the answer?

Answer: Confucius

Question: What is the only type of lizard that has a voice?

How curious are you to know the answer?

How confident are you that you know the answer?

Answer: Gecko

Question: What was put in place by the Greeks before and during all the Ancient Olympic festivals?

How curious are you to know the answer?

How confident are you that you know the answer?

Answer: A truce

Question: What title was Catherine of Aragon known by after she divorced Henry VIII?

How curious are you to know the answer?

How confident are you that you know the answer?

Answer: Dowager Princess of Wales

Question: What was the first animated film to win an Academy Award?

How curious are you to know the answer?

How confident are you that you know the answer?

Answer: Beauty and the Beast

Question: What animal can shed up to 30,000 teeth in its lifetime?

How curious are you to know the answer?

How confident are you that you know the answer?

Answer: Shark

Question: What item is stolen most often on the NYC subways?

How curious are you to know the answer?

How confident are you that you know the answer?

Answer: iPods

Question: What fictional character in Treasure Island lends its name to a fast food chain?

How curious are you to know the answer?

How confident are you that you know the answer?

Answer: Long John Silver

Question: What crime is punishable if attempted, but not if committed? 
How curious are you to know the answer?

How confident are you that you know the answer?

Answer: Suicide 


\section{Appendix N - Control Condition}

In the course of the upcoming week we would like you record your daily activities in a series of online logs. Specifically, your task is to provide as much detail as possible about the happenings of your life in the past $24 \mathrm{hr}$ period, in a series of fifteen-minute writing sessions.

For the next four days you will be emailed short daily surveys in which space will be provided for you to complete your writing assignment. Five days from today you will receive the same survey but this time you will be presented with a trivia task instead of the writing assignment.

\section{Review}

For the next five days you will be emailed daily surveys. These surveys will contain a number of brief questionnaires that should take approximately 10 minutes to complete. Additionally, space will be provided for you to complete your writing assignments. We ask that you spend approximately fifteen minutes on your writing assignments. On the fifth day, instead of providing space to write a log, the survey will present you with a trivia task.

Completion of these five daily surveys is worth up to a $1.25 \%$ grade increase (.25 for each). Additionally, for each completed daily survey you will be entered in a draw for a chance to win $\$ 250$.

Following the five daily surveys you will be asked to complete a final follow-up survey. The follow-up survey will be administered one day after the last daily survey and is worth a .5\% grade increase.

I acknowledge that I have read and understand the instructions for completing the remainder of the study 


\section{Appendix O - Control Condition Daily Log Task}

\section{The following instructions are the same for each writing log (Days 1-4):}

In the space below please record, in as much detail as possible, the happenings of your life in the past 24hrs. Please spend approximately fifteen minutes on this writing exercise.

\section{Instructions for Day 5:}

Today you will be presented with a series of trivia questions. Before the answers are presented each question you will be asked to rate how curious you are to know the answer, and how confident you are you know the answer. Please take a few moments to think about the answers to each question.

Please indicate your response using the following scale:

Not at all

1

Question: Which sports athlete has appeared in McDonalds, Nike, and Hanes advertisements?

How curious are you to know the answer?

How confident are you that you know the answer?

Answer: Michael Jordan

Question: What is the name of the galaxy that earth is a part of?

How curious are you to know the answer?

How confident are you that you know the answer?

Answer: Milky Way

Question: $\mathrm{H} 20$ is the chemical compound for what substance

How curious are you to know the answer?

How confident are you that you know the answer?

Answer: Water

Question: What is the capital of China?

How curious are you to know the answer?

How confident are you that you know the answer?

Answer: Beijing 
Question: What is the name of Calgary's NHL team?

How curious are you to know the answer?

How confident are you that you know the answer?

Answer: Calgary Flames

Question: Who was the first person to walk on the moon?

How curious are you to know the answer?

How confident are you that you know the answer?

Answer: Neil Armstrong

Question: Who is the current Prime Minister of Canada?

How curious are you to know the answer?

How confident are you that you know the answer?

Answer: Stephen Harper

Question: How many lbs (pounds) are in a kg (kilogram)?

How curious are you to know the answer?

How confident are you that you know the answer?

Answer: 2.2

Question: What team won the cricket Champions League in 2013?

How curious are you to know the answer?

How confident are you that you know the answer?

Answer: Chennai Super Kings

Question: On average, how long does it take to complete an honors degree at Carleton?

How curious are you to know the answer?

How confident are you that you know the answer?

Answer: 4 years

Question: What is the second most popular search engine in North America?

How curious are you to know the answer? 
How confident are you that you know the answer?

Answer: Bing

Question: Who was Time Magazine's person of the year in 2013

How curious are you to know the answer?

How confident are you that you know the answer?

Answer: Pope Francis

Question: Who plays Tony Stark in the Iron Man movies?

How curious are you to know the answer?

How confident are you that you know the answer?

Answer: Robert Downey Jr.

Question: Who is the current President of the United States?

How curious are you to know the answer?

How confident are you that you know the answer?

Answer: Barack Obama

Question: What is the name of Canada's national public radio and TV broadcaster?

How curious are you to know the answer?

How confident are you that you know the answer?

Answer: CBC

Question: Who is currently the richest person in the world?

How curious are you to know the answer?

How confident are you that you know the answer?

Answer: Carlos Slim Helu

Question: What man made object is currently orbiting earth and is known by the acronym ISS

How curious are you to know the answer?

How confident are you that you know the answer?

Answer: International Space Station 
Question: Who is the president of Russia?

How curious are you to know the answer?

How confident are you that you know the answer?

Answer: Vladimir Putin

Question: What company was founded by Mark Zuckerberg?

How curious are you to know the answer?

How confident are you that you know the answer?

Answer: Facebook

Question: What famous physicist developed the theory of relativity?

How curious are you to know the answer?

How confident are you that you know the answer?

Answer: Albert Einstein

Question: Which Canadian city hosted the winter Olympics in 2010?

How curious are you to know the answer?

How confident are you that you know the answer?

Answer: Vancouver

Question: How long were Jerry Seinfeld and his pals sentenced in the series finale of Seinfield?

How curious are you to know the answer?

How confident are you that you know the answer?

Answer: 1 year 


\section{Appendix P - Exploratory Analyses: Negative Affect}

\begin{tabular}{lccccccc}
\hline & \multicolumn{3}{c}{ Openness } & \multicolumn{3}{c}{ Control } \\
& $\mathrm{n}$ & $\mathrm{M}$ & $\mathrm{SD}$ & $\mathrm{n}$ & $\mathrm{M}$ & $\mathrm{SD}$ & $d$ \\
\hline Daily Task 1 & 96 & 1.55 & .73 & 107 & 1.65 & .84 & .13 \\
Daily Task 2 & 99 & 1.88 & .86 & 104 & 1.54 & .78 & .41 \\
Daily Task 3 & 94 & 1.51 & .71 & 99 & 1.63 & .92 & .15 \\
Daily Task 4 & 89 & 1.39 & .69 & 93 & 1.60 & .86 & .27 \\
Daily Task 5 & 88 & 1.32 & .59 & 97 & 1.47 & .80 & .21 \\
Overall & 466 & 1.54 & .75 & 500 & 1.58 & .84 & .05 \\
\hline
\end{tabular}

Table 22. Negative Affect descriptive statistics (daily assessments). Topics in the openness condition are aesthetics (Task1), emotions (Task 2), Ideas (Task3) and Introspection (Task4); Task 5 is the curiosity manipulation.

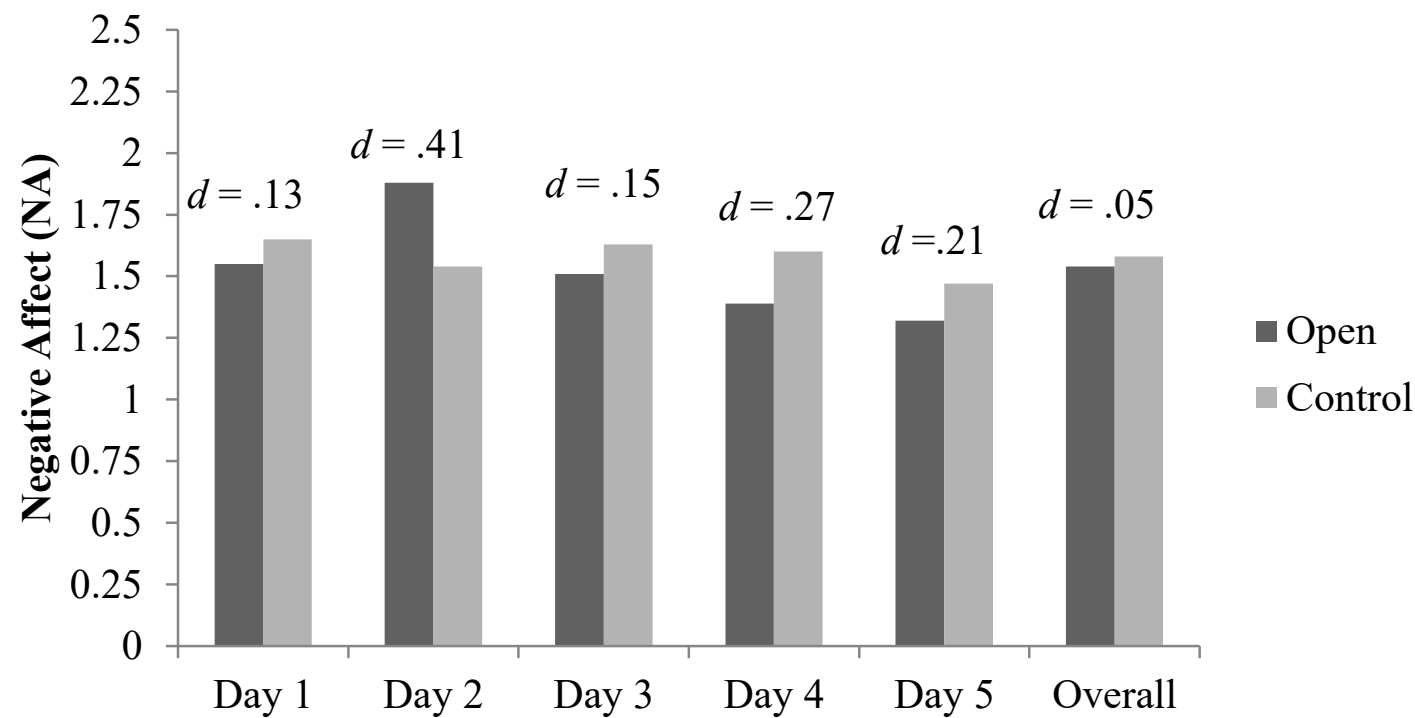

Figure 22. Mean Negative Affect scores across time (daily assessments). Topics in the openness condition are aesthetics (Task1), emotions (Task 2), Ideas (Task3) and Introspection (Task4); Task 5 is the curiosity manipulation.

\begin{tabular}{clccccc}
\hline Model & & $\begin{array}{c}\text { Parameter } \\
\text { Estimates }\end{array}$ & $\begin{array}{c}\text { Standard } \\
\text { Error }\end{array}$ & $\mathrm{t}$ & $\mathrm{z}$ & $\mathrm{p}$ \\
\hline \multirow{2}{*}{$\mathrm{A} \quad$} & & & & & & \\
& & & & & & \\
& Intercept $\left(\gamma_{00}\right)$ & -0.06 & 0.06 & 31.39 & & $<.001$ \\
& Time $\left(\gamma_{10}\right)$ & 0.45 & 0.01 & -6.20 & & $<.001$ \\
& Intercept $\left(\tau_{00}\right)$ & 0.19 & 0.01 & & 9.49 & $<.001$ \\
& Residual $\left(\sigma^{2}\right)$ & & 19.31 & $<.001$
\end{tabular}




\begin{tabular}{|c|c|c|c|c|c|c|}
\hline \multirow[t]{6}{*}{$\mathrm{B}$} & Intercept $\left(\gamma_{00}\right)$ & 1.75 & 0.06 & 30.14 & & $<.001$ \\
\hline & Time $\left(\gamma_{10}\right)$ & -0.06 & 0.01 & -5.61 & & $<.001$ \\
\hline & Intercept $\left(\tau_{00}\right)$ & 0.52 & 0.07 & & 7.21 & $<.001$ \\
\hline & Time $\left(\tau_{11}\right)$ & 0.01 & 0.00 & & 2.09 & .019 \\
\hline & $\operatorname{Cov}\left(\tau_{10}\right)$ & -0.02 & 0.01 & & -1.74 & .082 \\
\hline & Residual $\left(\sigma^{2}\right)$ & 0.17 & 0.01 & & 16.44 & $<.001$ \\
\hline \multirow[t]{8}{*}{$\mathrm{C}$} & Intercept $\left(\gamma_{00}\right)$ & 1.68 & 0.08 & 20.99 & & $<.001$ \\
\hline & Time $\left(\gamma_{10}\right)$ & -0.03 & 0.01 & -1.96 & & .051 \\
\hline & Condition $\left(\gamma_{01}\right)$ & 0.14 & 0.12 & 1.24 & & .217 \\
\hline & Time*Condition $\left(\gamma_{11}\right)$ & -0.07 & 0.02 & -3.18 & & .002 \\
\hline & Intercept $\left(\tau_{00}\right)$ & 0.52 & 0.07 & & 7.17 & $<.001$ \\
\hline & Time $\left(\tau_{11}\right)$ & 0.00 & 0.00 & & 1.69 & .046 \\
\hline & $\operatorname{Cov}\left(\tau_{10}\right)$ & -0.02 & 0.01 & & -1.52 & .130 \\
\hline & Residual $\left(\sigma^{2}\right)$ & 0.17 & 0.01 & & 16.45 & $<.001$ \\
\hline \multirow[t]{14}{*}{$\mathrm{D}$} & Intercept $\left(\gamma_{00}\right)$ & 1.62 & 0.09 & 18.39 & & $<.001$ \\
\hline & Time $\left(\gamma_{10}\right)$ & -0.01 & 0.02 & -0.31 & & .757 \\
\hline & Condition $\left(\gamma_{01}\right)$ & 0.12 & 0.13 & 0.97 & & .332 \\
\hline & Word Count $\left(\gamma_{20}\right)$ & 0.00 & 0.00 & 1.56 & & .119 \\
\hline & Trait Open & -0.03 & 0.17 & -0.16 & & .874 \\
\hline & Time*Trait Open & 0.01 & 0.03 & 0.28 & & .781 \\
\hline & Condition*Trait Open & -0.13 & 0.22 & -0.62 & & .539 \\
\hline & Time*Condition $\left(\gamma_{11}\right)$ & -0.06 & 0.03 & -1.86 & & .064 \\
\hline & Time*Word Count $\left(\gamma_{12}\right)$ & 0.00 & 0.00 & -1.45 & & .148 \\
\hline & Condition*Word Count $\left(\gamma_{21}\right)$ & 0.00 & 0.00 & 2.76 & & .006 \\
\hline & Intercept $\left(\tau_{00}\right)$ & 0.53 & 0.09 & & 6.21 & $<.001$ \\
\hline & Time $\left(\tau_{11}\right)$ & 0.01 & 0.01 & & 1.82 & .034 \\
\hline & $\operatorname{Cov}\left(\tau_{10}\right)$ & -0.03 & 0.02 & & -1.38 & .168 \\
\hline & Residual $\left(\sigma^{2}\right)$ & 0.17 & 0.13 & & 13.28 & $<.001$ \\
\hline \multirow[t]{11}{*}{$\mathrm{E}$} & Intercept $\left(\gamma_{00}\right)$ & 1.86 & .20 & 9.35 & & $<.001$ \\
\hline & Time $\left(\gamma_{10}\right)$ & -0.12 & .05 & -2.39 & & .017 \\
\hline & Condition $\left(\gamma_{01}\right)$ & -0.11 & .12 & -0.89 & & .376 \\
\hline & Word Count $\left(\gamma_{20}\right)$ & 0.00 & .00 & 3.91 & & $<.001$ \\
\hline & Trait Open & -0.07 & .11 & -0.67 & & .505 \\
\hline & Time*Condition & 0.06 & .03 & 1.75 & & .082 \\
\hline & Condition*Word Count & -0.00 & .00 & -2.58 & & .010 \\
\hline & Intercept $\left(\tau_{00}\right)$ & 0.51 & .03 & & 6.18 & $<.001$ \\
\hline & Time $\left(\tau_{11}\right)$ & 0.01 & .01 & & 169 & .046 \\
\hline & $\operatorname{Cov}\left(\tau_{10}\right)$ & -0.02 & .02 & & -1.21 & .226 \\
\hline & Residual $\left(\sigma^{2}\right)$ & 0.18 & .01 & & 13.32 & $<.001$ \\
\hline
\end{tabular}

Table 23. MML models for Negative Affect (daily assessments). 


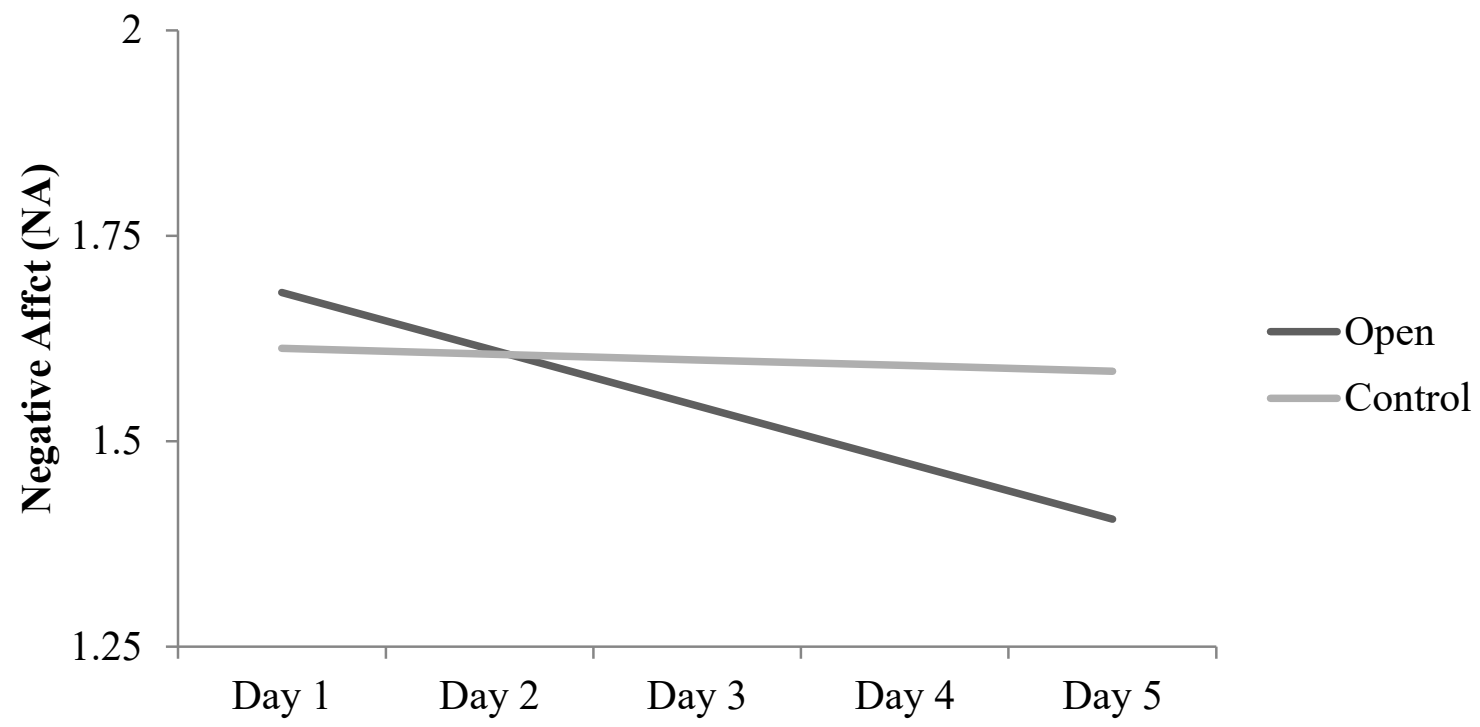

Figure 23. Simple slopes condition by time interaction predicting for negative affect (daily assessments).

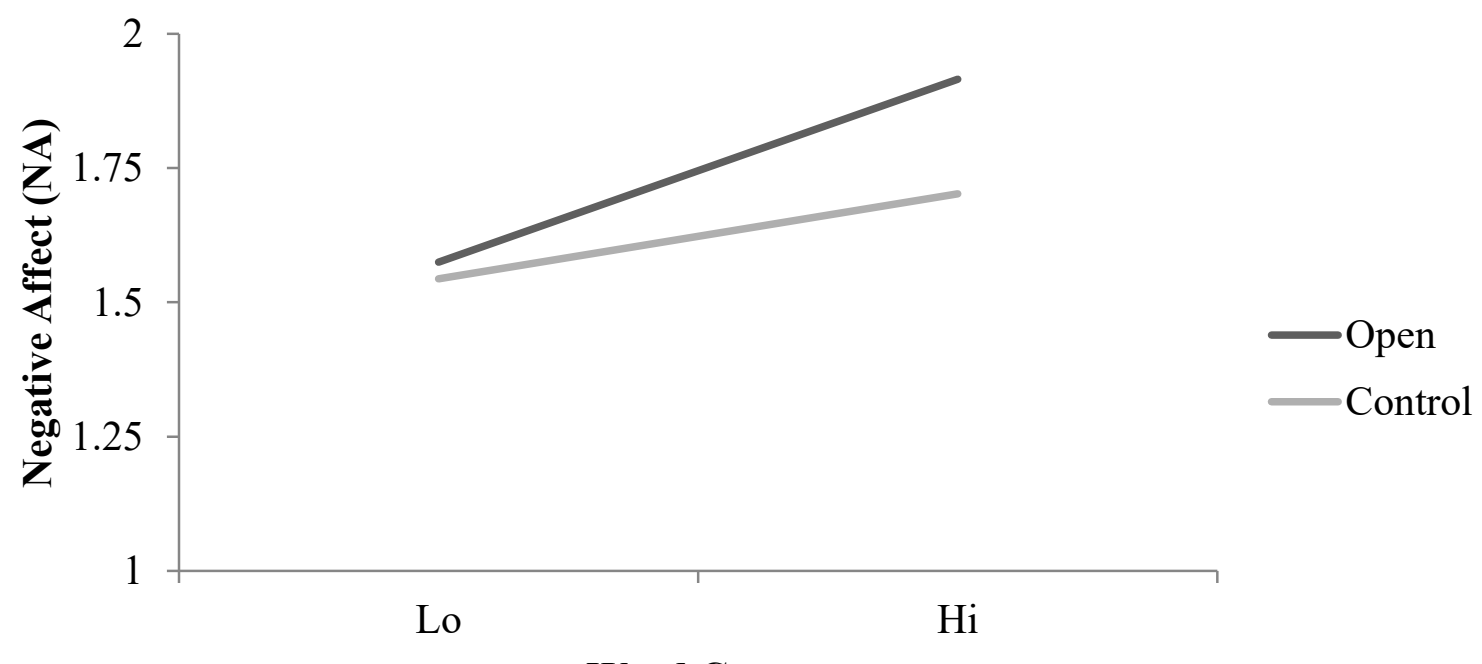

Figure 24. Simple slopes for condition by word count interaction predicting negative affect (daily assessments).

\begin{tabular}{lccccccc}
\hline & \multicolumn{3}{c}{ Openness } & \multicolumn{3}{c}{ Control } & \\
& $\mathrm{n}$ & $\mathrm{M}$ & $\mathrm{SD}$ & $\mathrm{n}$ & $\mathrm{M}$ & $\mathrm{SD}$ & $d$ \\
\hline Pretest & 106 & 2.37 & 0.71 & 115 & 2.49 & 0.83 & .16 \\
Posttest & 86 & 1.94 & 0.66 & 95 & 2.12 & 0.79 & .25 \\
Follow Up & 38 & 2.25 & 0.70 & 34 & 2.14 & 0.71 & .16 \\
\hline
\end{tabular}

Table 24. Negative affect descriptive statistics (pretest, posttest, and follow up assessments). 


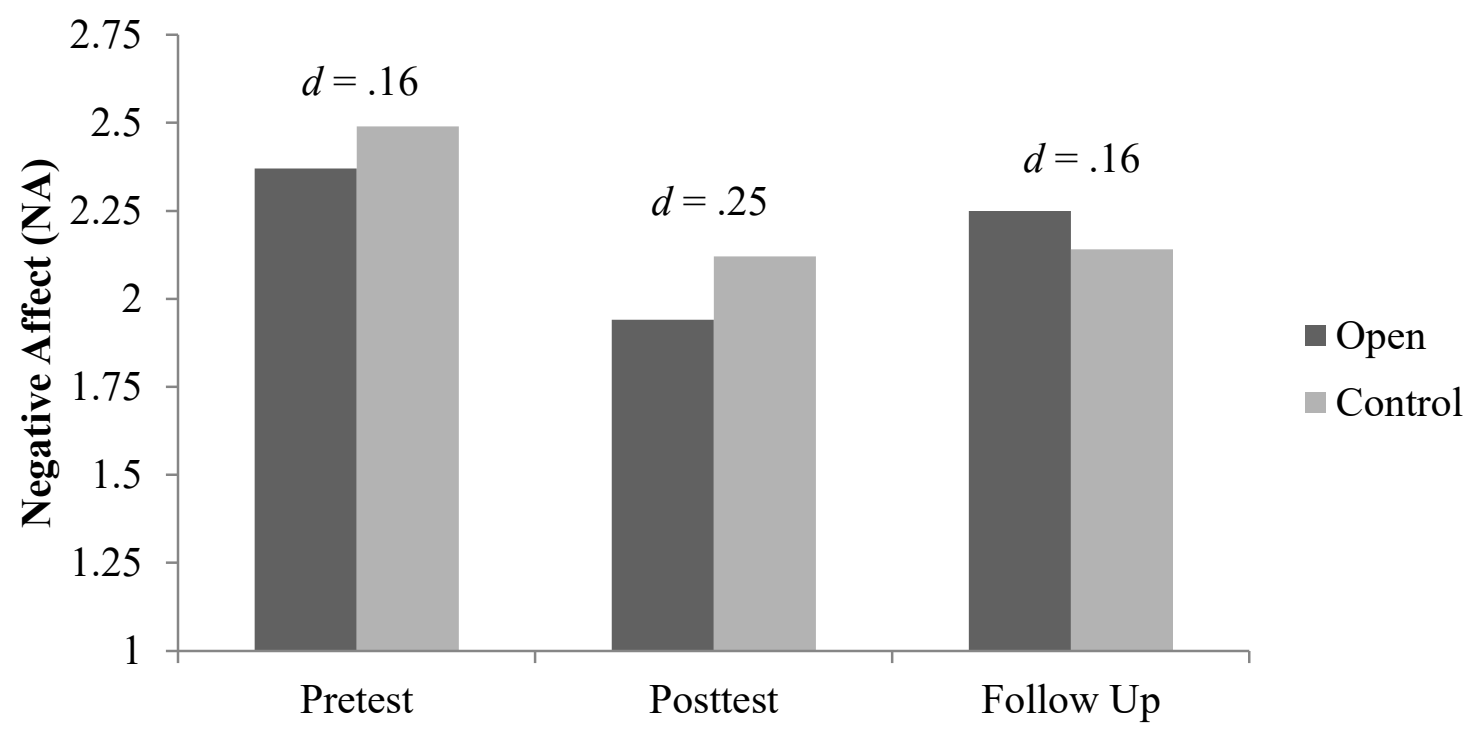

Figure 25. Means for negative affect over time (pretest, posttest and follow up assessments).

\begin{tabular}{|c|c|c|c|c|c|c|}
\hline \multicolumn{2}{|c|}{ Model } & $\begin{array}{l}\text { Parameter } \\
\text { Estimates }\end{array}$ & $\begin{array}{c}\text { Standard } \\
\text { Error }\end{array}$ & $\mathrm{t}$ & $\mathrm{Z}$ & $\mathrm{p}$ \\
\hline \multirow{4}{*}{ A } & Intercept $\left(\gamma_{00}\right)$ & 2.33 & 0.05 & 43.26 & & $<.001$ \\
\hline & Time $\left(\gamma_{10}\right)$ & -0.19 & 0.03 & -5.56 & & $<.001$ \\
\hline & Intercept $\left(\tau_{00}\right)$ & 0.32 & 0.05 & & 6.78 & $<.001$ \\
\hline & Residual $\left(\sigma^{2}\right)$ & 0.21 & 0.02 & & 10.21 & $<.001$ \\
\hline \multirow[t]{6}{*}{ B } & Intercept $\left(\gamma_{00}\right)$ & 2.33 & 0.06 & 41.58 & & $<.001$ \\
\hline & Time $\left(\gamma_{10}\right)$ & -0.19 & 0.03 & -5.55 & & $<.001$ \\
\hline & Intercept $\left(\tau_{00}\right)$ & 0.36 & 0.06 & & 6.25 & $<.001$ \\
\hline & Time $\left(\tau_{11}\right)$ & - & - & & - & - \\
\hline & $\operatorname{Cov}\left(\tau_{10}\right)$ & -0.03 & 0.02 & & -1.52 & .128 \\
\hline & Residual $\left(\sigma^{2}\right)$ & 0.21 & 0.02 & & 10.30 & $<.001$ \\
\hline \multirow[t]{6}{*}{$\mathrm{C}$} & Intercept $\left(\gamma_{00}\right)$ & 2.37 & 0.08 & 31.40 & & $<.001$ \\
\hline & Time $\left(\gamma_{10}\right)$ & -0.17 & 0.05 & -3.31 & & .001 \\
\hline & Condition $\left(\gamma_{01}\right)$ & -0.09 & 0.11 & -0.82 & & .416 \\
\hline & Time* Condition $\left(\gamma_{11}\right)$ & -0.05 & 0.07 & -0.75 & & .453 \\
\hline & Intercept $\left(\tau_{00}\right)$ & 0.32 & 0.05 & & 6.76 & $<.001$ \\
\hline & Residual $\left(\sigma^{2}\right)$ & 0.21 & 0.02 & & 10.19 & $<.001$ \\
\hline \multirow[t]{2}{*}{$\mathrm{D}$} & Intercept $\left(\gamma_{00}\right)$ & 2.38 & 0.08 & 31.56 & & $<.001$ \\
\hline & Time $\left(\gamma_{10}\right)$ & -0.18 & 0.05 & -3.58 & & $<.001$ \\
\hline
\end{tabular}




\begin{tabular}{|c|c|c|c|c|c|}
\hline Word Count $\left(\gamma_{20}\right)$ & 0.00 & 0.00 & -0.41 & & .684 \\
\hline Condition $\left(\gamma_{01}\right)$ & -0.09 & 0.11 & -0.84 & & .405 \\
\hline Trait Open $\left(\gamma_{02}\right)$ & 0.35 & 0.16 & 2.18 & & .031 \\
\hline Trait Open*Condition $\left(\gamma_{03}\right)$ & -0.13 & 0.21 & -0.59 & & .556 \\
\hline Trait Open*Time $\left(\gamma_{12}\right)$ & -0.11 & 0.07 & -1.45 & & .148 \\
\hline Time*Condition $\left(\gamma_{11}\right)$ & -0.04 & 0.07 & -0.58 & & .559 \\
\hline Time*Word Count $\left(\gamma_{30}\right)$ & 0.00 & 0.00 & 1.47 & & .143 \\
\hline Condition*Word Count $\left(\gamma_{21}\right)$ & 0.00 & 0.00 & -0.99 & & .324 \\
\hline Intercept $\left(\tau_{00}\right)$ & 0.31 & 0.05 & & 6.66 & $<.001$ \\
\hline Residual $\left(\sigma^{2}\right)$ & 0.21 & 0.02 & & 10.15 & $<.001$ \\
\hline Intercept & 2.44 & .07 & 33.21 & & $<.001$ \\
\hline Time & -0.74 & .09 & -8.15 & & $<.001$ \\
\hline Condition & -0.10 & .10 & -0.95 & & .344 \\
\hline Trait Open & 0.20 & .11 & 1.90 & & .060 \\
\hline Word Count & -0.00 & .00 & -0.73 & & .464 \\
\hline Time*Time & 0.34 & .05 & 6.40 & & $<.001$ \\
\hline Time*Time*Condition & -0.04 & .03 & -1.09 & & .277 \\
\hline Intercept $\left(\tau_{00}\right)$ & 0.33 & .05 & & 7.08 & $<.001$ \\
\hline Residual $\left(\sigma^{2}\right)$ & 0.18 & .02 & & 10.18 & $<.001$ \\
\hline
\end{tabular}

Table 25. MLM models for negative affect (pretest, posttest and follow up assessment). 


\section{Appendix Q - Exploratory Analyses: Effort}

The authenticity and effort scale contains an 'effort' subscale designed to capture subjective assessments of the effort required to complete behaviour in a given time frame (Whelan, 2015).

\begin{tabular}{lccccccc}
\hline & \multicolumn{3}{c}{ Openness } & \multicolumn{3}{c}{ Control } \\
& $\mathrm{n}$ & $\mathrm{M}$ & $\mathrm{SD}$ & $\mathrm{n}$ & $\mathrm{M}$ & $\mathrm{SD}$ & $d$ \\
\hline Daily Task 1 & 96 & 5.53 & 1.18 & 107 & 5.70 & 1.16 & .15 \\
Daily Task 2 & 99 & 5.76 & 1.35 & 104 & 5.54 & 1.31 & .17 \\
Daily Task 3 & 94 & 5.67 & 1.31 & 99 & 5.74 & 1.35 & .05 \\
Daily Task 4 & 89 & 5.79 & 1.26 & 93 & 5.66 & 1.47 & .09 \\
Daily Task 5 & 88 & 5.89 & 1.22 & 97 & 6.02 & 1.23 & .11 \\
Overall & 466 & 5.73 & 1.27 & 500 & 5.73 & 1.31 & .00 \\
\hline
\end{tabular}

Table 26. Effort descriptive statistics (daily assessments). Topics in the openness condition are aesthetics (task 1), emotions (task 2), ideas (task 3 ) and introspection (task 4); task 5 is the curiosity manipulation.

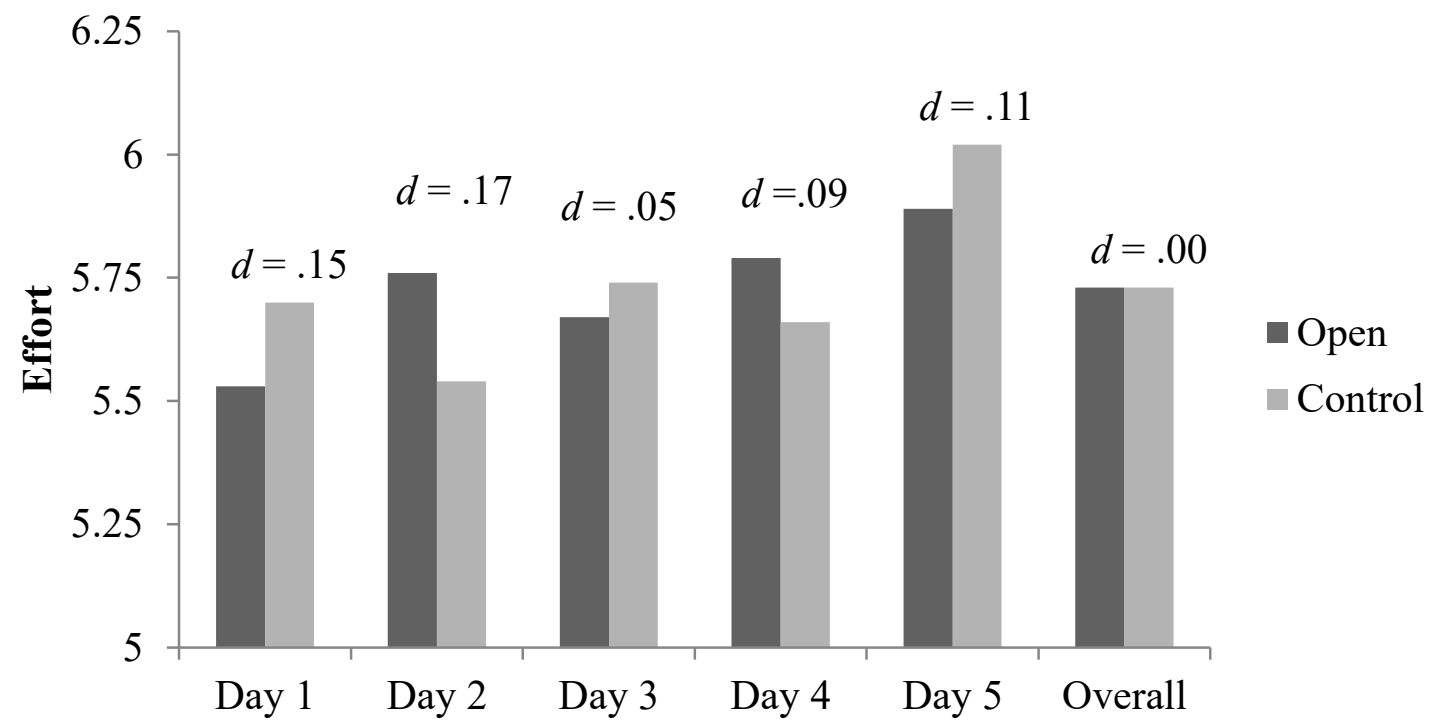

Figure 26. Means for effort over time (daily assessments). Topics in the openness condition are aesthetics (task 1), emotions (task 2), ideas (task 3 ) and introspection (task 4); task 5 is the curiosity manipulation. 


\begin{tabular}{|c|c|c|c|c|c|c|}
\hline Mode & & $\begin{array}{l}\text { Parameter } \\
\text { Estimates }\end{array}$ & $\begin{array}{c}\text { Standard } \\
\text { Error }\end{array}$ & $\mathrm{t}$ & $\mathrm{z}$ & $\mathrm{p}$ \\
\hline \multirow[t]{4}{*}{ A } & Intercept $\left(\gamma_{00}\right)$ & 2.66 & 0.09 & 28.68 & & $<.001$ \\
\hline & Time $\left(\gamma_{10}\right)$ & -0.14 & 0.02 & -7.23 & & $<.001$ \\
\hline & Intercept $\left(\tau_{00}\right)$ & 1.07 & 0.12 & & 8.97 & $<.001$ \\
\hline & Residual $\left(\sigma^{2}\right)$ & 0.66 & 0.03 & & 19.27 & $<.001$ \\
\hline \multirow[t]{6}{*}{ B } & Intercept $\left(\gamma_{00}\right)$ & 2.66 & 0.10 & 26.26 & & $<.001$ \\
\hline & Time $\left(\gamma_{10}\right)$ & -0.14 & 0.02 & -6.35 & & $<.001$ \\
\hline & Intercept $\left(\tau_{00}\right)$ & 1.50 & 0.22 & & 6.85 & $<.001$ \\
\hline & Time $\left(\tau_{11}\right)$ & 0.03 & 0.01 & & 2.86 & .002 \\
\hline & $\operatorname{Cov}\left(\tau_{10}\right)$ & -0.12 & 0.05 & & -2.86 & .004 \\
\hline & Residual $\left(\sigma^{2}\right)$ & 0.59 & 0.04 & & 16.42 & $<.001$ \\
\hline \multirow[t]{8}{*}{$\mathrm{C}$} & Intercept $\left(\gamma_{00}\right)$ & 2.57 & 0.14 & 18.36 & & $<.001$ \\
\hline & Time $\left(\gamma_{10}\right)$ & -0.13 & 0.03 & -4.29 & & $<.001$ \\
\hline & Condition $\left(\gamma_{01}\right)$ & 0.17 & 0.20 & 0.85 & & .399 \\
\hline & Time*Condition $\left(\gamma_{11}\right)$ & -0.02 & 0.04 & -0.41 & & .684 \\
\hline & Intercept $\left(\tau_{00}\right)$ & 1.50 & 0.22 & & 6.84 & $<.001$ \\
\hline & Time $\left(\tau_{11}\right)$ & 0.03 & 0.01 & & 2.89 & .002 \\
\hline & $\operatorname{Cov}\left(\tau_{10}\right)$ & -0.12 & 0.04 & & -2.87 & .004 \\
\hline & Residual $\left(\sigma^{2}\right)$ & 0.59 & 0.04 & & 16.42 & $<.001$ \\
\hline \multirow[t]{14}{*}{$\mathrm{D}$} & Intercept $\left(\gamma_{00}\right)$ & 2.58 & 0.15 & 17.18 & & $<.001$ \\
\hline & Time $\left(\gamma_{10}\right)$ & -0.13 & 0.04 & -2.82 & & .005 \\
\hline & Word Count $\left(\gamma_{20}\right)$ & 0.00 & 0.00 & -1.06 & & .288 \\
\hline & Condition $\left(\gamma_{01}\right)$ & 0.12 & 0.21 & 0.54 & & .591 \\
\hline & Trait Open $\left(\gamma_{02}\right)$ & 0.00 & 0.29 & 0.02 & & .986 \\
\hline & Trait Open*Condition $\left(\gamma_{03}\right)$ & -0.71 & 0.34 & -2.06 & & .040 \\
\hline & Trait Open*Time $\left(\gamma_{12}\right)$ & 0.05 & 0.06 & 0.76 & & .447 \\
\hline & Time*Condition $\left(\gamma_{11}\right)$ & 0.00 & 0.06 & 0.06 & & .955 \\
\hline & Time*Word Count $\left(\gamma_{30}\right)$ & 0.00 & 0.00 & -0.07 & & .945 \\
\hline & Condition*Word Count $\left(\gamma_{21}\right)$ & 0.00 & 0.00 & 2.27 & & .024 \\
\hline & Intercept $\left(\tau_{00}\right)$ & 1.25 & 0.25 & & 5.08 & $<.001$ \\
\hline & Time $\left(\tau_{11}\right)$ & 0.04 & 0.02 & & 1.70 & .044 \\
\hline & $\operatorname{Cov}\left(\tau_{10}\right)$ & -0.07 & 0.06 & & -1.18 & .236 \\
\hline & Residual $\left(\sigma^{2}\right)$ & 0.65 & 0.05 & & 13.42 & $<.001$ \\
\hline \multirow[t]{7}{*}{$\mathrm{E}$} & Intercept $\left(\gamma_{00}\right)$ & 2.83 & .26 & 10.95 & & $<.001$ \\
\hline & Time $\left(\gamma_{10}\right)$ & -0.12 & .03 & -3.96 & & $<.001$ \\
\hline & Word Count $\left(\gamma_{20}\right)$ & 0.00 & .00 & 2.05 & & .041 \\
\hline & Condition $\left(\gamma_{01}\right)$ & -0.12 & .15 & 0.80 & & .426 \\
\hline & Trait Open $\left(\gamma_{02}\right)$ & -1.29 & .54 & -2.39 & & .018 \\
\hline & Trait Open*Condition $\left(\gamma_{03}\right)$ & 0.71 & .34 & 2.06 & & .040 \\
\hline & Condition*Word Count $\left(\gamma_{21}\right)$ & -0.00 & .00 & -2.35 & & .020 \\
\hline
\end{tabular}




$\begin{array}{lcccc}\text { Intercept }\left(\tau_{00}\right) & 1.24 & .24 & 5.09 & <.001 \\ \text { Time }\left(\tau_{11}\right) & 0.03 & .02 & 1.67 & .047 \\ \operatorname{Cov}\left(\tau_{10}\right) & -0.07 & .06 & -1.14 & .256 \\ \text { Residual }\left(\sigma^{2}\right) & 0.65 & .05 & 13.44 & <.001\end{array}$

Table 27. MLM models for effort (daily assessments).

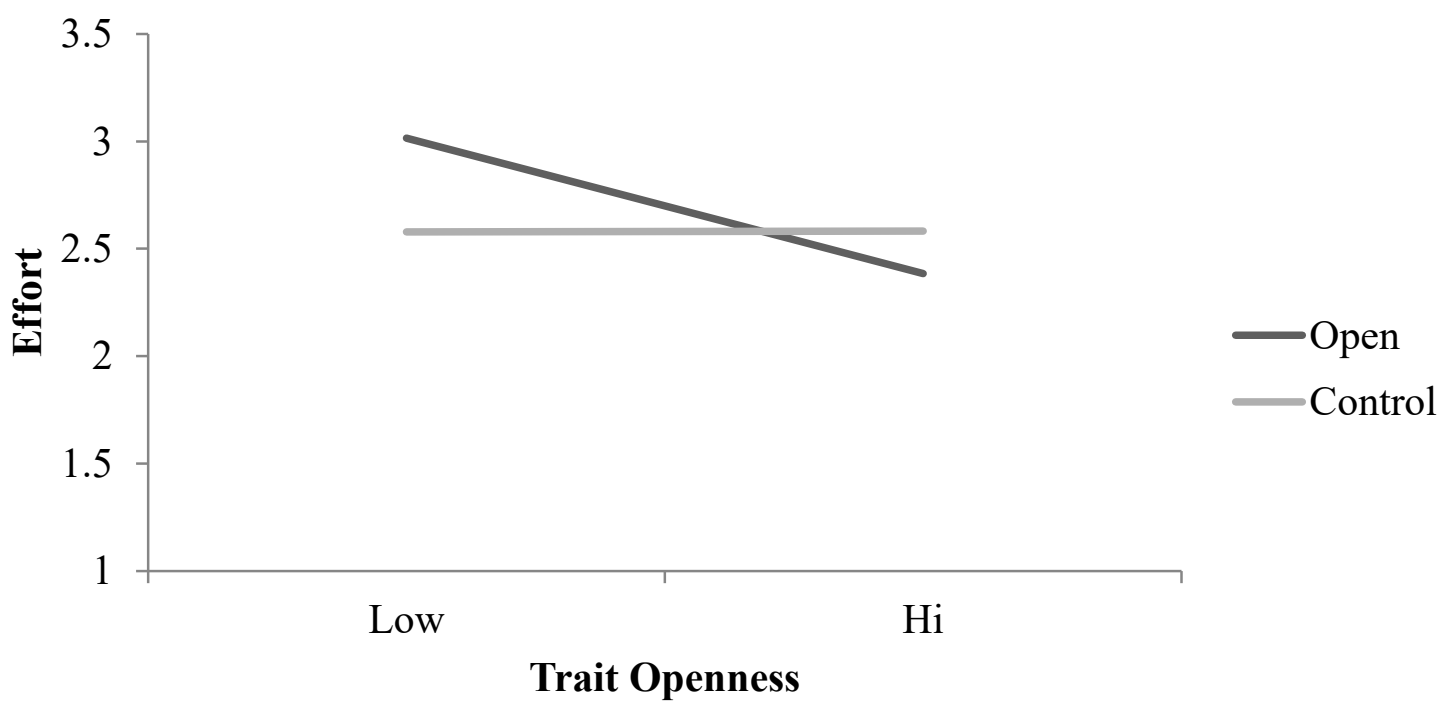

Figure 27 Simple slopes for condition by trait openness interaction predicting effort (daily assessments).

\begin{tabular}{lccccccc}
\hline & \multicolumn{3}{c}{ Openness } & \multicolumn{3}{c}{ Control } & \\
& $\mathrm{n}$ & $\mathrm{M}$ & $\mathrm{SD}$ & $\mathrm{n}$ & $\mathrm{M}$ & $\mathrm{SD}$ & $d$ \\
\hline Pretest & 106 & 3.56 & 1.00 & 115 & 3.68 & 1.15 & .11 \\
Posttest & 84 & 3.10 & 1.16 & 92 & 3.18 & 1.26 & .07 \\
Follow Up & 38 & 3.42 & 1.13 & 33 & 3.43 & 1.23 & .01 \\
\hline
\end{tabular}

Table 28. Effort descriptive statistics (pretest, posttest, and follow-up assessments). 


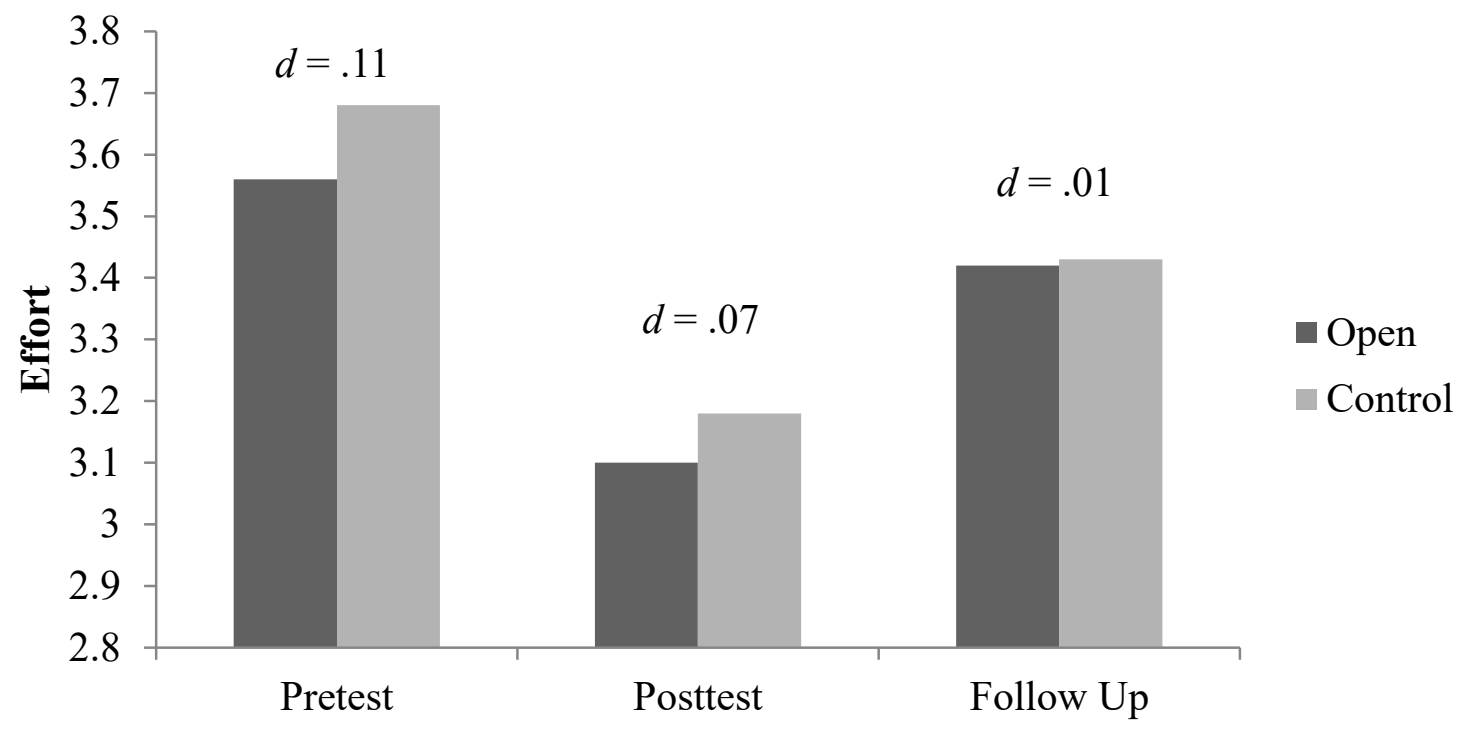

Figure 28. Means for effort over time (pretest, posttest, and follow-up assessments).

\begin{tabular}{|c|c|c|c|c|c|c|}
\hline \multicolumn{2}{|c|}{ Model } & $\begin{array}{l}\text { Parameter } \\
\text { Estimates }\end{array}$ & $\begin{array}{c}\text { Standard } \\
\text { Error }\end{array}$ & $\mathrm{t}$ & $\mathrm{Z}$ & $\mathrm{p}$ \\
\hline \multirow[t]{4}{*}{$\mathrm{A}$} & Intercept $\left(\gamma_{00}\right)$ & 3.50 & .09 & 40.99 & & $<.001$ \\
\hline & Time $\left(\gamma_{10}\right)$ & -0.21 & .07 & -3.10 & & .002 \\
\hline & Intercept $\left(\tau_{00}\right)$ & 0.58 & .11 & & 5.32 & $<.001$ \\
\hline & Residual $\left(\sigma^{2}\right)$ & 0.79 & .08 & & 10.18 & $<.001$ \\
\hline \multirow[t]{6}{*}{$\mathrm{B}$} & Intercept $\left(\gamma_{00}\right)$ & 3.50 & .08 & 43.65 & & $<.001$ \\
\hline & Time $\left(\gamma_{10}\right)$ & -0.20 & .07 & -2.99 & & .003 \\
\hline & Intercept $\left(\tau_{00}\right)$ & 0.42 & .13 & & 3.21 & $<.001$ \\
\hline & Time $\left(\tau_{11}\right)$ & - & - & & - & - \\
\hline & $\operatorname{Cov}\left(\tau_{10}\right)$ & 0.12 & .07 & & 1.74 & .081 \\
\hline & Residual $\left(\sigma^{2}\right)$ & 0.79 & .08 & & 10.08 & $<.001$ \\
\hline \multirow[t]{6}{*}{$\mathrm{C}$} & Intercept $\left(\gamma_{00}\right)$ & 3.49 & .12 & 29.07 & & $<.001$ \\
\hline & Time $\left(\gamma_{10}\right)$ & -0.20 & .10 & -2.01 & & .045 \\
\hline & Condition $\left(\gamma_{01}\right)$ & 0.01 & .17 & 0.04 & & .967 \\
\hline & Time* Condition $\left(\gamma_{11}\right)$ & -0.02 & .13 & -0.15 & & .879 \\
\hline & Intercept $\left(\tau_{00}\right)$ & 0.59 & .11 & & 5.31 & $<.001$ \\
\hline & Residual $\left(\sigma^{2}\right)$ & 0.79 & .08 & & 10.16 & $<.001$ \\
\hline \multirow[t]{4}{*}{$\mathrm{D}$} & Intercept $\left(\gamma_{00}\right)$ & 3.49 & .12 & 29.32 & & $<.001$ \\
\hline & Time $\left(\gamma_{10}\right)$ & -0.19 & .10 & -1.89 & & .061 \\
\hline & Word Count $\left(\gamma_{20}\right)$ & -0.00 & .00 & -0.59 & & .556 \\
\hline & Condition $\left(\gamma_{01}\right)$ & 0.06 & .17 & 0.33 & & .740 \\
\hline
\end{tabular}




\begin{tabular}{|c|c|c|c|c|c|c|}
\hline \multicolumn{2}{|c|}{ Trait Open $\left(\gamma_{02}\right)$} & 0.18 & .24 & 0.75 & & .456 \\
\hline & Trait Open*Condition $\left(\gamma_{03}\right)$ & -0.09 & .32 & -0.28 & & .780 \\
\hline & Trait Open*Time $\left(\gamma_{12}\right)$ & -0.11 & .14 & -0.76 & & .451 \\
\hline & Time* Condition $\left(\gamma_{11}\right)$ & -0.00 & .13 & -0.02 & & .982 \\
\hline & Time*Word Count $\left(\gamma_{30}\right)$ & -0.00 & .00 & -0.14 & & .890 \\
\hline & Condition*Word Count $\left(\gamma_{21}\right)$ & -0.00 & .00 & -2.28 & & .024 \\
\hline & Intercept $\left(\tau_{00}\right)$ & 0.55 & .11 & & 5.11 & $<.001$ \\
\hline & Residual $\left(\sigma^{2}\right)$ & 0.79 & .08 & & 10.15 & $<.001$ \\
\hline $\mathrm{E}$ & Intercept $\left(\gamma_{00}\right)$ & 3.58 & .12 & 30.96 & & $<.001$ \\
\hline & Time $\left(\gamma_{10}\right)$ & -0.98 & .18 & -5.40 & & $<.001$ \\
\hline & Condition $\left(\gamma_{01}\right)$ & 0.07 & .16 & 0.46 & & .646 \\
\hline & Trait Open $\left(\gamma_{02}\right)$ & 0.06 & .16 & 0.40 & & 692 \\
\hline & Word Count $\left(\gamma_{20}\right)$ & -0.00 & .00 & -0.76 & & .449 \\
\hline & Condition*Word Count $\left(\gamma_{21}\right)$ & -0.00 & .00 & -2.45 & & .016 \\
\hline & Time*Time & 0.47 & .11 & 4.44 & & $<.001$ \\
\hline & Time*Time*Condition & -0.03 & .07 & -0.40 & & .690 \\
\hline & Intercept $\left(\tau_{00}\right)$ & 0.57 & .10 & & 5.45 & $<.001$ \\
\hline & Residual $\left(\sigma^{2}\right)$ & 0.72 & .07 & & 10.16 & $<.001$ \\
\hline
\end{tabular}

Table 29. MLM models for effort (pretest, posttest, and follow-up assessments).

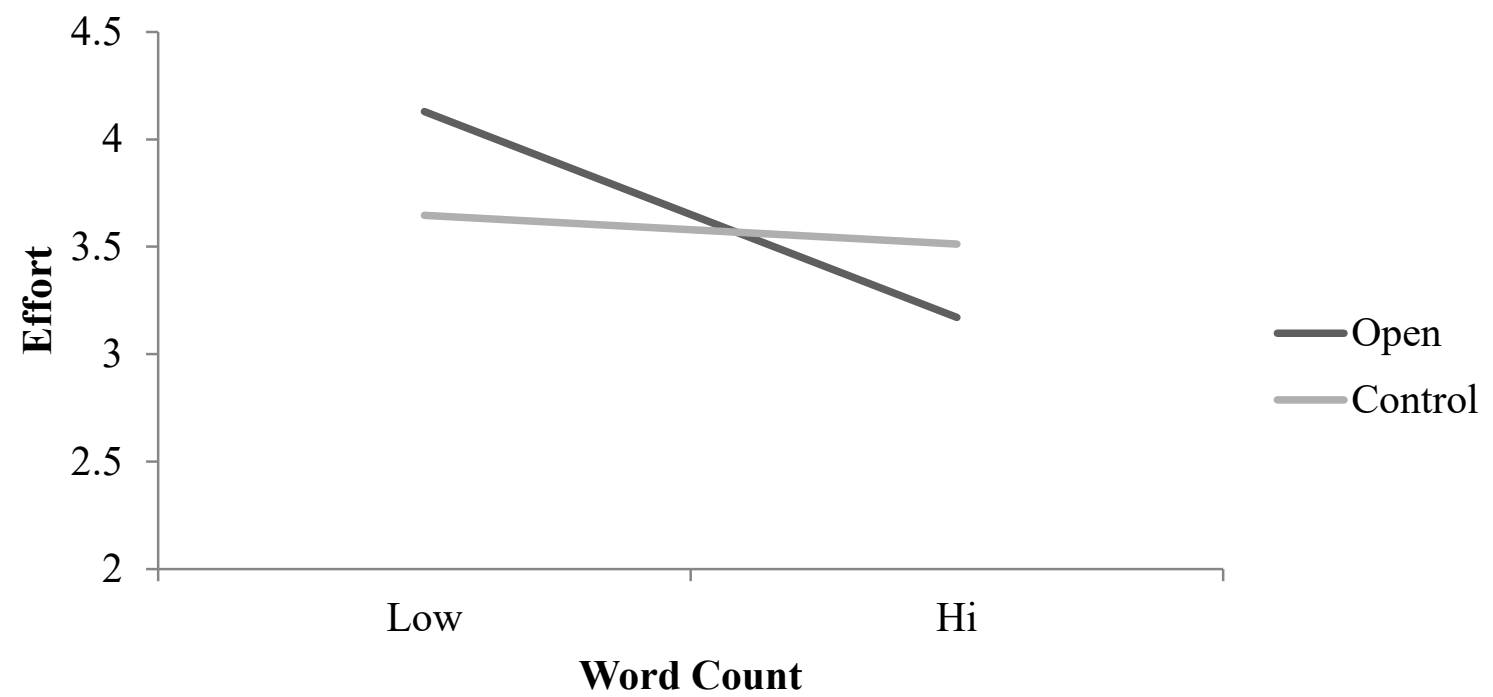

Figure 29. Simple slopes for control by word count interaction predicting effort (pretest, posttest, and follow-up assessments). 